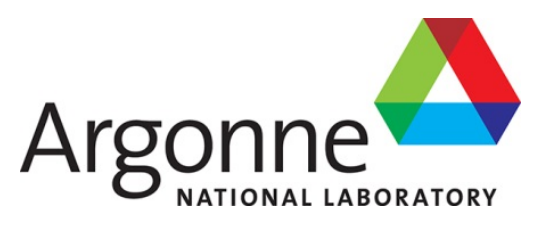

\title{
Report on Year-2 of Water NSTF Matrix Testing
}

Two-Phase Baseline \& Repeatability

Nuclear Science \& Engineering 


\section{About Argonne National Laboratory}

Argonne is a U.S. Department of Energy laboratory managed by UChicago Argonne, LLC

under contract DE-AC02-06CH11357. The Laboratory's main facility is outside Chicago, at 9700 South Cass Avenue, Argonne, Illinois 60439. For information about Argonne

and its pioneering science and technology programs, see www.anl.gov.

\section{DOCUMENT AVAILABILITY}

Online Access: U.S. Department of Energy (DOE) reports produced after 1991 and a growing number of pre-1991 documents are available free via DOE's SciTech Connect (http://www.osti.gov/scitech/)

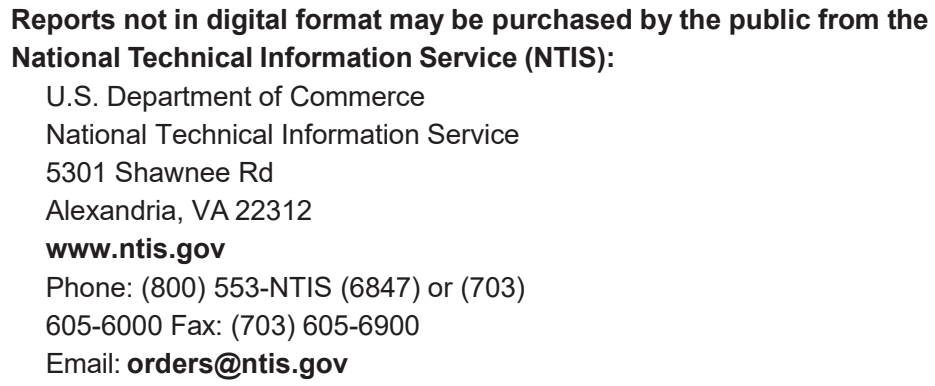

Reports not in digital format are available to DOE and DOE contractors from the Office of Scientific and Technical Information (OSTI):

U.S. Department of Energy

Office of Scientific and Technical Information

P.O. Box 62

Oak Ridge, TN 37831-0062

www.osti.gov

Phone: (865) 576-8401

Fax: (865) 576-5728

Email: reports@osti.gov

\section{Disclaimer}

This report was prepared as an account of work sponsored by an agency of the United States Government. Neither the United States Government nor any agency thereof, nor UChicago Argonne, LLC, nor any of their employees or officers, makes any warranty, express or implied, or assumes any legal liability or responsibility for the accuracy, completeness, or usefulness of any information, apparatus, product, or process disclosed, or represents that its use would not infringe privately owned rights. Reference herein to any specific commercial product, process, or service by trade name, trademark, manufacturer, or otherwise, does not necessarily constitute or imply its endorsement, recommendation, or favoring by the United States Government or any agency thereof. The views and opinions of document authors expressed herein do not necessarily state or reflect those of the United States Government or any agency thereof, Argonne National Laboratory, or UChicago Argonne, LLC. 


\section{Report on Year-2 of Water NSTF Matrix Testing}

Two-Phase Baseline \& Repeatability

prepared by:

Darius Lisowski, Qiuping Lv, Nathan Bremer, Rui Hu, Adam Kraus, Dennis Kilsdonk, Stephen Lomperski, and Mitch Farmer

Nuclear Science \& Engineering, Argonne National Laboratory

September 2020 


\section{Executive Summary}

Under support from the Department of Energy (DOE) and the Office of Advanced Reactor Technologies (ART), a large scale test facility has been constructed at Argonne National Laboratory to generate NQA-1 qualified validation data for passive decay heat removal systems of advanced reactors. The Natural convection Shutdown heat removal Test Facility (NSTF) reflects key features of a $1 \frac{2}{2}$ scale, water-based, Reactor Cavity Cooling System (RCCS) and is intended to study the behavior, bound performance, and ultimately guide design decisions for passive decay heat removal systems for advanced reactors. Since the facility also retains all aspects common to a fundamental boiling water thermosiphon, the generated experimental data sets are well poised to advance the understanding of fundamental natural circulation boiling and two-phase flow phenomena.

This report serves as a summary of the testing activities conducted during the program's second year of operation. Matrix testing began with establishing two-phase conditions that would serve as a common reference basis for nominal behavior, system parameters, and to monitor system repeatability. This twophase reference, or baseline test case, identified specific initial and boundary conditions that were derived from openly available literature of the full scale reactor concept. For the NSTF, these conditions defined a nominal decay heat load of $51.6 \mathrm{~kW}_{\mathrm{t}}, 80 \%$ fill of the primary tank or approximately 3,800 liters of liquid inventory, riser discharge configured into tank center port, and 86.5- $\mathrm{cm}$ cooling panel to heated wall setback distance. An auxiliary heat removal system was configured to act as a steam condensation network, with boil-off condensate removed from the system and stored in collection reservoirs. Following power ramp and boiling incipience, the facility was allowed to maintain quasi-steady conditions with natural boil-off for a minimum period of 4 hours. With two-phase natural circulation phenomena able to invoke a wide range of thermal hydraulic behaviors with minimal variations in operating conditions, attention was then given to repeating test conditions and establishing confidence in the facility's ability to generate similar results. Upon establishment of the baseline two-phase test case and repeating facility behavior across separate test runs, parametric testing began with variations of the initial system inventory. These parametric tests examine the influence of static (initial) and dynamic (transient) system inventory, with four volumes identified that will study inventories ranging from overfilled, baseline, reduced, and depletion. During this year, one static inventory parametric test was completed at a reduced initial fill level of $70 \%$.

Over a 12-month period, a total of five matrix test cases were conducted at two-phase boiling operating conditions. Of these, four were performed at standard two-phase baseline conditions for the purposes of establishing confidence in the test facility's and operator's ability to generate repeatable results. Following, the inventory parametric test series was initiated and resulted in a successfully completed fifth test that demonstrated the influence of a reduced inventory level at baseline conditions. 


\section{Contents}

Executive Summary

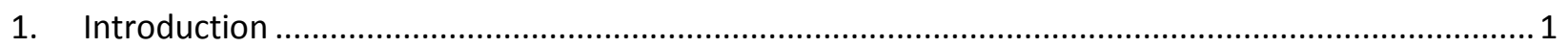

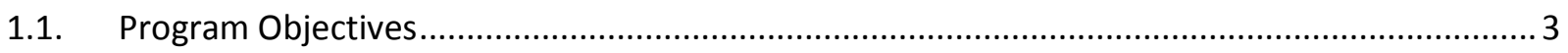

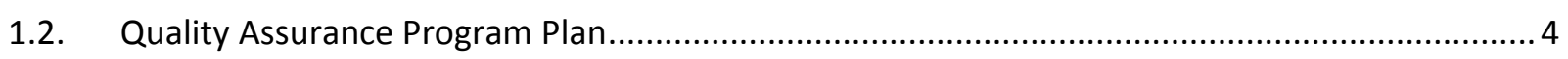

1.3. Previous Water Testing Accomplishments ...................................................................... 4

2. Facility Design (reference ANL-ART-98) ................................................................................. 5

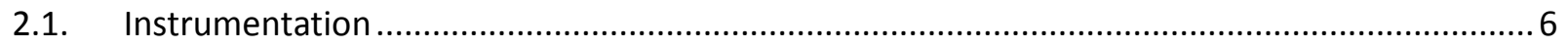

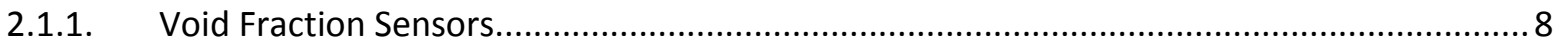

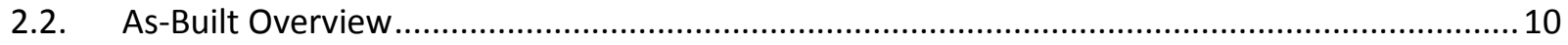

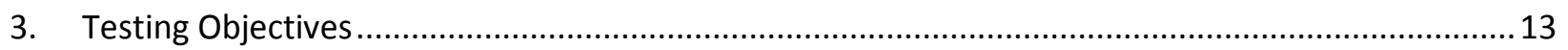

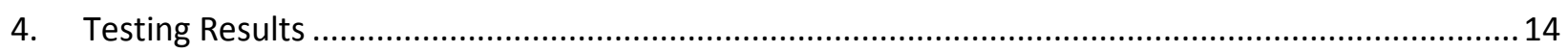

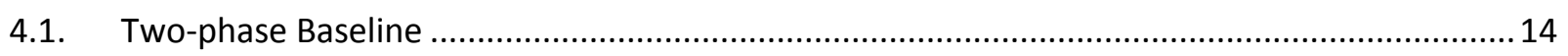

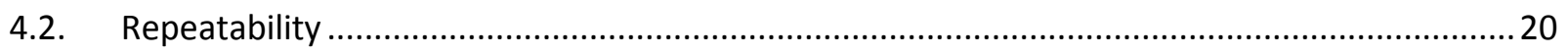

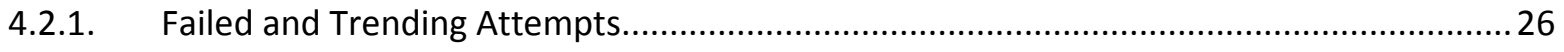

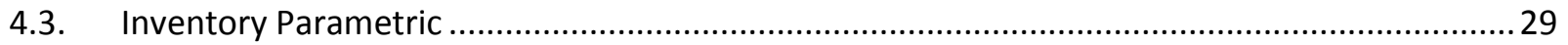

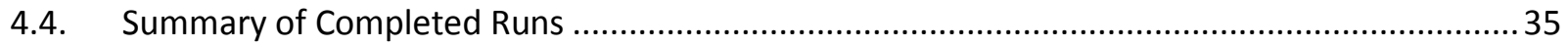

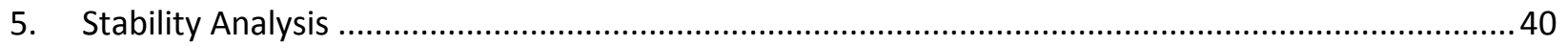

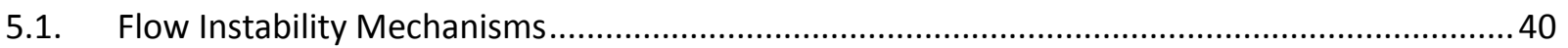

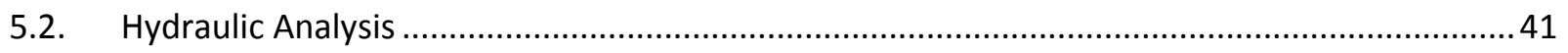

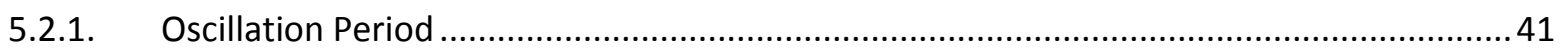

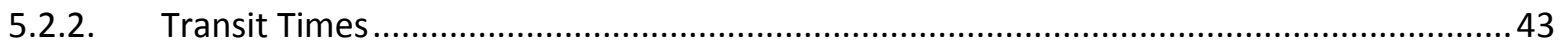

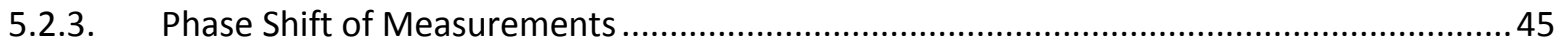

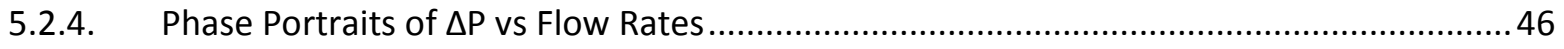

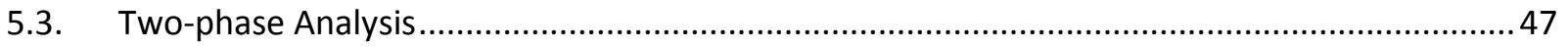

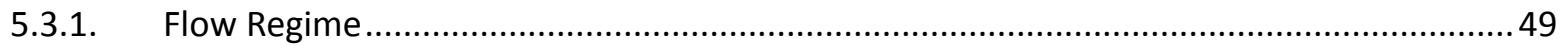

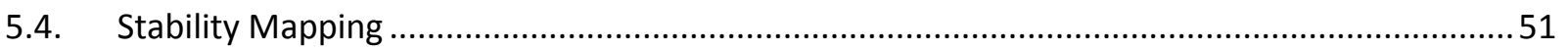

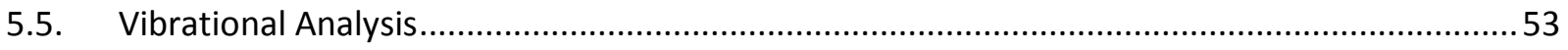

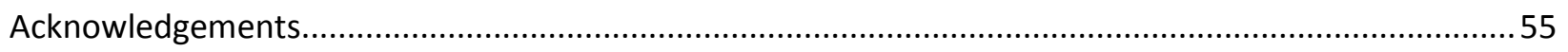

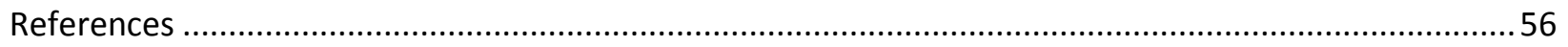




\section{List of Figures}

Figure 1: Solid model render of complete water NSTF in laboratory high-bay ...................................... 2

Figure 2: Cross section of single subassembly cooling panel unit ...........................................................5

Figure 3: Overview of instrumentation locations on water NSTF....................................................... 7

Figure 4: Location of void fraction sensors along upper chimney network .......................................... 8

Figure 5: Gamma densitometer (top) and twin tip optical probe (bottom) ............................................. 8

Figure 6: Raw binary signals generated by twin tip optical probe...........................................................

Figure 7: As-built dimensions of water NSTF, front (East facing) view .................................................. 11

Figure 8: As-built dimensions of water NSTF, side (South facing) view............................................... 12

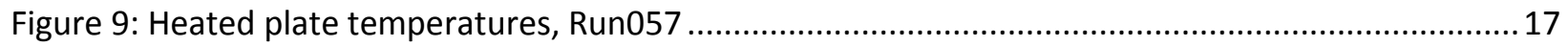

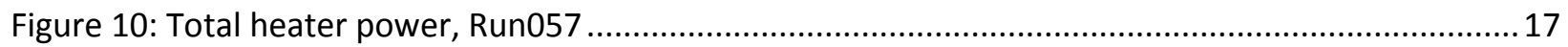

Figure 11: Test section tube wall temperatures, Run057 ................................................................ 17

Figure 12: Test section fin wall temperatures, Run057 .................................................................. 17

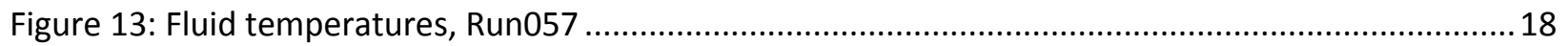

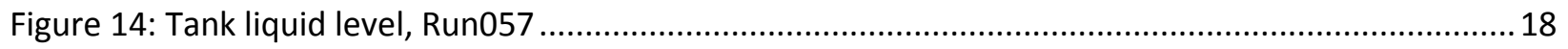

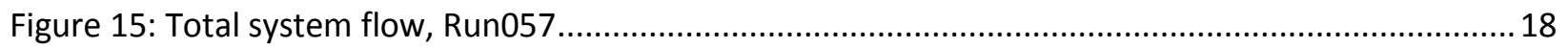

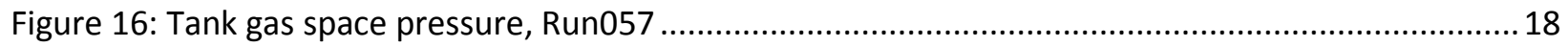

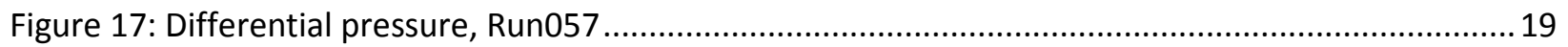

Figure 18: Chimney void fraction showing boiling/flashing, Run057 ................................................... 19

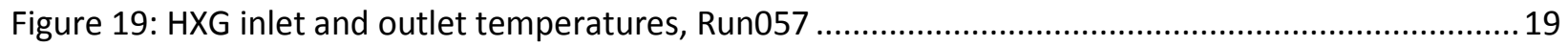

Figure 20: Near-linear condensate level increase, Run057 ................................................................ 19

Figure 21: Comparison of system flow rate between Run057 and Run059 ..........................................2 21

Figure 22: Comparison of system flow oscillation period between Run057 and Run059........................22

Figure 23: Comparison of tank water level between Run057 and Run059 .............................................22

Figure 24: Comparison of tank gas space pressure between Run057 and Run059..................................23

Figure 25: Comparison of condensate volume generated between Run057 and Run059........................23

Figure 26: Comparison of liquid temperatures between Run057 and Run059....................................24

Figure 27: Comparison of volumetric void fraction in chimney between Run057 and Run059.................24

Figure 28: Influence on gas space pressure and tank level sensors after opening impulse valve..............26

Figure 29: Unexpected increase in the measured tank gas space pressure at 17.5 hours in Run058 ....... 27

Figure 30: Steam inlet temperature below $100^{\circ} \mathrm{C}$ during Run058 indicating condensate accumulation .. 27

Figure 31: Progression of dissimilarities as three baseline test cases develop and begin to stabilize....... 28

Figure 32: CAD drawing of water tank with levels shown for various fill levels. Dimensions in inches ..... 29

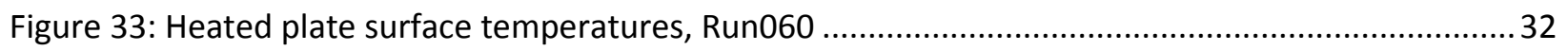

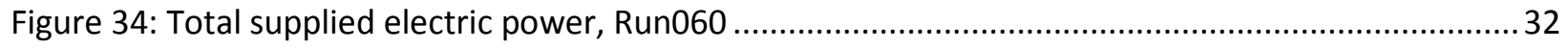

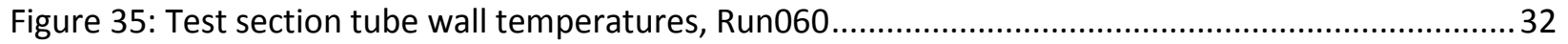

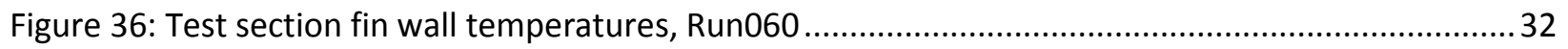

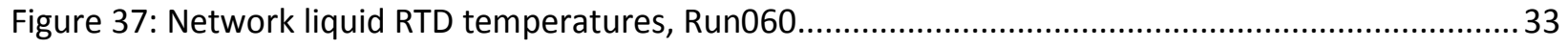

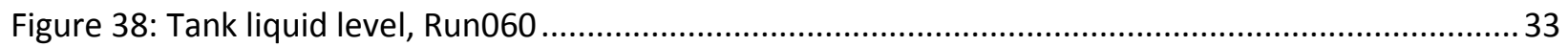

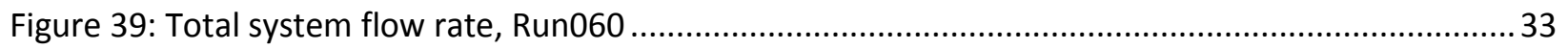

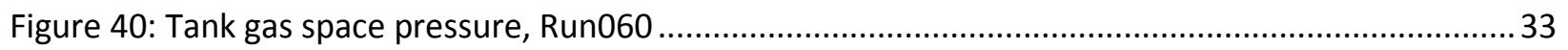

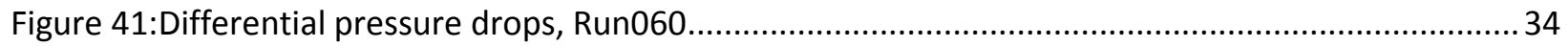

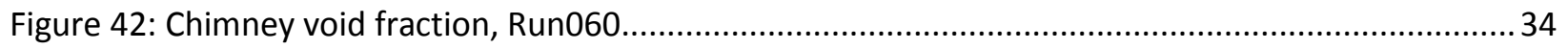

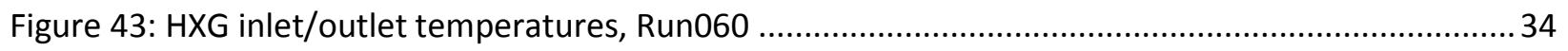

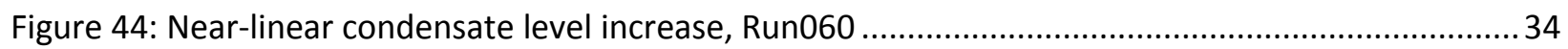




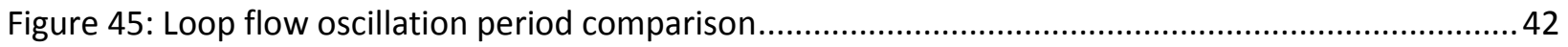

Figure 46: Fundamental frequencies in the upper chimney pressure drop ......................................... 42

Figure 47: Fluid transit time in the channel vs oscillation period.......................................................... 44

Figure 48: Fluid transit time of entire system vs oscillation period.......................................................... 44

Figure 49: Phase shifted differential pressure curves during two-phase oscillations ............................... 45

Figure 50: Phase portrait of flow-upper chimney pressure drop in Run057 ........................................... 46

Figure 51: Overlay system flow rate and measured void fraction, Run058 ............................................ 47

Figure 52: Influence on calculated void fraction with varying time constants ........................................48

Figure 53: Comparison between two void fraction sensors during boiling operation in Run060.............. 49

Figure 54: System flow rate during Run060; reference for two-phase flow regimes periods A-D..............50

Figure 55: Regime path during approach to boiling, period A .............................................................50

Figure 56: Regime path during large oscillations, period B ..................................................................50

Figure 57: Regime path during decay into stability, period C...........................................................50

Figure 58: Regime path during stable two-phase, period D ...............................................................5 50

Figure 59: Flow instabilities in Run060 compared with the stability map by Fukuda and Kobori [20] ......52

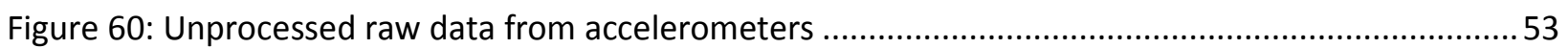

Figure 61: Fast Fourier Transform (FFT) phase plots of vibrations along chimney, structure, and tank....54

Figure 62: Time history of measured peak acceleration magnitude ...................................................54 


\section{List of Tables}

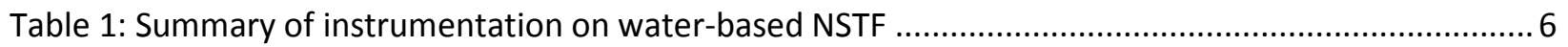

Table 2: Primary operating features of the as-built water NSTF .............................................................. 10

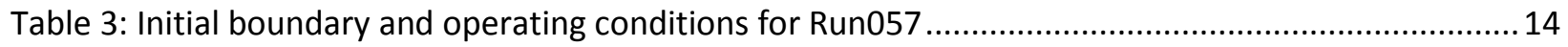

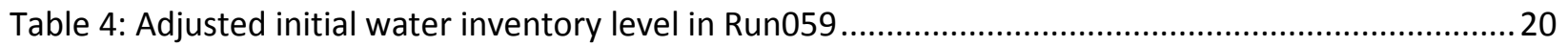

Table 5: Measured values during the acceptance criteria window, two-phase repeatability ...................22

Table 6: Statistical comparison between Run057 and Run059. Values averaged over 1-hour window .... 25

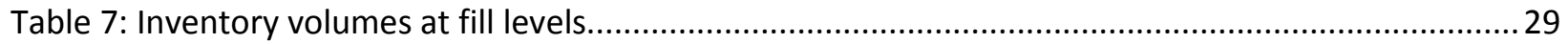

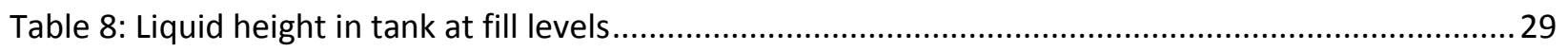

Table 9: Initial boundary and operating conditions for Run060 .......................................................... 30

Table 10: Comparison of acceptance criteria between baseline test case and inventory parametric .......31

Table 11: Summary of completed matrix test cases during Year 2 of Water NSTF testing ....................... 35

Table 12: Summary of fluid hydraulic parameters. Statistics spanning 1-hour period starting from 1st

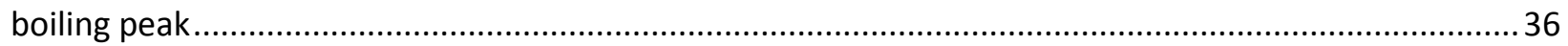

Table 13: Summary of structural temperatures and power levels. Statistics spanning 1-hour period starting from 1st boiling peak.

Table 14: Summary of fluid hydraulic parameters. Statistics spanning 1-hour period starting from 2.5 hours after 1st boiling peak .38

Table 15: Summary of structural temperatures and power levels. Statistics spanning 1-hour period starting from 2.5 hours after 1st boiling peak 


\section{Introduction}

The Natural convection Shutdown heat removal Test Facility (NSTF) at Argonne National Laboratory (Argonne) is a large scale test facility constructed to study the performance of passive safety systems for advanced nuclear reactor concepts. First initiated in 2005, this Department of Energy (DOE) sponsored research program has included both experimental and computational activities. Between 2010 and 2016 the program focused on examining the performance and stability of an air-based Reactor Cavity Cooling System (RCCS) concept. During this time, the NSTF was built to reflect a $\frac{1}{2}$ scale and $19^{\circ}$ sector slice of the design proposed by General Atomics for use in their $350 \mathrm{MW}_{\mathrm{t}}$ MHTGR. Details of this air-based program, including design bases, testing results, and project conclusions, can be found in previously published reports [1].

Following completion of the air-based objectives, the program transitioned to an alternative design concept and began efforts to convert the facility to water-based cooling. This water-based NSTF was then designed to align with major features of the Framatome (formerly AREVA) 625 MW SC-HTGR RCCS. Details of the design bases for the conceptual prototype, along with scaling and preparation tasks can be found in earlier reports [2][3]. A design report of the current, as-built, water-based facility, along with new program requirements and testing plan, can similarly be found in previous reports [4]. 


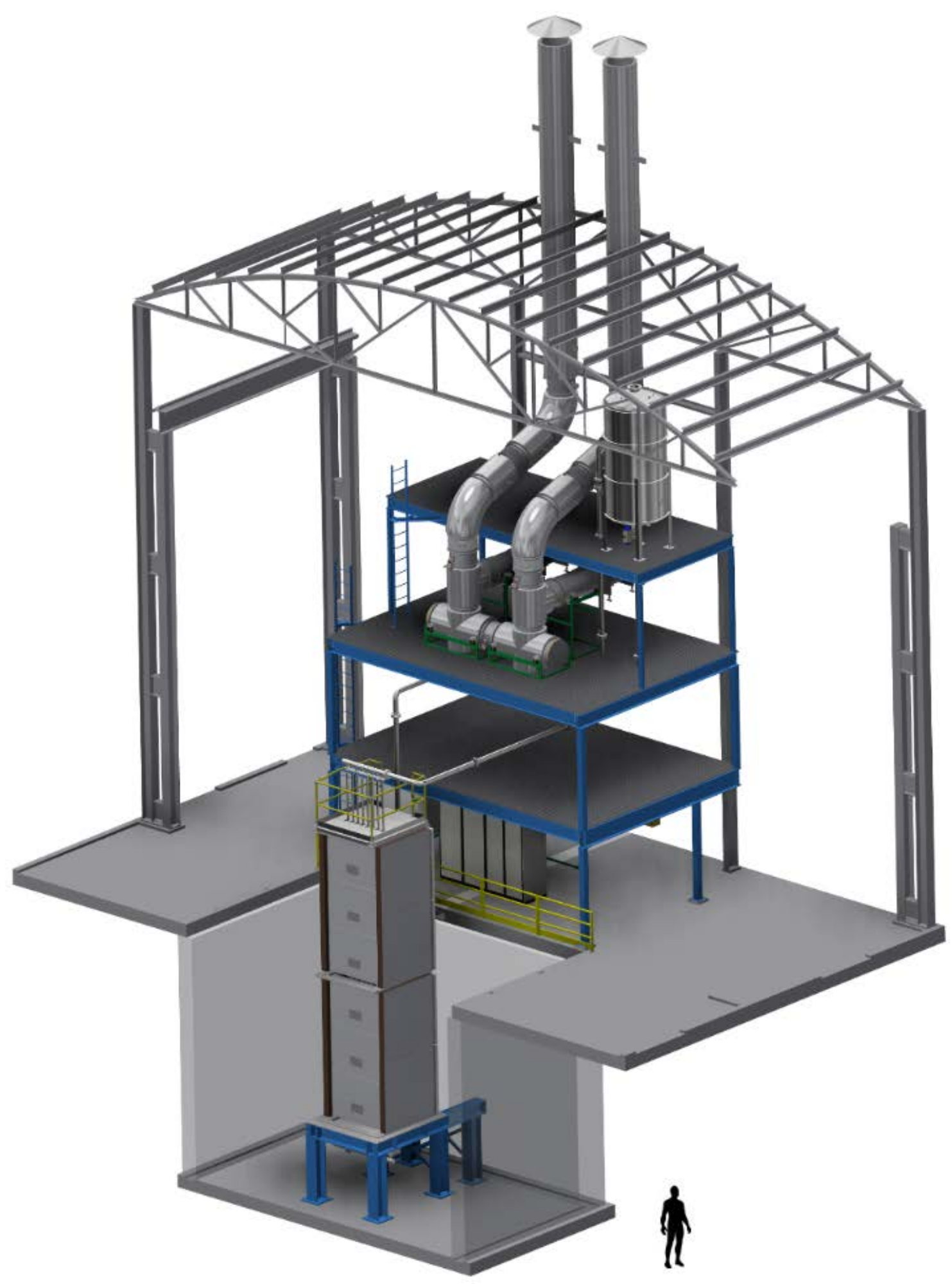

Figure 1: Solid model render of complete water NSTF in laboratory high-bay 


\subsection{Program Objectives}

The effort at Argonne is focused on an experimental test facility for data generation, coined the Natural convection Shutdown heat removal Test Facility (NSTF). Since 2005, this program has supported the DOE vision to provide US vendors with data suitable for characterizing the RCCS concept for passive decay heat removal. With previous iterations of the facility design focusing on variants of an air-based RCCS concept, this latest iteration is focused on a water-based design of the RCCS concept.

This program also aims to advance the basic understanding of natural circulation phenomena, which is an integral feature of many advanced safety concepts. By coupling large scale, integral-level observations with local, high-resolution measurements, the NSTF intends to create a shift from uncertainty to predictability, allowing industry realization of a successful decay heat removal solution.

The purpose of the generated data is centered on two industry needs: validation of codes that can be used in licensing, and optimization of the advanced conceptual designs. These demand a diverse set of requirements for the experimental capabilities and operating conditions, and furthermore, create a need for applicability to full scale systems if the data is to be relevant. Thus, a rigorous scaling methodology and validation process is required to support the provided data. The scaling basis and similarity relationships have been carefully derived to ensure preservation of key thermal hydraulic behaviors [5] from full scale conditions [6], and are primary driving factors in providing a technical basis for extrapolation of testing results to real conditions.

To successfully generate data that is relevant to nuclear codes and industry designers, the data must be produced within a controlled, traceable, and NQA-1 compliant program. Furthermore, the data must encompass the complete range of thermal hydraulic phenomena. Measurements of integral behavior such as system flow rate and heated section temperature rise become highly valuable only if they can be coupled with high fidelity measurements of local parameters. Integrated system codes such as RELAP5 and MELCOR are currently the standard for licensing; however computational fluid dynamics (CFD) codes continue to mature and are now playing major roles in advancing model development and phenomenological understanding. These advanced codes demand higher resolution data and must be considered when determining the overall instrumentation suite. Within the NSTF specifically, computational efforts have been active since the program's inception and will remain an area of continued development as experimental data becomes available. Efforts to date on modeling of the water-based facility can be found in published reports [8].

Finally, the ability to study design optimization hinges on successful engineering and review processes of facility design. The foresight to include flexibility in facility operation and configuration is a crucial 
aspect in determining an experimental program's long term sustainability and relevance. The ability to easily adapt to new discoveries, changes in industry requirements, or currently-unforeseen scenarios directly supports this design optimization objective and has been given a high priority in early design stages.

\subsection{Quality Assurance Program Plan}

The research and development activities of this experimental program are under the control of an NQA-1 compliant quality assurance program plan (QAPP) based on the requirements set forth in the American Society of Mechanical Engineers (ASME) NQA-1-2008 (with 1a 2009 addenda) Quality Assurance (QA) requirements for nuclear facility applications [9]. These guidelines have been established to provide reliable, reproducible, and timely data on the effects of the reactor cavity cooling system on the heat removal from the reactor vessel wall. Assessments, both internal and formal external audits, will be conducted on a regular basis throughout the entirety of the water-based testing program.

\subsection{Previous Water Testing Accomplishments}

In first year of matrix testing with the water-based NSTF, the program had completed four bake-out and shakedown test procedures, six single-phase heated test cases, three isothermal characterization tests, and one two-phase demonstration. In total, 370 hours of active test operations were logged across 12 separate test operations. Details of these test cases, including results and observations, can be found in previously published works by the program team [7]. The following sections detail the objectives, completed test cases, and results from the second year of matrix testing. 


\section{Facility Design (reference ANL-ART-98)}

In its current configuration, the test facility stands 59.2-ft (18.1-m) tall with an eight riser cooling panel test section extending 30-ft $(9.2-\mathrm{m})$ in total length. The water tubes are constructed from 316L stainless steel pipe, 1.5-inch nominal diameter, and Schedule 160 wall thickness. Spaced apart by a pitch of 5.91-inch, 1018 carbon steel fins, 5/16-inch in thickness, are welded to the tube centerline for a final pitch-to-diameter ratio of 3.1. However, the fins extend only along a 6.75-m length, which reflects the portion located within bounds of the heated cavity.

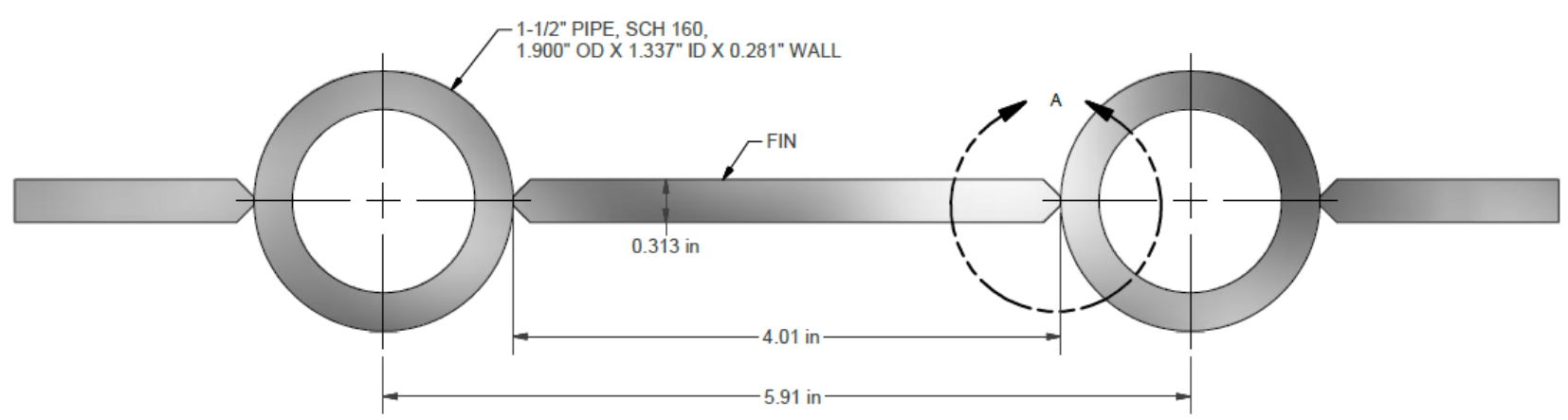

Figure 2: Cross section of single subassembly cooling panel unit

The primary piping is a single path network that joins the heat source and heat sink of the test facility, creating a single closed loop for natural circulation. Consisting of a chimney (hot line) and downcomer (cold line) segment, the chimney joins the outlet of the heated test section to the inlet of the water storage tank, while the downcomer joins the outlet of the water storage tank to the inlet of the heated test section cooling panel, Figure 3. Both sections are constructed entirely from 316L stainless steel piping, sized 4.0inch and Schedule 40. A total of 105-linear feet of piping, 9 long-radius elbows, and 34 flanges make up the network. Flange types are split between weld-neck and lap-joint style assemblies, with weld-neck favored for sections of high stress or cyclic loading.

The water storage tank was designed in-house and fabricated by an outside vendor to meet a number of project requirements. Primarily, the tank features a height-to-diameter ratio of 2, is able to hold a minimum 1,000-gallon capacity, includes dual side inlet port locations, and can be pressurized to 2 atmospheres. Additionally, several instrumentation access ports were included along the top dome, bottom dish, and side walls of the tank, ranging from 0.25-inch Swagelok fittings for thermocouples and pressure taps, to an 8.0-inch weld neck flange for future instrumentation and access needs, Figure 3. Finally, a 6.0-inch clear sight glass was added to the top dome, along with an 18-inch manway access port to the side wall, facilitating inspections. 


\subsection{Instrumentation}

A suite of sensors within the water NSTF allow measurement of pertinent thermal hydraulic behaviors during both single- and two-phase mode of operations. Instruments have been selected to minimize disturbance of the natural circulation flow. The instrumentation suite is diverse enough to quantify both integral and local behaviors across the full extent of the system components. To address the high priority system measurements, e.g. thermal and mass balance, both temperature and flow measurements utilize sensors that are minimally intrusive and exhibit very low uncertainty. Details of each sensor are provided in the following sections, with a high level summary provided in Table 1, a facility diagram of installed locations in Figure 3, and complete details in previous reports [4].

Table 1: Summary of instrumentation on water-based NSTF

\begin{tabular}{|c|c|c|c|c|c|c|}
\hline Measurement & Sensor Type & Location & Qty. & Mfg. & Model & Range \\
\hline Flow rate & Magnetic & Inlet header & $\mathrm{x} 1$ & Krohne & Optiflux 4000 & $\pm 5 \mathrm{~kg} / \mathrm{s}$ \\
\hline Flow rate & Magnetic & Inlet riser & $\mathrm{x} 8$ & Krohne & Optiflux 4000 & $\pm 1 \mathrm{~kg} / \mathrm{s}$ \\
\hline Static head & Strain & Inlet header & $\mathrm{x} 1$ & Rosemount & $3051 S$ & $0-10$ bar \\
\hline Steam pressure & Strain & Gas space & $\mathrm{x} 1$ & Rosemount & $3051 \mathrm{~S}$ & $0-2$ bar $_{a b s}$ \\
\hline$\Delta \mathrm{P}$ & Strain & Chimney & $\mathrm{x} 2$ & Rosemount & $3051 S$ & $\pm 6 \mathrm{kPa}$ \\
\hline$\Delta \mathrm{P}$ & Strain & Risers & x3 & Rosemount & $3051 S$ & $\pm 62 \mathrm{kPa}$ \\
\hline Liquid level & Strain & Tank & $\mathrm{x} 1$ & Rosemount & $3051 \mathrm{~S}$ & $0-3 \mathrm{~m}$ \\
\hline Void fraction & Optical & Chimney & $\mathrm{x} 2$ & RBI & Twin-tip & $0-100 \%$ \\
\hline Void fraction & $\gamma$-Density & Chimney & $\mathrm{x} 1$ & ThermoFisher & DensityPRO & $0-100 \%$ \\
\hline Temperature & RTD & Fluid & $\mathrm{x} 4$ & Omega & UP, $1 / 10$ DIN & $0-250^{\circ} \mathrm{C}$ \\
\hline Temperature & T-type TC & Fluid & $\mathrm{x} 128$ & ARi & $\mathrm{T}-31 \mathrm{~N}$ & $0-400^{\circ} \mathrm{C}$ \\
\hline Temperature & K-type TC & Test section & x24 & ARi & $\mathrm{T}-31 \mathrm{~N}$ & $0-600^{\circ} \mathrm{C}$ \\
\hline Temperature & K-type TC & Structures & x286 & ARi & Silica 20AWG & $0-600^{\circ} \mathrm{C}$ \\
\hline Temperature & DTS & Test section & $\mathrm{x} 20$ & LUNA & ODiSI-A & $0-300^{\circ} \mathrm{C}$ \\
\hline Acceleration & Surface mount & Structural & $\mathrm{x} 4$ & PCB & 353C03 & $10 \mathrm{~Hz}-10 \mathrm{kHz}$ \\
\hline Water $\mathrm{pH}$ & pH Meter & Inlet header & $\mathrm{x} 1$ & Emerson & RBI 547 & $0-14 \mathrm{pH}$ \\
\hline Conductivity & Insertion & Inlet header & $\mathrm{x} 1$ & Sensorex & CS675HTTC & $10-2000 \mu \mathrm{S} / \mathrm{cm}$ \\
\hline
\end{tabular}




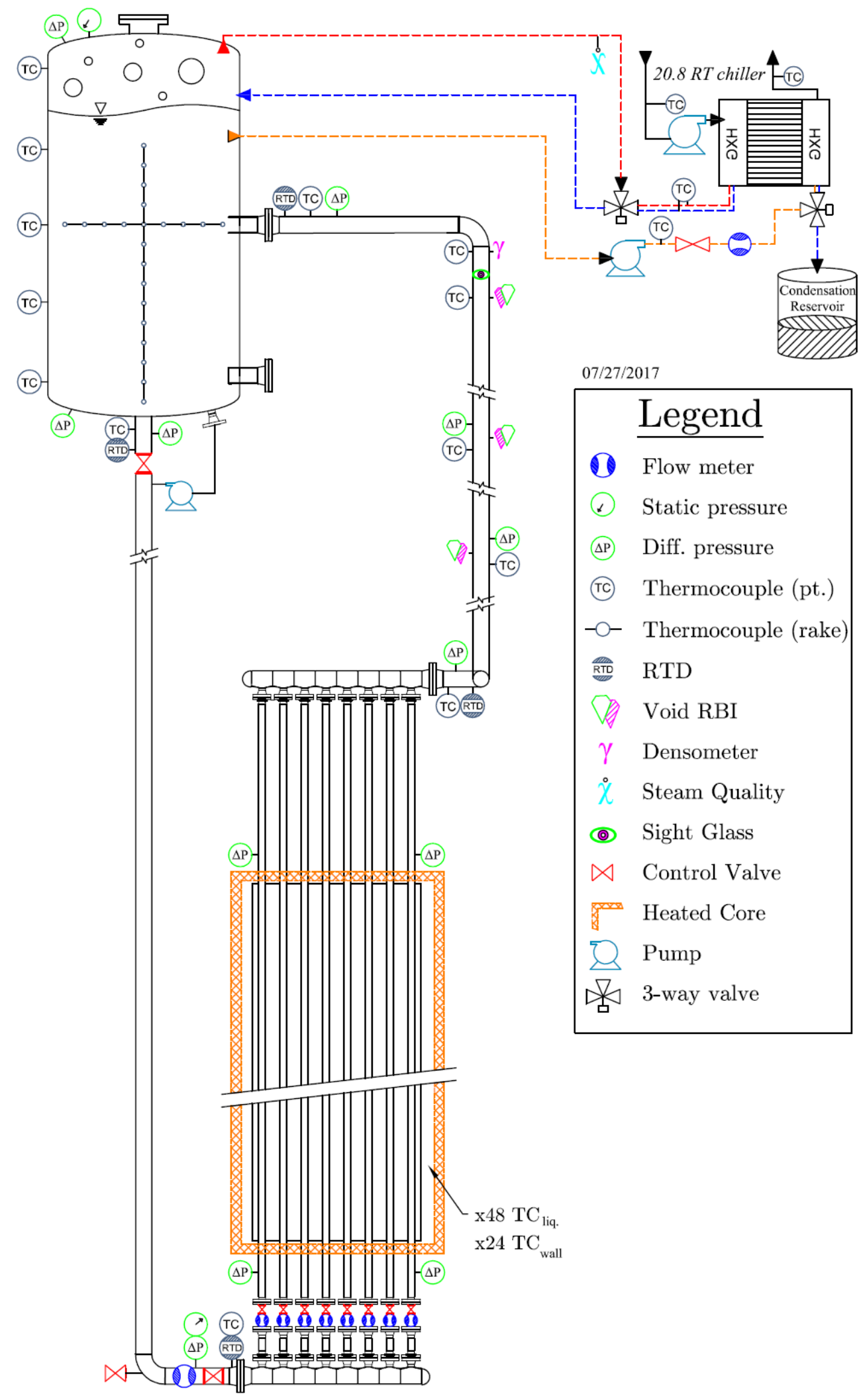

Figure 3: Overview of instrumentation locations on water NSTF 


\subsubsection{Void Fraction Sensors}

Two devices are used for quantitative measurement of the void fraction, and include both point (local) and bulk (volumetric) void fraction. Both are installed on the vertical chimney section, immediately prior to the inlet of the water storage tank, in a best attempt to capture the full network two-phase flow patterns. A third device, a transparent sight glass, Model 255 from Ernst Co., is planned and will provide means for visual or qualitative observation of the two-phase flow regimes. At the time of this report, installation of the sight glass has been delayed due to concerns of personnel safety and co-located equipment.

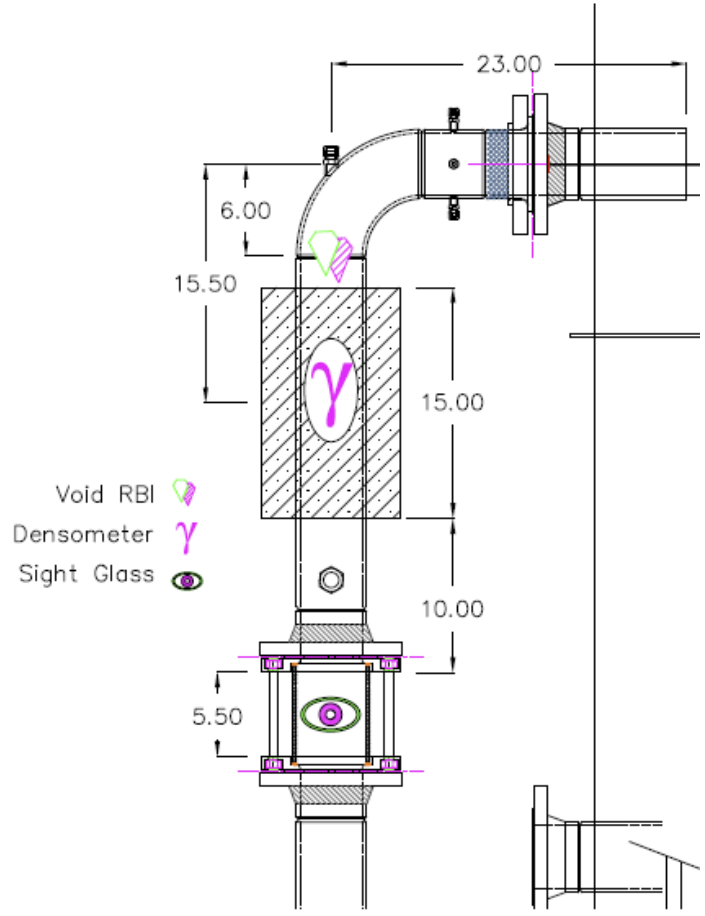

Figure 4: Location of void fraction sensors along upper chimney network

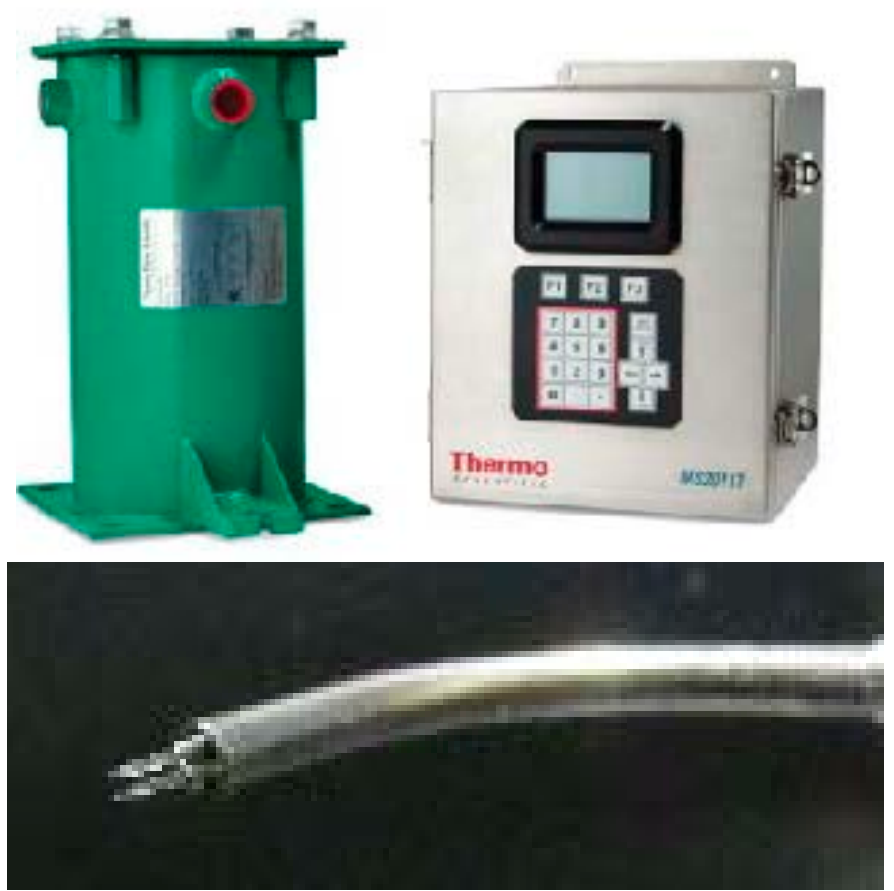

Figure 5: Gamma densitometer (top) and twin tip optical probe (bottom)

The first device, a gamma densitometer, model DensityPRO from ThermoScientific is commonly used in industry applications as a simple density gauge [10]. Consisting of a source head, detector, and transmitter, the radioisotope (Cs-137) emits gamma radiation, passing through the piping wall and medium, to finally be measured at the detector. The amount of transmitted radiation varies inversely with the medium density, or in the case of steam-liquid two-phase flow in the NSTF, correspondingly with the void fraction within the fluid. This device requires an initial online calibration of 0 and $100 \%$ voids, along with temperature compensation to accurate measure the void fraction. A proportional 4 - $20 \mathrm{~mA}$ signal output allows it to be seamlessly integrated into the overall data suite. The device's output signal provides a measurement of volume averaged void fraction and is fully non-intrusive to the flow field. 
The second device allows higher granularity in the measurement of two-phase flow and calculation of various statistics. Fabricated by RBI in France, this device consists of twin sapphire tips (i.e. Descartes prisms) extending from a 3-mm stainless sheath. Based on Snell's law of refraction, each probe outputs a low $(0-\mathrm{V})$ signal when immersed in a liquid phase, and a high $(5-\mathrm{V})$ signal when exposed to a gas phase, Figure 6. Each tip was sampling simultaneously at $10 \mathrm{kHz}$ rate and written onto the disk drive of the data acquisition computer. Post processing of the raw data from either tip allows one to determine the averaged local void fraction based on the duration of signals within the gas phase divide by the total duration of the acquisition period, Eqn. 1. Due to the dual tip construction of the RBI void fraction probes, other two-phase parameters such as the time of flight, Eqn. 2, superficial gas velocity, Eqn. 3, bubble diameter, etc. can be calculated. These parameters require accurate knowledge of the tip spacing, $d_{\text {tips }}$, along the flow axis, along with accurate time stamps on the probe signals, $\delta$.

$$
\alpha=\frac{1}{T} \sum_{i=1}^{N} \tau_{N} \quad[1] \quad \text { TOF }=\frac{1}{N} \sum_{i=1}^{N} \delta_{N} \quad \text { [2] } \quad \vec{u}=\frac{d_{\text {tips }}}{\text { TOF }}
$$

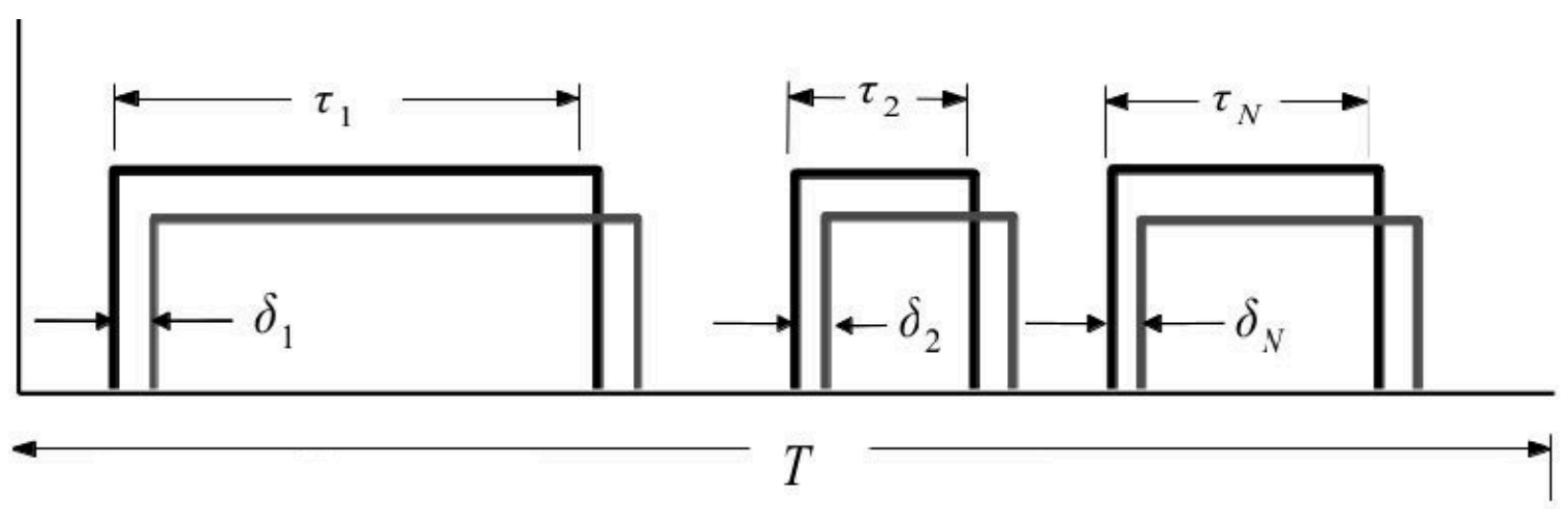

Figure 6: Raw binary signals generated by twin tip optical probe 


\subsection{As-Built Overview}

In summary, the final assembly of the water NSTF reflects a $1 / 2$ axial scale and $12.5^{\circ}$ sector slice of the primary design features of a full scale RCCS concept. High level design specifications are itemized below, general operating parameters listed in Table 2, front-facing facility view in Figure 7, and sidefacing facility view in Figure 8.

- Riser tubes: 1.5-inch Sch. 160, 5.91-inch (150-mm) pitch, 316L stainless

- Heat transfer panels: 5/16-inch plates, 4.01-inch (102-mm) width, full penetration HLAW weld to risers, 1018 carbon steel

- Cooling panel: Eight (x8) riser tubes and ten (x10) heat transfer panels, fabricated into banks of two (x2) riser tubes and three (x3) fins, joined by 5/16-inch carbon steel plates to form a single section

- Network piping: 4.0-inch Sch. 40, 316L stainless

- Water tank: 4,260-liter capacity, H/D ratio of 2.0, rated to 2 bar over pressure

Table 2: Primary operating features of the as-built water NSTF

Facility type Natural circulation, boiling water, thermal hydraulic test facility

Overall facility height $18 \mathrm{~m}$ (59 ft.)

i) Natural or forced circulation

Operating modes ii) Single-phase with active cooling

iii) Two-phase with steam boil-off

Working fluid Deionized water with $\mathrm{NaClO}$ added for conductivity / algae control

Liquid inventory 4,260 liter storage tank, 389 liter piping and test section

Heated section area

Rectangular, $132 \mathrm{~cm}$ wide cavity with adjustable cavity depth ranging from 45 to $150 \mathrm{~cm}$ in $2.5 \mathrm{~cm}$ increments

Heated section length $6.7 \mathrm{~m}(22 \mathrm{ft}$.)

Heating distribution One long side heated; other 3 sides adiabatic

Heated operating modes $\begin{aligned} & \text { i) Constant heat flux (heater maximum: } 23 \mathrm{~kW} / \mathrm{m}^{2} \text { ) } \\ & \text { ii) Constant temperature (maximum: } 500^{\circ} \mathrm{C} \text { ) }\end{aligned}$

Total input power $220 \mathrm{~kW}_{\mathrm{e}}$

Heated zone resolution $\mathrm{x} 10$ axial segments, $\mathrm{x} 4$ azimuthal control zones 


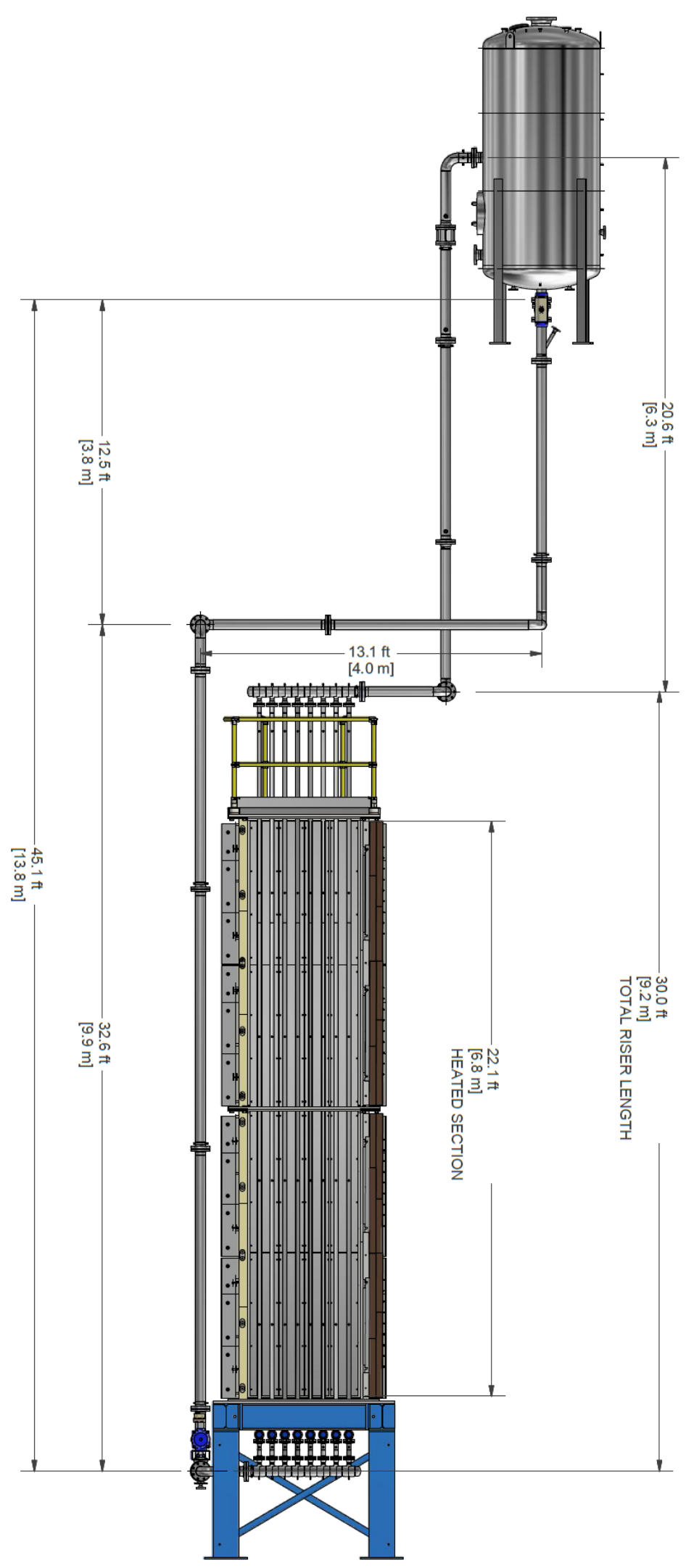

Figure 7: As-built dimensions of water NSTF, front (East facing) view 


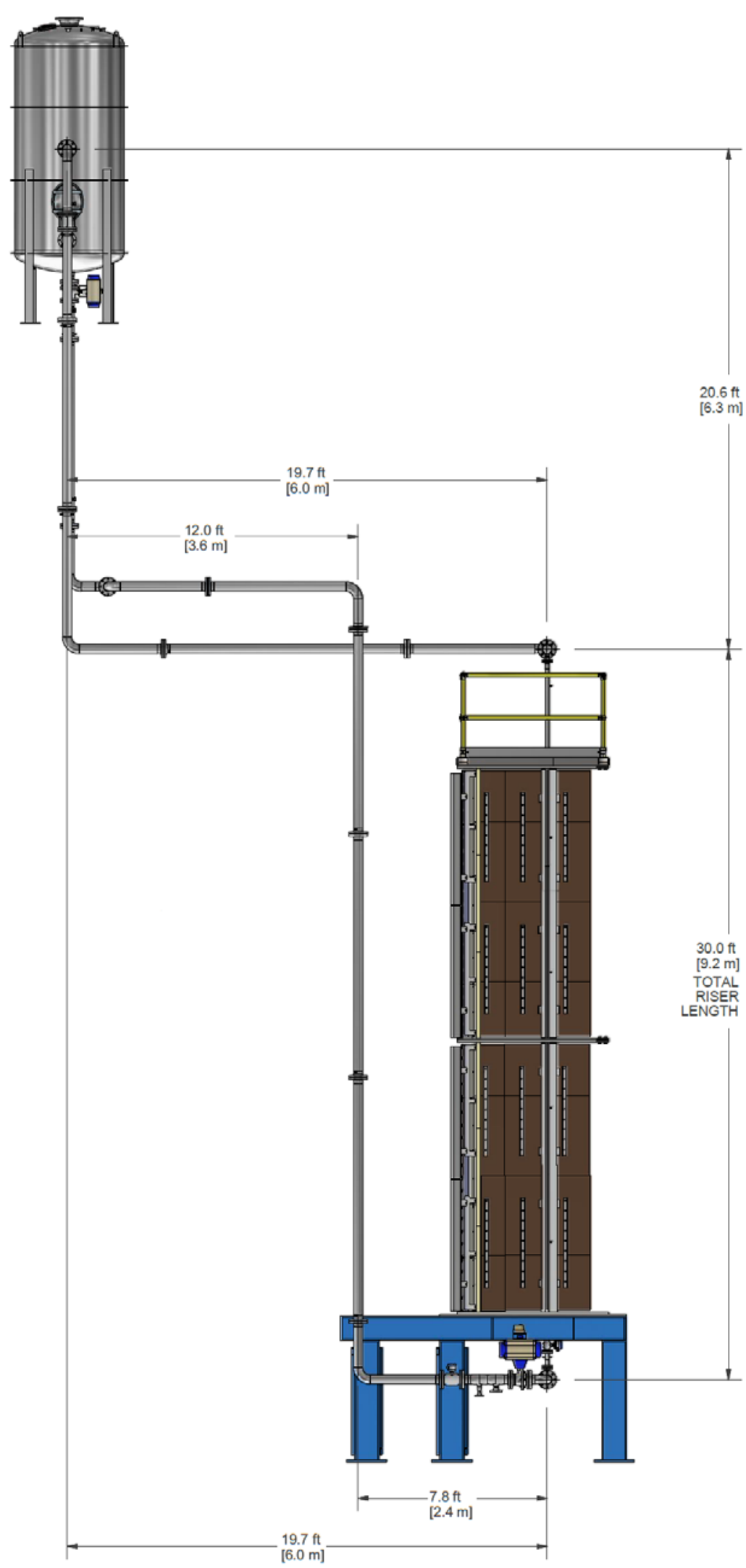

Figure 8: As-built dimensions of water NSTF, side (South facing) view 


\section{Testing Objectives}

Testing during the second year of the water-based NSTF program focused primarily on establishing confidence in the facility and operators' ability to repeat baseline conditions during two-phase flow mode of operation. This baseline scenario is based off a heat load that matches vendor specified power levels anticipated during transient accident conditions [6].

At full scale, 2.1 $\mathrm{MW}_{\mathrm{t}}$ of decay heat load will be rejected off the reactor pressure vessel and onto the RCCS. When scaled using similarity parameters derived in earlier works, the resulted heat load on the NSTF will be $51.6 \mathrm{~kW}_{\mathrm{t}}$. Similar to the single-phase baseline test cases performed in the previous year, the network geometry was routed to the mid-height tank inlet port and the water storage tank filled to $80 \%$ volume inventory. The heat removal system was configured to act as a steam condensation network, with boil-off condensate removed from the system after passing through the heat exchanger. As temperatures rise in the fluid and begin to experience boiling, the network inventory saw gradual reduction due to boiloff. Thus, without replenishment, only a quasi-steady state operation was achieved. For the test cases performed in this report, natural boil-off was established without replenishment, and the test facility maintained at quasi-steady conditions for a minimum period of 4 hours.

The inherent sensitivity of natural circulation systems can invoke a wide range of thermal hydraulic phenomena with minimal variations in operating conditions. This is due to the complex and uncertain thermal hydraulic behavior commonly associated with two-phase phenomena. Thus, attention was given to repeating exact test conditions and the ability to generate similar results. Note that results were not expected to be identical across repeated tests; instead, analysis was used to establish statistically significant similarity and confidence in achieving similar operation and behavior across separate data sets.

With completion of the baseline two-phase test case and confidence in the ability to repeat facility behavior across separate test runs, parametric testing began with variations of system inventory. These tests are intended to examine the influence of static (initial) and dynamic (transient) system liquid inventory. Static cases will vary only the starting system inventory, with four volumes identified that will study inventories ranging from overfilled, to reduced, to near-depletion. During this year, one inventory parametric test was completed at a reduced $70 \%$ initial fill level. 


\section{Testing Results}

The following sections detail completed cases conducted during the second year of matrix testing for the water-based NSTF. For the purposes of reader clarity, the use of RunONN and DataQualityONN are interchangeable.

\subsection{Two-phase Baseline}

The first objective during this year's testing was to complete and establish a known set of test conditions and facility response to establish a reference, or baseline, set of operating conditions. This twophase baseline case defines a nominal full scale decay heat load of $2.1 \mathrm{MW}_{\mathrm{t}}$, or $51.6 \mathrm{~kW}_{\mathrm{t}}$ for the NSTF scale, 80\% initial tank inventory, riser discharge into tank center port, and 86.5-cm (34.05-inch) riser tube to heated wall setback distance. The first successful baseline test was conducted during Run057, with facility setup at the geometry configurations summarized in Table 3. The heater power was applied across a 90-minute linear power ramp and then maintained constant to allow heating up of the NSTF facility and water inventory. Upon reaching saturation, boiling/flashing of water was first observed in the upper chimney region, and sustained for over 4 hours, followed by power ramp down. Results of this test are presented in this section.

Table 3: Initial boundary and operating conditions for Run057

\begin{tabular}{|c|c|}
\hline \multicolumn{2}{|l|}{ Facility geometry } \\
\hline Heated - riser spacing & 34.05 inch \\
\hline Chimney-tank inlet position & Center tank \\
\hline \multicolumn{2}{|l|}{ Heat load: } \\
\hline Power control & Burst firing \\
\hline Distribution & Linear / uniform across 40 zones \\
\hline Power level & $72 \mathrm{~kW}_{\mathrm{e}}$ \\
\hline \multicolumn{2}{|l|}{ Valves position } \\
\hline Tank outlet: & Open \\
\hline Loop inlet throttle: & Open \\
\hline Riser(s) inlet: & All eight open \\
\hline Riser(s) outlet: & All eight open \\
\hline \multicolumn{2}{|l|}{ Differential pressure } \\
\hline$\Delta \mathrm{P}-01$ & Test section, $\left(\mathrm{DP}_{20}-\mathrm{DP}_{44}\right)$ \\
\hline$\Delta \mathrm{P}-02$ & Lower chimney, $\left(\mathrm{DP}_{22}-\mathrm{DP}_{20}\right)$ \\
\hline$\Delta \mathrm{P}-03$ & Mid chimney, $\left(\mathrm{DP}_{23}-\mathrm{DP}_{22}\right)$ \\
\hline$\Delta \mathrm{P}-04$ & Upper chimney, $\left(\mathrm{DP}_{25}-\mathrm{DP}_{23}\right)$ \\
\hline$\Delta \mathrm{P}-05$ & Full loop/water tank $\left(\mathrm{DP}_{25}-\mathrm{DP}_{40}\right)$ \\
\hline \multicolumn{2}{|l|}{ Liquid inventory } \\
\hline Inventory fill amount & $80 \%$ tank level, $~ 1,004$ gal \\
\hline Inventory fill level & 84.875-inch (sight glass), 105.94-inch $(\Delta \mathrm{P})$ \\
\hline Liquid conductivity & $30.62 \mu \mathrm{S} / \mathrm{cm} @ 21.7^{\circ} \mathrm{C}$ \\
\hline $\mathrm{pH}$ & $7.02-$ \\
\hline
\end{tabular}


The total heater power applied in this test began with a 90-minute power ramp, then maintained at a constant $72 \mathrm{~kW}_{\mathrm{e}}$, Figure 10. The ceramic electric heater temperatures, the highest in the entire NSTF system, were closely monitored and stayed below the preset safety trip point of $650^{\circ} \mathrm{C}$ during the test. Temperatures of the heated plate, test section tube wall, test section fin wall, and test fluid are shown in Figure 9 - Figure 13. The heated plate temperatures seem to be more dependent on the source power, while the riser tube wall temperatures more dependent on the fluid (heat sink) temperatures. Upon reaching saturation, boiling/flashing started at $13.2 \mathrm{hr}$ into the test, indicated by the fluid temperature oscillations in the test section and chimney, Figure 13. The oscillations are caused by the two-phase flow instabilities, which will be discussed later. The fluid temperatures in the downcomer did not exhibit any oscillations mainly due to the damping effect of the water tank and the fluid being slightly subcooled. The oscillation effects were also observed in the riser tube wall temperatures due to the efficient heat transfer between the riser walls and the fluid. However, mainly due to the high thermal resistance of the thermal radiation process, this effect did not propagate to the heated plate, which showed as stable trend after boiling/flashing started. The riser fin walls, which were controlled by both the thermal radiation from the heat source and thermal conduction to the heat sink, experienced an average effect in terms of reduced temperature oscillations compared to the riser walls that had direct contact with the fluid.

The total system flow and tank gas space pressure are shown in Figure 15 and Figure 16, respectively. As can be seen, single-phase natural circulation flow was successfully developed after $1.7 \mathrm{hr}$ of heating. There was an abrupt jump in the single-phase flow when natural circulation initiated, following which the flow increased gradually until boiling. At $13.2 \mathrm{hr}$ when saturation was reached, two-phase boiling/flashing initiated causing flow instabilities typical of low-pressure boiling system, Figure 15. The two-phase flow featured an initial violent oscillation with a peak value of $6.6 \mathrm{~kg} / \mathrm{s}$ right after boiling/flashing initiated, and then slowly damped as the test progressed. Flow instabilities persisted during the 4-hour two-phase quasi-steady state and before a power ramp down was initiated at 19 hrs. The tank gas space pressure stayed constant during the single-phase operation, and started to increase upon initiation of boiling mainly due to the flow resistance in the steam condensation network, Figure 16. The tank inventory level experienced a constant reduction upon initiation of boiling/flashing, Figure 14.

An energy balance analysis was performed for this test. During the two-phase test, the heat exchanger was operated at the condensing mode and there condensate rate was measured only be a level sensor in the condensate reservoir. As will be discussed later, boiling/flashing occurs at the upper chimney portion based on the observations of phase shifts in the differential pressure measurements. This suggests that the fluid remains single-phase in the test section, and the thermal power over the test section can be calculated as $c_{p} \dot{m} \Delta T$. Toward the end of the 4-hour two-phase quasi-steady state window, the thermal power input into the test section is approximately $46 \mathrm{~kW}_{\mathrm{t}}$, resulting in a thermal efficiency of $64 \%$. The 
reduced efficiency, compared to the value of $71 \%$ in the previous single-phase tests [7], is mainly due to the increases ambient losses due to higher fluid temperatures and cavity temperatures.

A close examination on the system behaviors during the 4-hour two-phase quasi-steady state is shown in Figure 18 - Figure 20. The initiation of two-phase boiling/flashing was successfully captured by the void measurement, Figure 18. At early stage of the two-phase operation, the vapor generation is in an excursion mode with the measured void fraction intermittently reaching zero. As the test progressed (after $17 \mathrm{hr}$.), vapor generation becomes more stable and continuous. The heat exchanger steam side inlet temperature starts to see an increase at $12.5 \mathrm{hr}$., earlier than the bulk boiling/flashing occurs, Figure 19. This was due to the increased water evaporation when approaching the saturation temperature. During this time, the vapor generation rate was insufficient that most of the steam was condensed before reaching the heat exchanger inlet. Upon initiation of boiling/flashing, the heat exchanger steam inlet temperature stays near the water saturation temperature. Lastly, the stable, two-phase operation can be demonstrated by the near-linear increase of the condensate level in the collection tank, Figure 20. Some of the primary measured values of interest during this phase are summarized in Table 5. 
Heated plate (front, data-quality) temperature - DataQuality057 (LabVIEW)

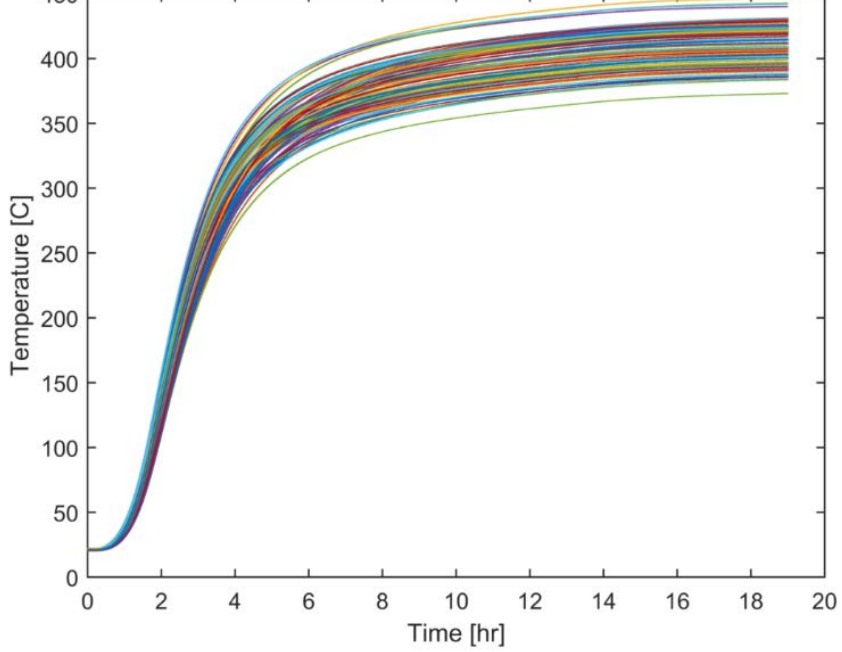

Figure 9: Heated plate temperatures, Run057

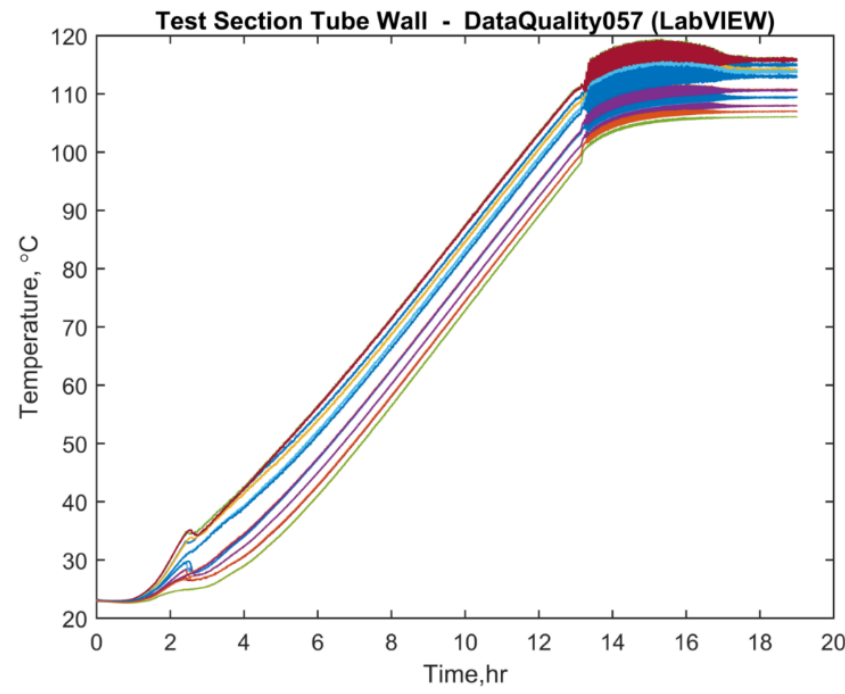

Figure 11: Test section tube wall temperatures, Run057

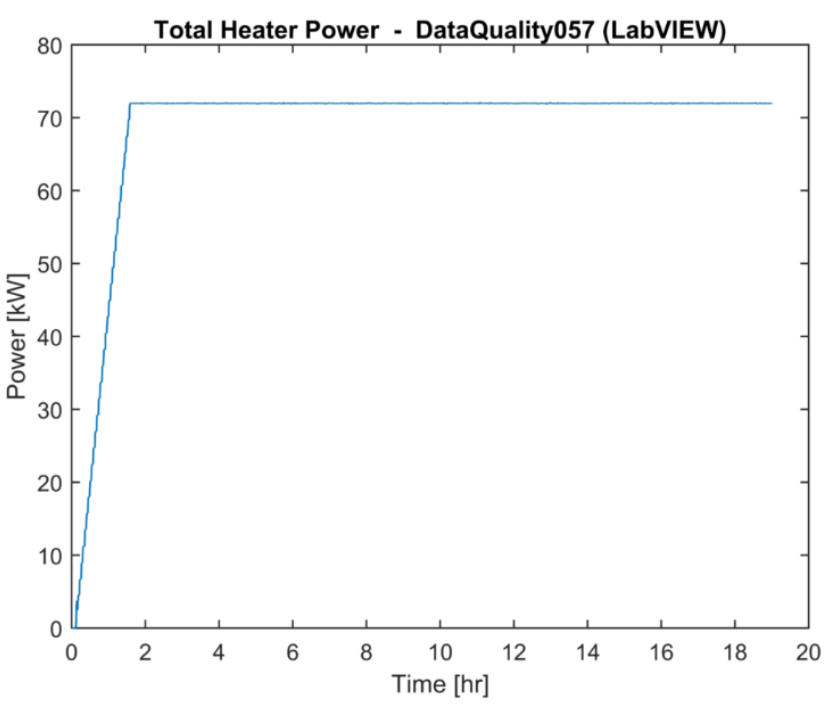

Figure 10: Total heater power, Run057

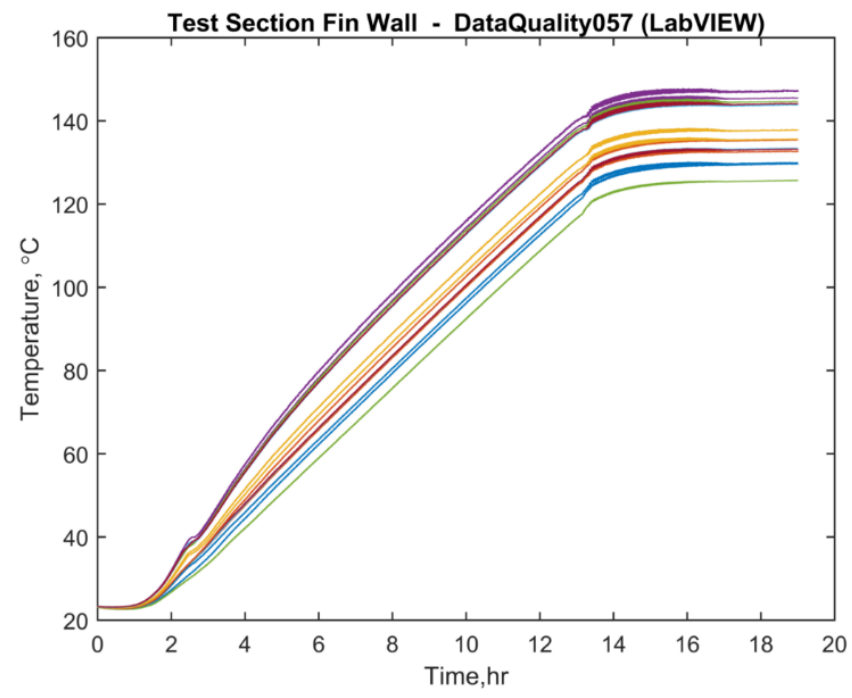

Figure 12: Test section fin wall temperatures, Run057 


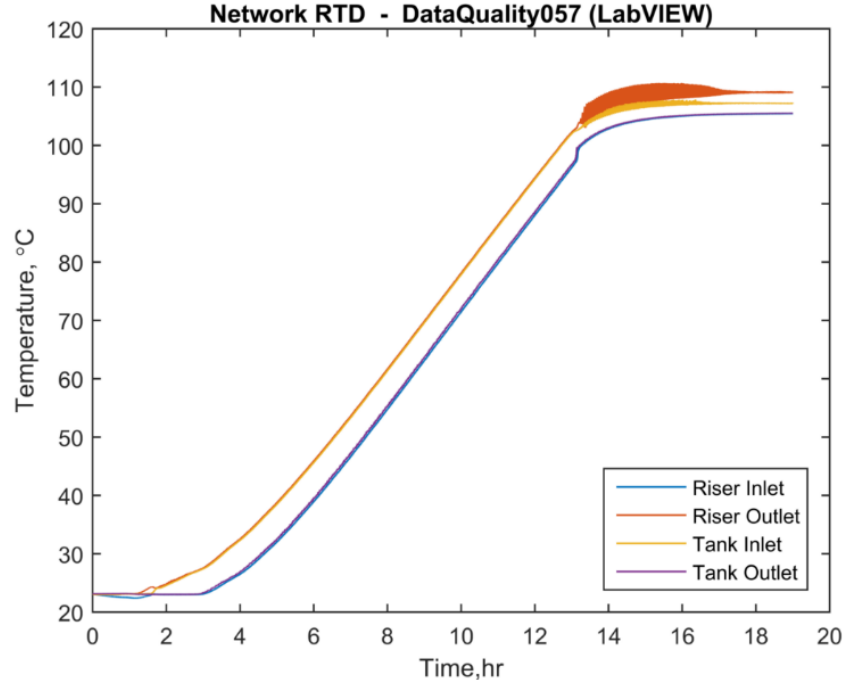

Figure 13: Fluid temperatures, Run057

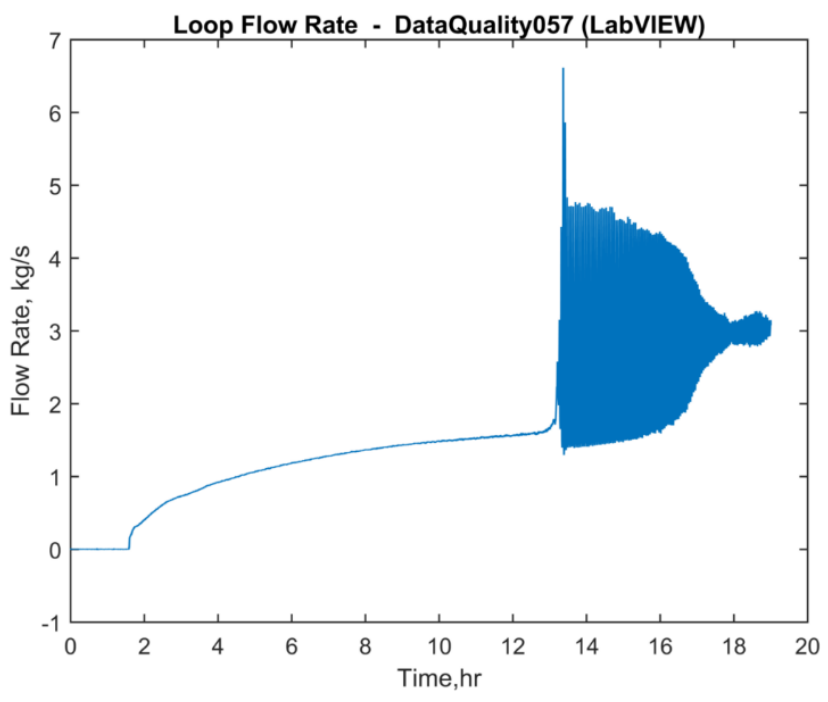

Figure 15: Total system flow, Run057

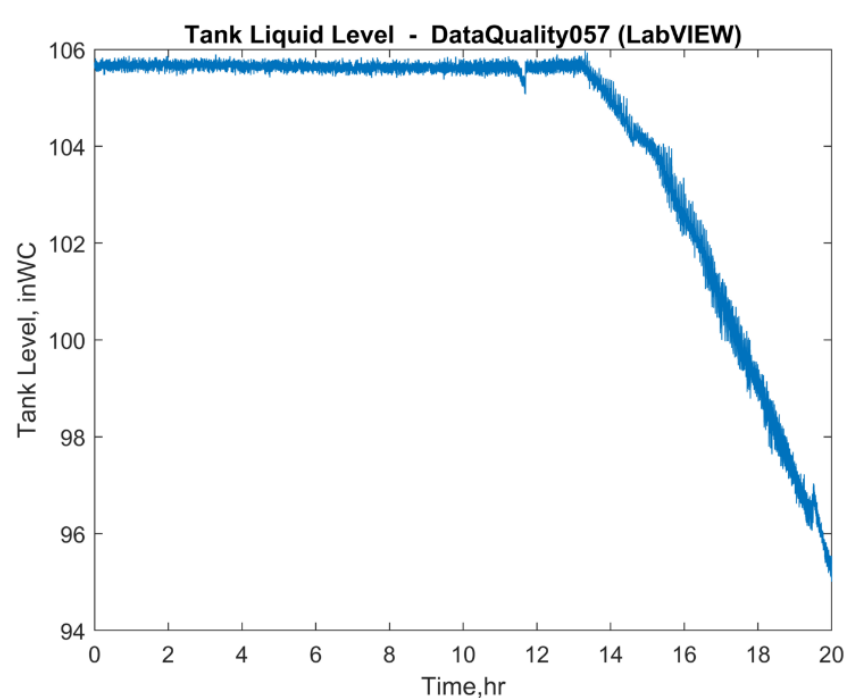

Figure 14: Tank liquid level, Run057

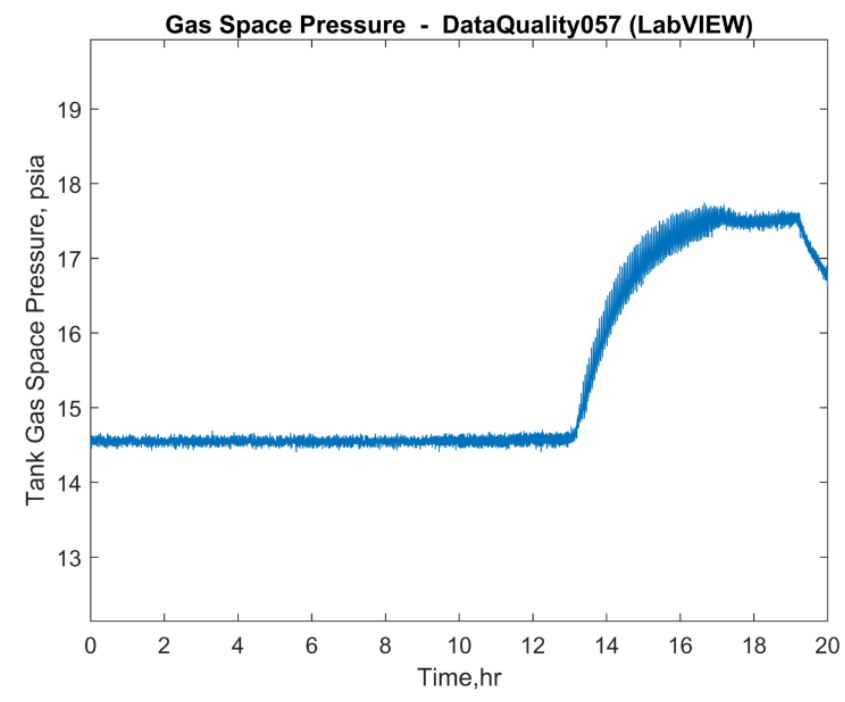

Figure 16: Tank gas space pressure, Run057 


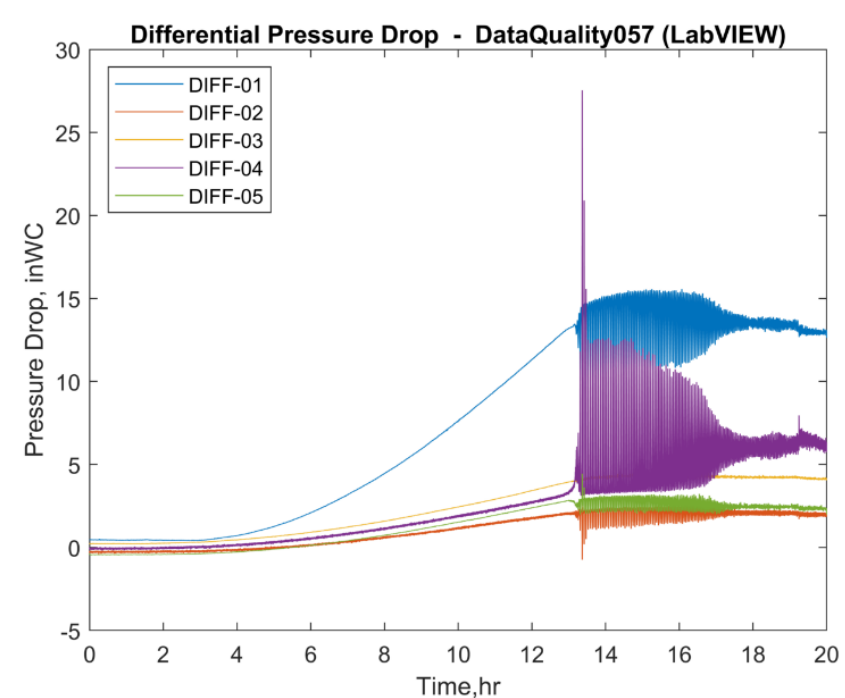

Figure 17: Differential pressure, Run057

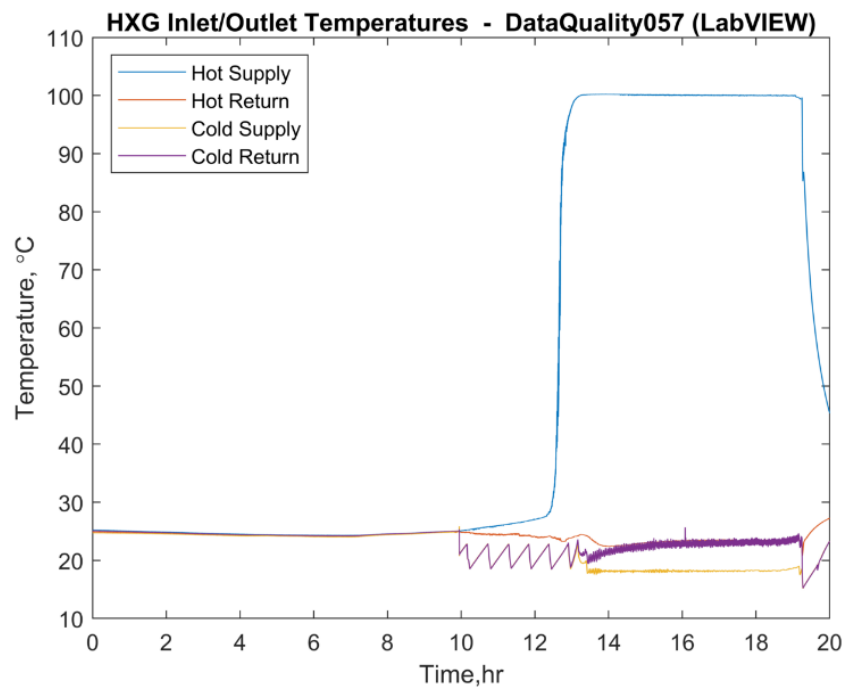

Figure 19: HXG inlet and outlet temperatures, Run057

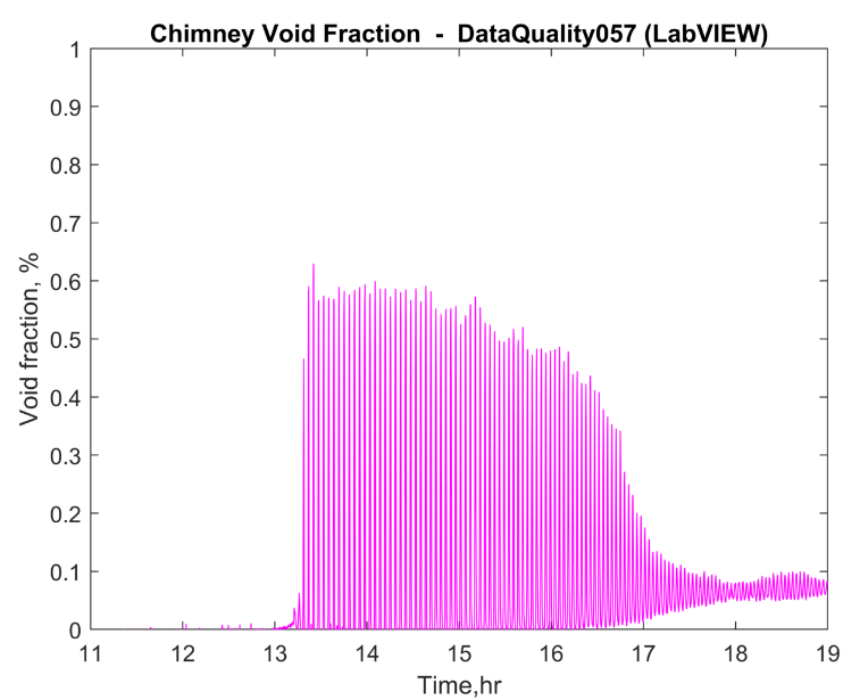

Figure 18: Chimney void fraction showing boiling/flashing, Run057

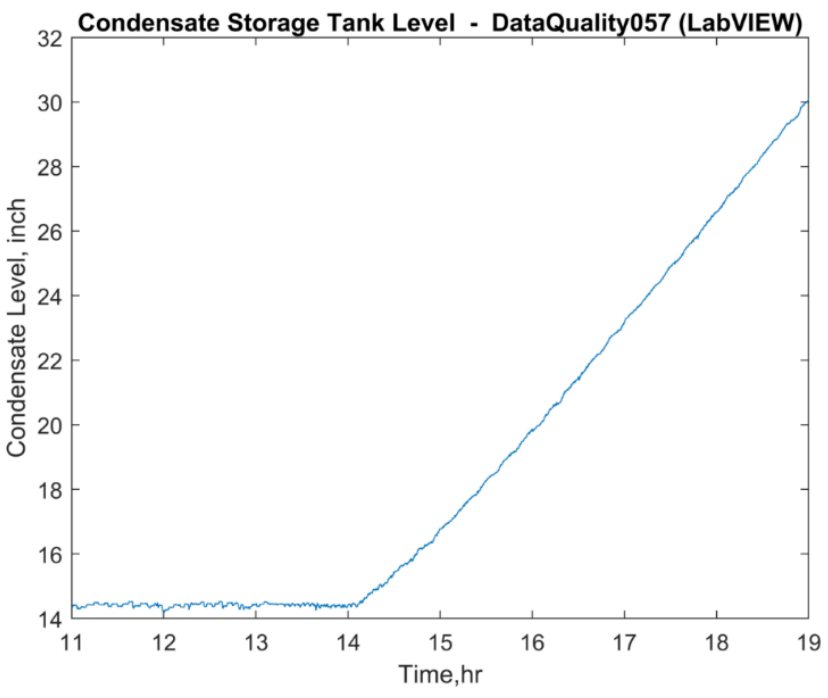

Figure 20: Near-linear condensate level increase, Run057 


\subsection{Repeatability}

Repeatability of the system behaviors, especially during two-phase operation is high interest for safety systems. To investigate the repeatability of the NSTF system performance with identical (more practically with variations within specified tolerances) initial and boundary conditions, a number of repeat attempts were made on the two-phase baseline test conditions. Four tests were conducted in total, one of which was classified as failed, another as trending, and two as successful. The previously conducted two-phase baseline (Run057) was repeated (Run059) with the same test procedure. The facility geometry used in Run059 was configured to match parameters during Run057, Table 3. Among the factors affecting the repeatability of the system behaviors, the initial water inventory level is deemed the most important. Therefore, efforts were made in Run059 to adjust the initial water inventory level to match the value in Run057. The adjusted initial inventory level was well within tolerances, Table 4.

Table 4: Adjusted initial water inventory level in Run059

$\begin{array}{lccc} & \begin{array}{c}\text { Target } \\ \text { (from } \text { Run057) }\end{array} & \text { Tolerance } & \begin{array}{c}\text { Actual } \\ \text { (tested in Run059) }\end{array} \\ \text { Tank Bulk } & 24.31^{\circ} \mathrm{C} & \pm 2^{\circ} \mathrm{C} & 23.20^{\circ} \mathrm{C} \\ \text { Loop RTD Average } & 23.09^{\circ} \mathrm{C} & \pm 2^{\circ} \mathrm{C} & 21.60^{\circ} \mathrm{C} \\ \text { Tank Level DP } & \mathbf{1 0 5 . 7 0} \text { inWC } & \pm 0.1 \text { inWC } & \mathbf{1 0 5 . 6 4} \text { inWC } \\ \text { Static Inlet } & \mathbf{3 8 . 0 8} \mathbf{~ p s i a} & \pm 0.50 \text { psia } & \mathbf{3 7 . 8 9} \mathbf{~ p s i a}\end{array}$

The system behaviors and cavity temperatures, fluid temperatures, and system flow rates observed during Run059 shared strong similarities compared to Run057, indicating good repeatability for the baseline case. To further demonstrate the repeatability achieved in Run059, the system flow instability characteristics following initiation of boiling/flashing were compared, Figure 21. It should be noted that the time scale has be normalized for the comparison due to a small difference in the single-phase transient duration caused by the minor difference in the initial system temperatures between the two tests. As seen, the system flow agrees very well between the two tests, even oscillation by oscillation early into the twophase transient. After $17 \mathrm{hr}$, the oscillation amplitude starts to diverge between the two tests. The system flow oscillation period is also compared between the two tests, shown in Figure 22. As seen, strong agreement is achieved. Since the system behaviors are most sensitive to the fluid inventory level, the agreement in the system flow instability characteristics is driven by the matched tank water level during the transient, Figure 23. The matched liquid temperatures, Figure 26, are mainly due to the strong agreement in the tank gas space pressure that affects the liquid saturation temperatures, Figure 24. The well matched void fraction results, Figure 27, are consistent with the agreement in generated condensate volume between the two tests, Figure 25. The key measured values during the 4-hour two-phase quasisteady state in Run059 are also summarized in Table 5, showing strong similarities in the flow instability characteristics. 
Table 5: Measured values during the acceptance criteria window, two-phase repeatability

\begin{tabular}{|c|c|c|c|c|c|c|c|}
\hline \multicolumn{2}{|l|}{ Porind Start Timo/Date } & \multicolumn{3}{|c|}{ Run057 } & \multicolumn{3}{|c|}{ Run059 } \\
\hline \multicolumn{2}{|l|}{ Period Start Time/Date } & \multicolumn{3}{|c|}{$10: 30,11 / 08 / 19$} & \multicolumn{3}{|c|}{$08: 30,03 / 05 / 20$} \\
\hline \multicolumn{2}{|l|}{ Period Duration } & \multicolumn{3}{|c|}{$13.2-17.2 \mathrm{hr}$} & \multicolumn{3}{|c|}{$13.3-17.3 \mathrm{hr}$} \\
\hline Loop Flow & & $\max$ & $\min$ & mean & $\max$ & $\min$ & mean \\
\hline Oscillation period (peak-to-peak) & sec & 202.0 & 152.0 & 183.5 & 205.0 & 156.0 & 183.5 \\
\hline Average flow (per cycle) & $\mathrm{kg} / \mathrm{s}$ & 2.92 & 2.17 & 2.55 & 2.90 & 2.21 & 2.55 \\
\hline Oscillation amplitude (peak-average) & $\mathrm{kg} / \mathrm{s}$ & 4.44 & 0.56 & 1.86 & 3.75 & 0.69 & 1.82 \\
\hline \multicolumn{8}{|l|}{ Two-phase Boil-Off } \\
\hline Maximum void fraction & $\%$ & \multicolumn{3}{|c|}{64.3} & \multicolumn{3}{|c|}{64.4} \\
\hline Average condensate rate & $\mathrm{gal} / \mathrm{min}$ & \multicolumn{3}{|c|}{0.29} & \multicolumn{3}{|c|}{0.26} \\
\hline Generated condensate volume & gal & \multicolumn{3}{|c|}{92.3} & \multicolumn{3}{|c|}{83.8} \\
\hline \multicolumn{8}{|l|}{ Post Loop Cool Down } \\
\hline Ending tank inventory level & inWC & \multicolumn{3}{|c|}{90.57} & \multicolumn{3}{|c|}{91.51} \\
\hline Estimate total inventory loss & gal & \multicolumn{3}{|c|}{$\sim 148$} & \multicolumn{3}{|c|}{$\sim 138$} \\
\hline
\end{tabular}

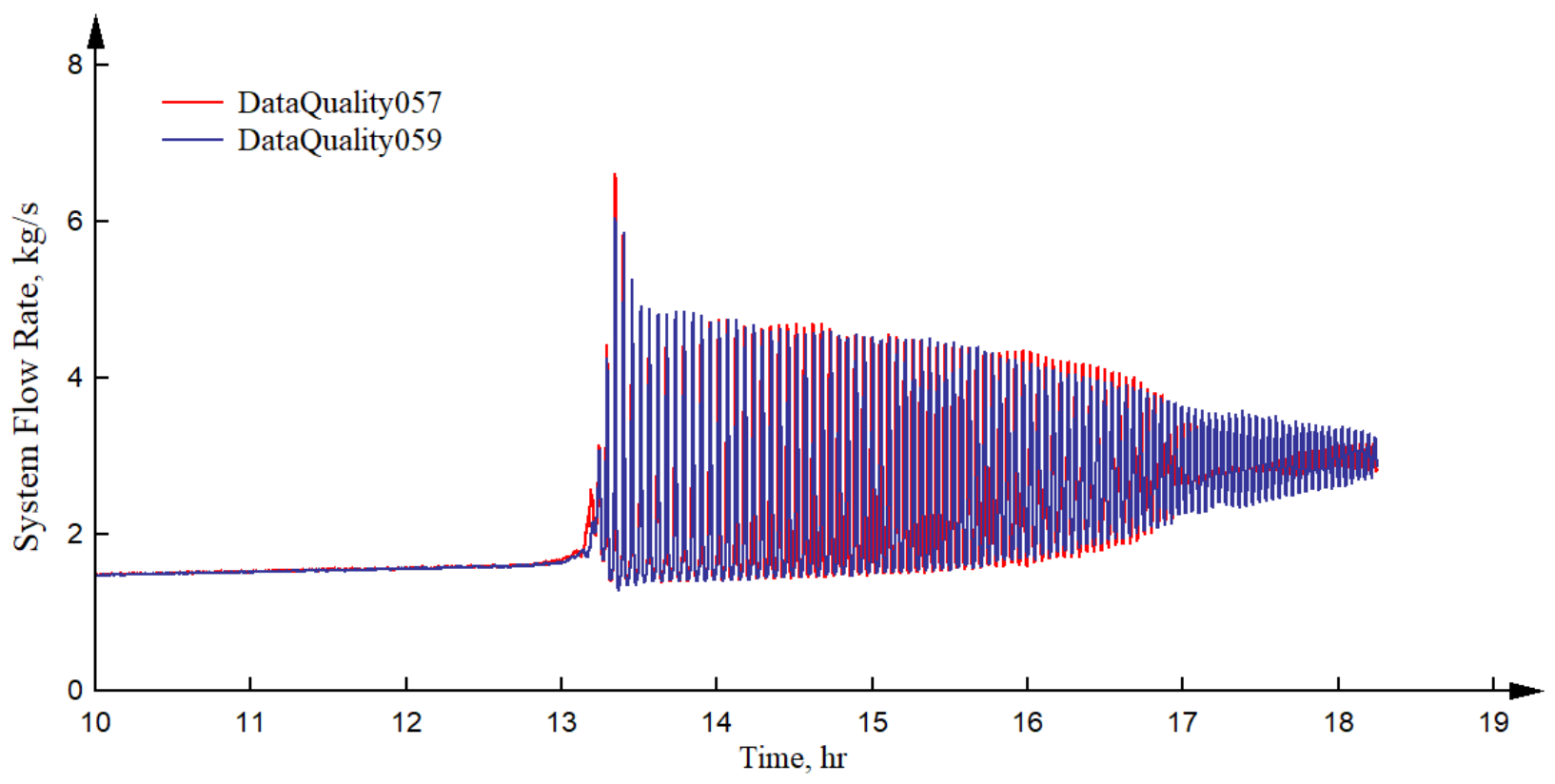

Figure 21: Comparison of system flow rate between Run057 and Run059 


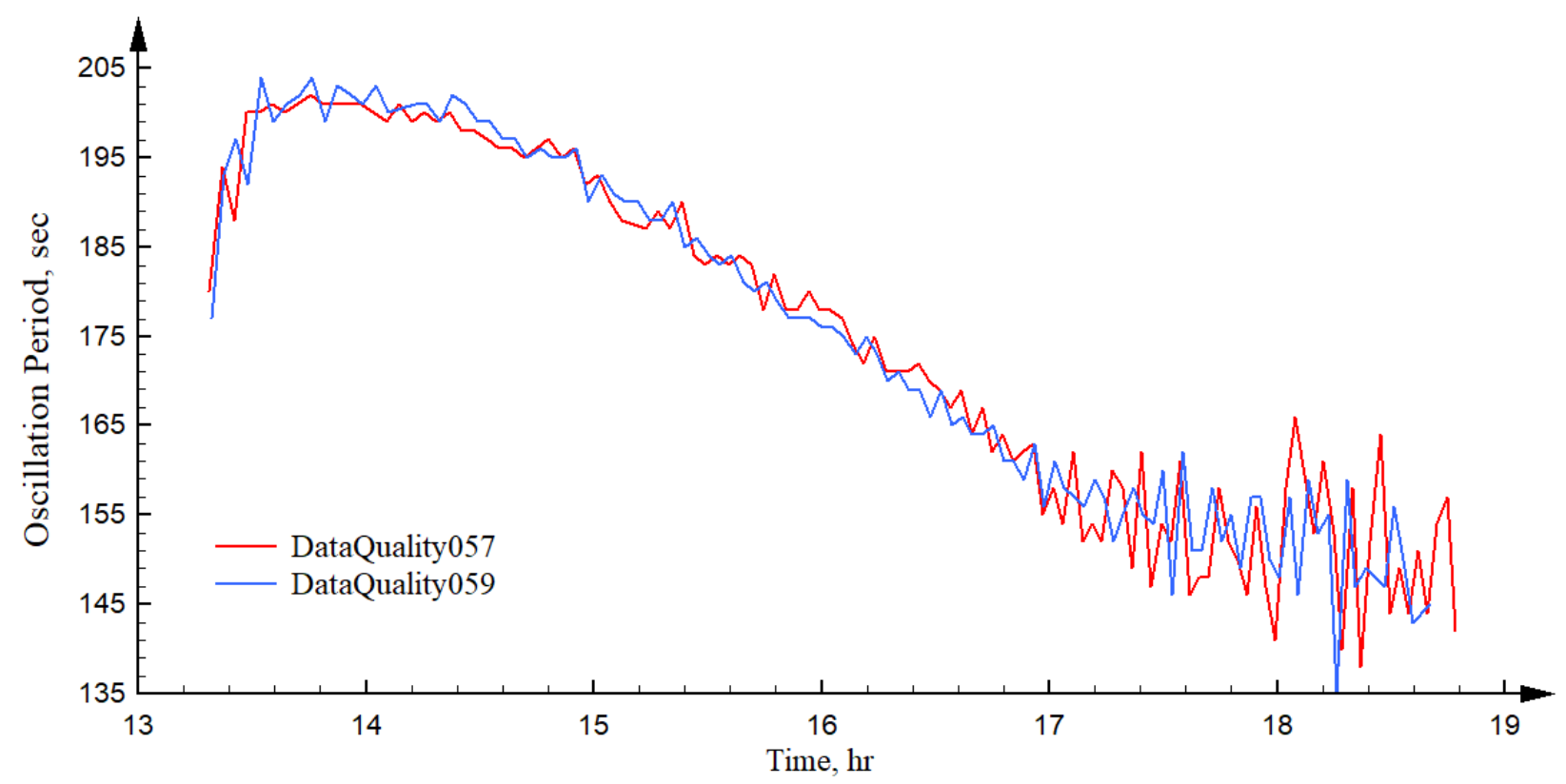

Figure 22: Comparison of system flow oscillation period between Run057 and Run059

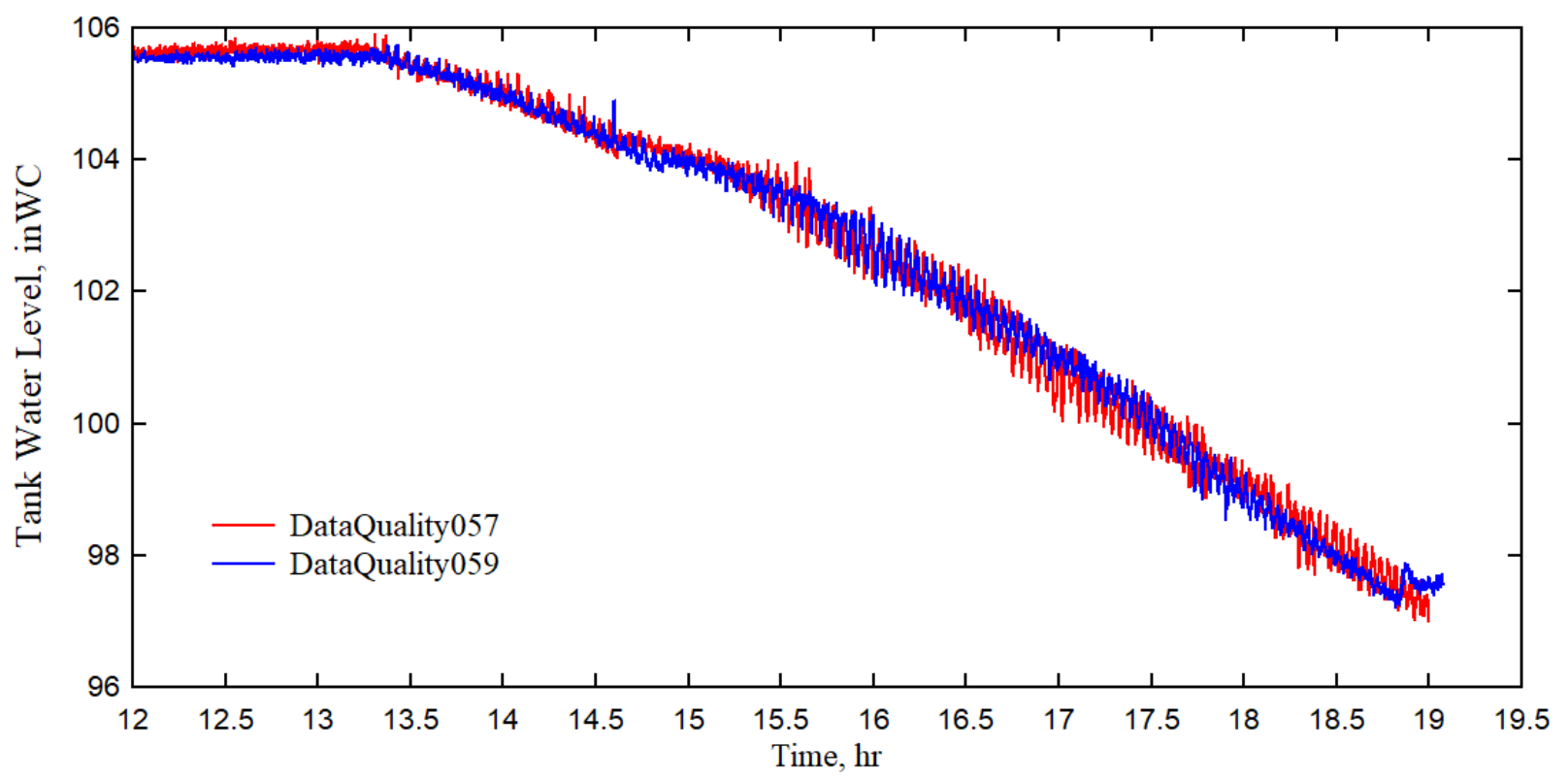

Figure 23: Comparison of tank water level between Run057 and Run059 


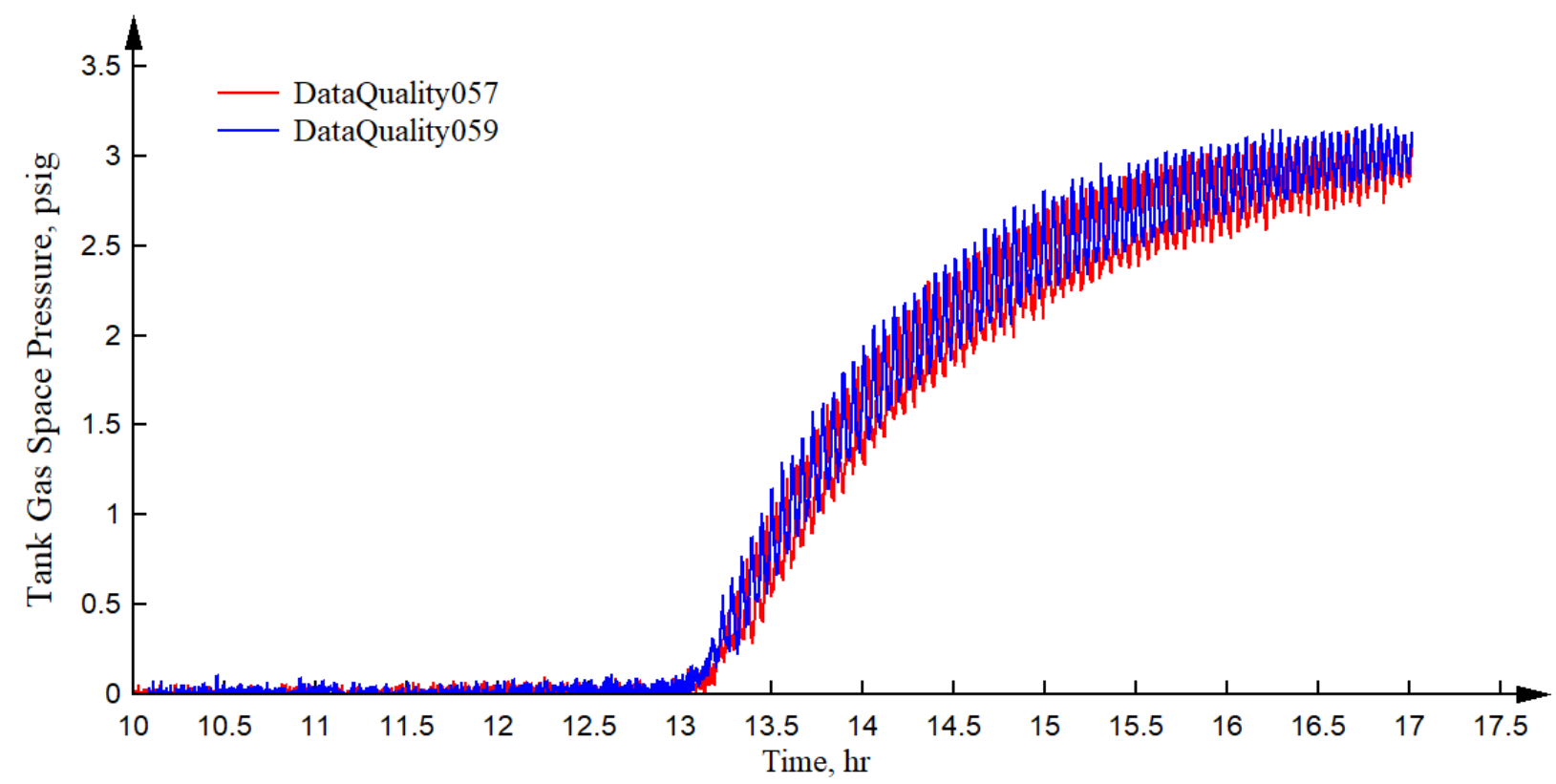

Figure 24: Comparison of tank gas space pressure between Run057 and Run059

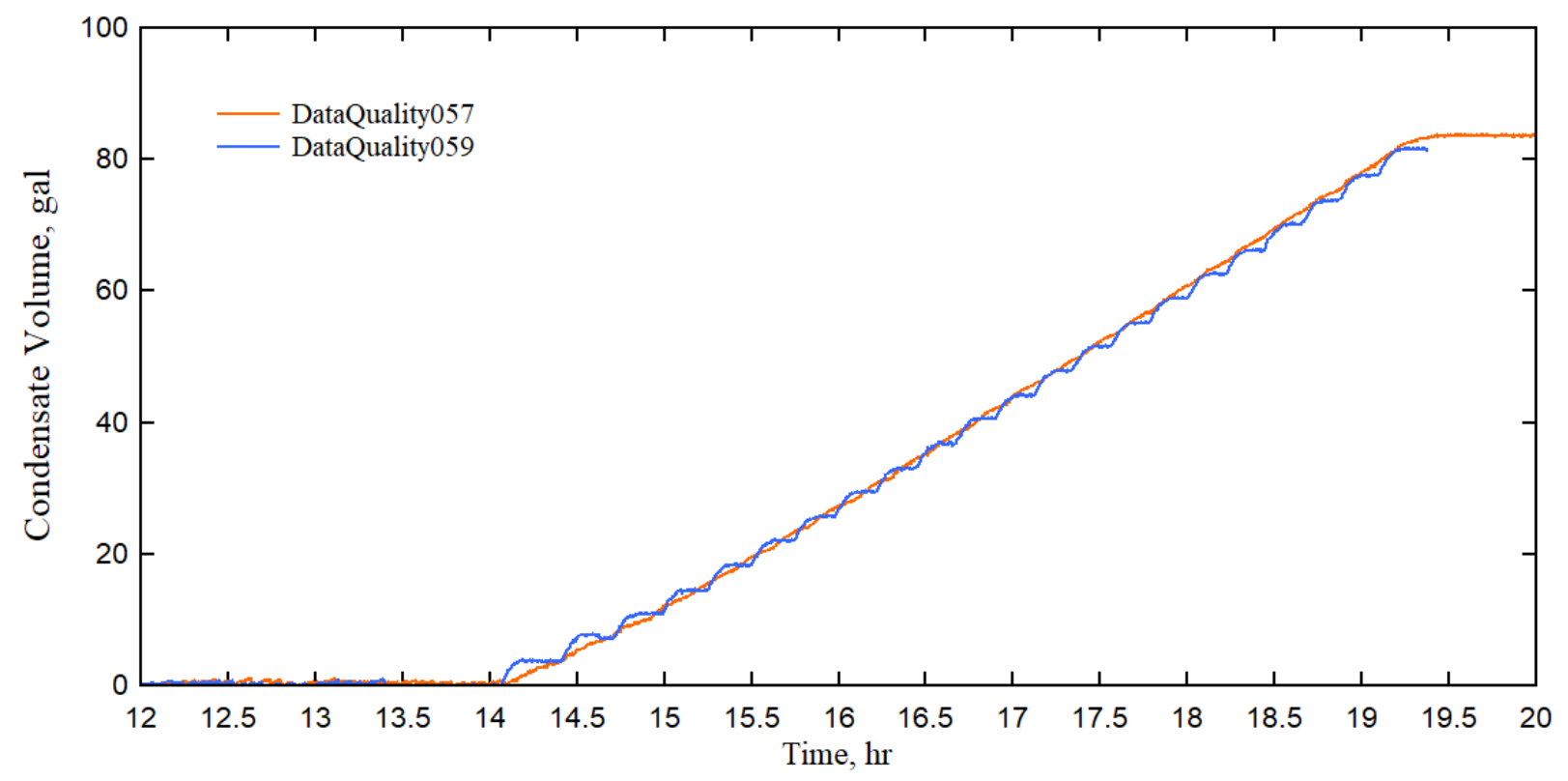

Figure 25: Comparison of condensate volume generated between Run057 and Run059 


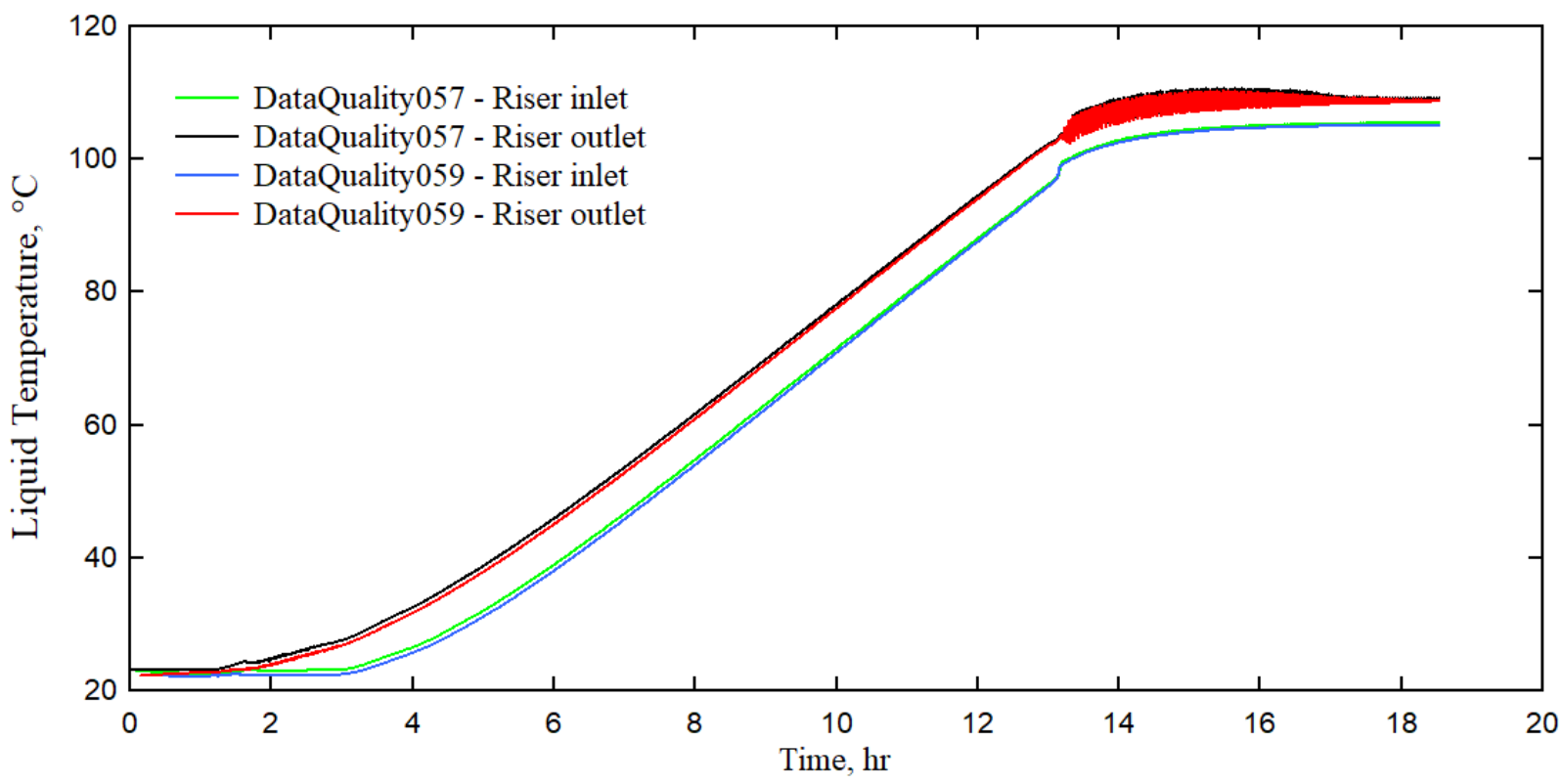

Figure 26: Comparison of liquid temperatures between Run057 and Run059

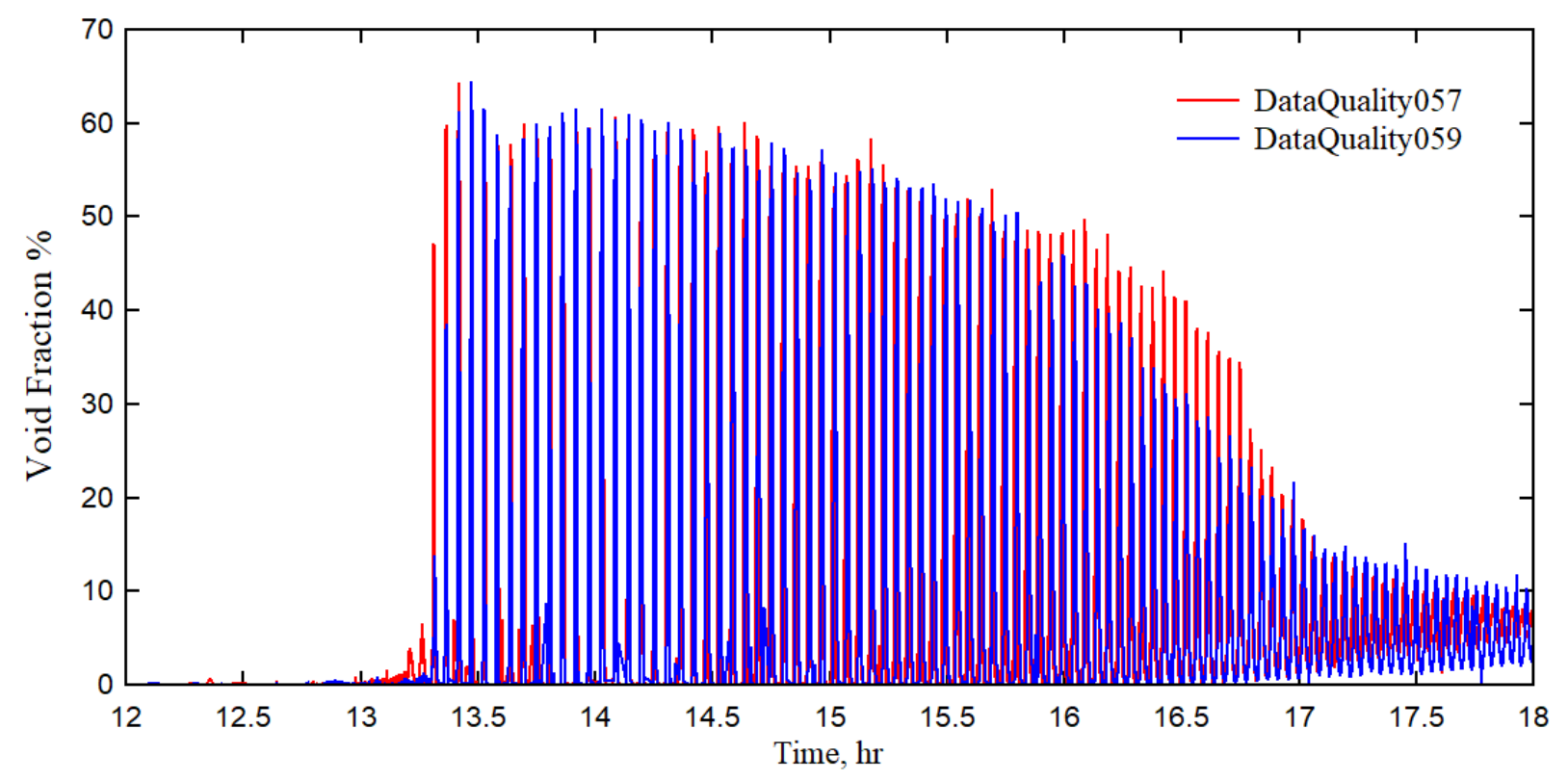

Figure 27: Comparison of volumetric void fraction in chimney between Run057 and Run059 
Test report on Year 2 of water NSTF matrix testing program September 2020

Table 6: Statistical comparison between Run057 and Run059. Values averaged over 1-hour window

\begin{tabular}{|c|c|c|c|c|c|c|c|}
\hline & & & Start: $t_{\text {boil }}$ & & & t: $t_{\text {boil }}+2.5$ & \\
\hline & & Run057 & Run059 & $\%$ diff. & Run057 & Run059 & $\%$ diff. \\
\hline Static pressure, inlet & psia & 38.24 & 38.04 & $0.5 \%$ & 39.82 & 39.65 & $0.4 \%$ \\
\hline Tank gas space & psia & 15.62 & 15.43 & $1.3 \%$ & 17.39 & 17.21 & $1.0 \%$ \\
\hline Tank water level & inWC & 105.26 & 105.04 & $0.2 \%$ & 102.26 & 102.04 & $0.2 \%$ \\
\hline$\Delta \mathrm{P} 01$, Test Section & inWC & 13.51 & 13.33 & $1.4 \%$ & 13.83 & 13.88 & $0.4 \%$ \\
\hline$\Delta$ P02, Low chimney & inWC & 2.01 & 2.07 & $2.9 \%$ & 2.09 & 2.18 & $4.2 \%$ \\
\hline$\Delta \mathrm{P} 03$, Mid chimney & inWC & 4.17 & 3.91 & $6.5 \%$ & 4.30 & 4.13 & $4.0 \%$ \\
\hline$\Delta$ P04, Up chimney & inWC & 5.12 & 5.06 & $1.2 \%$ & 5.67 & 5.62 & $0.9 \%$ \\
\hline$\Delta \mathrm{P} 05$, Tank & inWC & 2.77 & 2.68 & $3.1 \%$ & 2.65 & 2.56 & $3.5 \%$ \\
\hline VOID-01 & - & 0.15 & 0.15 & $1.5 \%$ & 0.16 & 0.14 & $13.9 \%$ \\
\hline Tank inlet, fluid & ${ }^{\circ} \mathrm{C}$ & 104.76 & 104.40 & $0.3 \%$ & 107.23 & 106.89 & $0.3 \%$ \\
\hline Tank outlet, fluid & ${ }^{\circ} \mathrm{C}$ & 102.04 & 101.69 & $0.3 \%$ & 105.18 & 104.88 & $0.3 \%$ \\
\hline Riser inlet, fluid & ${ }^{\circ} \mathrm{C}$ & 101.79 & 101.45 & $0.3 \%$ & 105.08 & 104.77 & $0.3 \%$ \\
\hline Riser outlet, fluid & ${ }^{\circ} \mathrm{C}$ & 106.46 & 106.15 & $0.3 \%$ & 109.24 & 108.85 & $0.4 \%$ \\
\hline HXG Hot, inlet & ${ }^{\circ} \mathrm{C}$ & 100.17 & 99.71 & $0.5 \%$ & 100.06 & 99.75 & $0.3 \%$ \\
\hline HXG Hot, outlet & ${ }^{\circ} \mathrm{C}$ & 23.19 & 23.71 & $2.2 \%$ & 23.41 & 22.71 & $3.0 \%$ \\
\hline Flow, primary loop & $\mathrm{kg} / \mathrm{s}$ & 2.321 & 2.316 & $0.2 \%$ & 2.681 & 2.711 & $1.1 \%$ \\
\hline Flow, Riser 01 & $\mathrm{~kg} / \mathrm{s}$ & 0.288 & 0.288 & $0.1 \%$ & 0.330 & 0.334 & $1.2 \%$ \\
\hline Flow, Riser 02 & $\mathrm{~kg} / \mathrm{s}$ & 0.285 & 0.285 & $0.1 \%$ & 0.330 & 0.335 & $1.4 \%$ \\
\hline Flow, Riser 03 & $\mathrm{~kg} / \mathrm{s}$ & 0.283 & 0.281 & $0.6 \%$ & 0.327 & 0.329 & $0.7 \%$ \\
\hline Flow, Riser 04 & $\mathrm{~kg} / \mathrm{s}$ & 0.291 & 0.290 & $0.4 \%$ & 0.337 & 0.340 & $0.9 \%$ \\
\hline Flow, Riser 05 & $\mathrm{~kg} / \mathrm{s}$ & 0.293 & 0.293 & $0.1 \%$ & 0.339 & 0.343 & $1.1 \%$ \\
\hline Flow, Riser 06 & $\mathrm{~kg} / \mathrm{s}$ & 0.287 & 0.286 & $0.3 \%$ & 0.331 & 0.335 & $1.0 \%$ \\
\hline Flow, Riser 07 & $\mathrm{~kg} / \mathrm{s}$ & 0.293 & 0.292 & $0.2 \%$ & 0.339 & 0.343 & $1.1 \%$ \\
\hline Flow, Riser 08 & $\mathrm{~kg} / \mathrm{s}$ & 0.308 & 0.307 & $0.3 \%$ & 0.357 & 0.360 & $1.0 \%$ \\
\hline Cavity cold wall & ${ }^{\circ} \mathrm{C}$ & 112.27 & 111.88 & $0.3 \%$ & 118.49 & 117.10 & $1.2 \%$ \\
\hline Cavity side walls & ${ }^{\circ} \mathrm{C}$ & 210.36 & 210.95 & $0.3 \%$ & 219.59 & 219.37 & $0.1 \%$ \\
\hline Riser Tube, hot & ${ }^{\circ} \mathrm{C}$ & 111.39 & 111.14 & $0.2 \%$ & 113.95 & 113.54 & $0.4 \%$ \\
\hline Riser Tube, cold & ${ }^{\circ} \mathrm{C}$ & 104.50 & 104.19 & $0.3 \%$ & 107.52 & 107.16 & $0.3 \%$ \\
\hline Panel Fin, hot & ${ }^{\circ} \mathrm{C}$ & 133.22 & 132.86 & $0.3 \%$ & 136.70 & 136.11 & $0.4 \%$ \\
\hline Panel Fin, cold & ${ }^{\circ} \mathrm{C}$ & 133.62 & 133.40 & $0.2 \%$ & 137.05 & 136.60 & $0.3 \%$ \\
\hline Heater plate: & ${ }^{\circ} \mathrm{C}$ & 403.98 & 404.53 & $0.1 \%$ & 408.31 & 408.60 & $0.1 \%$ \\
\hline Electric heaters: & ${ }^{\circ} \mathrm{C}$ & 545.63 & 545.76 & $0.0 \%$ & 549.93 & 549.86 & $0.0 \%$ \\
\hline Electric power: & $k W_{e}$ & 71.96 & 71.96 & $0.0 \%$ & 71.96 & 71.96 & $0.0 \%$ \\
\hline Riser $\Delta \mathrm{T}$ : & ${ }^{\circ} \mathrm{C}$ & 4.67 & 4.70 & $0.7 \%$ & 4.17 & 4.08 & $2.2 \%$ \\
\hline Power Loop: & $k W_{t}$ & 43.24 & 43.28 & $0.1 \%$ & 45.72 & 45.49 & $0.5 \%$ \\
\hline
\end{tabular}




\subsection{1. $\quad$ Failed and Trending Attempts}

In addition to the two successful tests discussed in the previous section, two other two-phase baseline tests were conducted, Run056 and Run058, with the former classified as trending while the latter failed. Run056 consists of two parts, with the first part attempting to repeat a previous single-phase $2.1 \mathrm{MW}_{\mathrm{t}}$ baseline test (Run052) and the second part being the first two-phase baseline test. The single-phase part was completed successfully; however, one issue was identified during the two-phase portion of the test. At 50 hrs into the test when two-phase boiling already started, it was found that the tank gas space pressure sensing line had been left in the closed position. While re-opening the valve to place it into the correct position, an abrupt jump in the measured tank gas space pressure, Figure 28, was observed. Information on the tank gas space pressure prior to this time was not accurately reflected in the measured data due to the closed pressure sensing line, nor was the tank level given the shared impulse tubing connection to the tank gas space. Since the gas space pressure and fluctuations in tank level are some of the most important parameters to characterize the two-phase boiling/flashing phenomenon, it was decided to classify Run056 as trending and perform another attempt for the two-phase baseline.
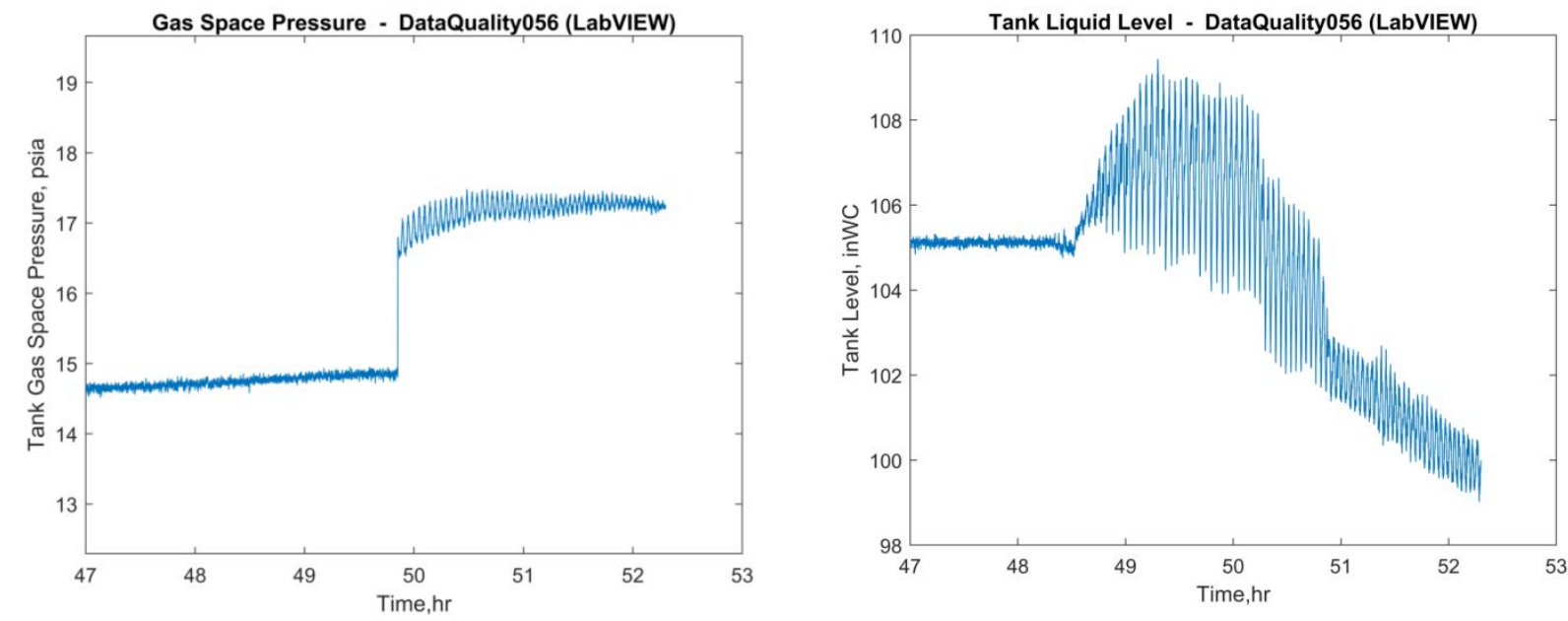

Figure 28: Influence on gas space pressure and tank level sensors after opening impulse valve

An additional attempt for repeatability that was not successful was Run058, which similar to the previous runs defined the standard two-phase baseline initial and boundary conditions. During the quasisteady boiling portion of the test, approximately $17.5 \mathrm{hr}$ into active heating, the operators observed that the tank gas space pressure began to unexpectedly increase, Figure 29. Through post-test data processing, an issue was identified with the heat exchanger temperatures. At approximately $14.4 \mathrm{hr}$ into the test, the steam side inlet temperature fell below the saturation temperature of $100^{\circ} \mathrm{C}$ for a period of time, Figure 30. Upon investigation, it was determined that blockage of the condensate drain line allowed condensate to accumulate in the heat exchanger, which affected the back pressure on the steam discharge line and 
caused the observed increase in the tank gas space pressure. The blockage was the result of the routing and inadequate flow area of the discharge hose used to transfer condensate from the heat exchanger hot outlet to the intermediate condensate reservoir. The issue was resolved by upgrading the hose to a larger rigid pipe that provides ample flow area for condensate to freely exit the heat exchanger.

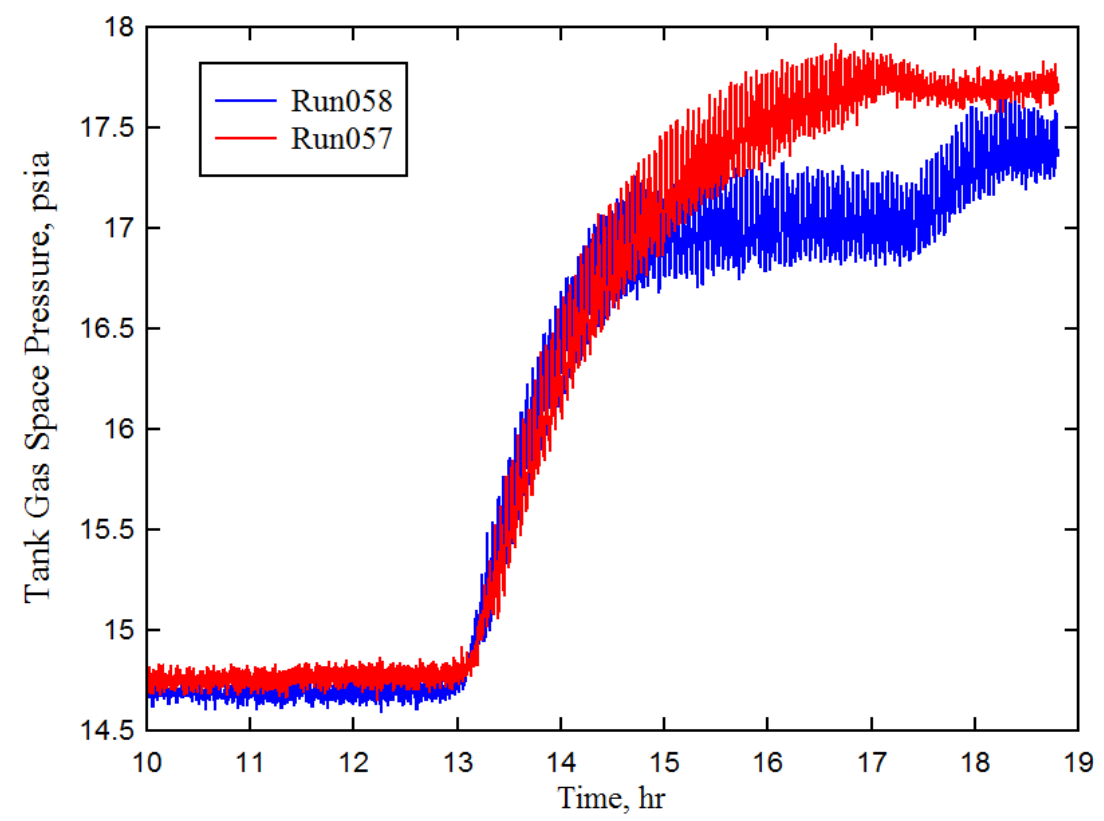

Figure 29: Unexpected increase in the measured tank gas space pressure at 17.5 hours in Run058

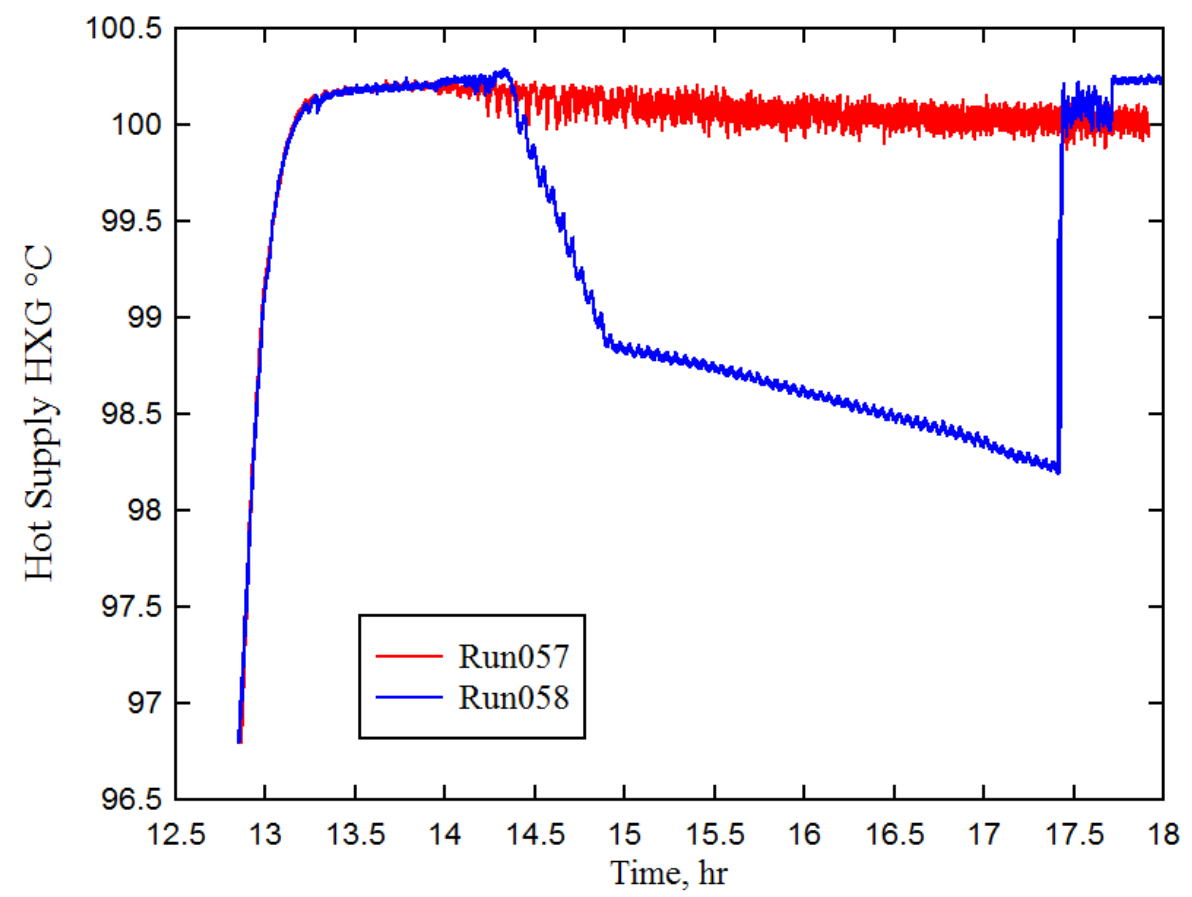

Figure 30: Steam inlet temperature below $100^{\circ} \mathrm{C}$ during Run058 indicating condensate accumulation 
As a final remark on the success, or failure, of repeating test parameters, is the importance to allow flow conditions to extend past initial start-up perturbations and allow the facility to reach a developed quasi-steady state mode of operation. When comparing three of the trending or failed against a successful baseline case, initial observations suggest that the three share similar behaviors, including flow magnitudes, oscillation periods, etc. As the flow continues to progress with time, indications of discrepancies begin to appear across the three. Finally, as each is allowed to fully mature, reach a quasisteady state of operation, and begin to stabilize, their dissimilarities become readily apparent, Figure 31 .
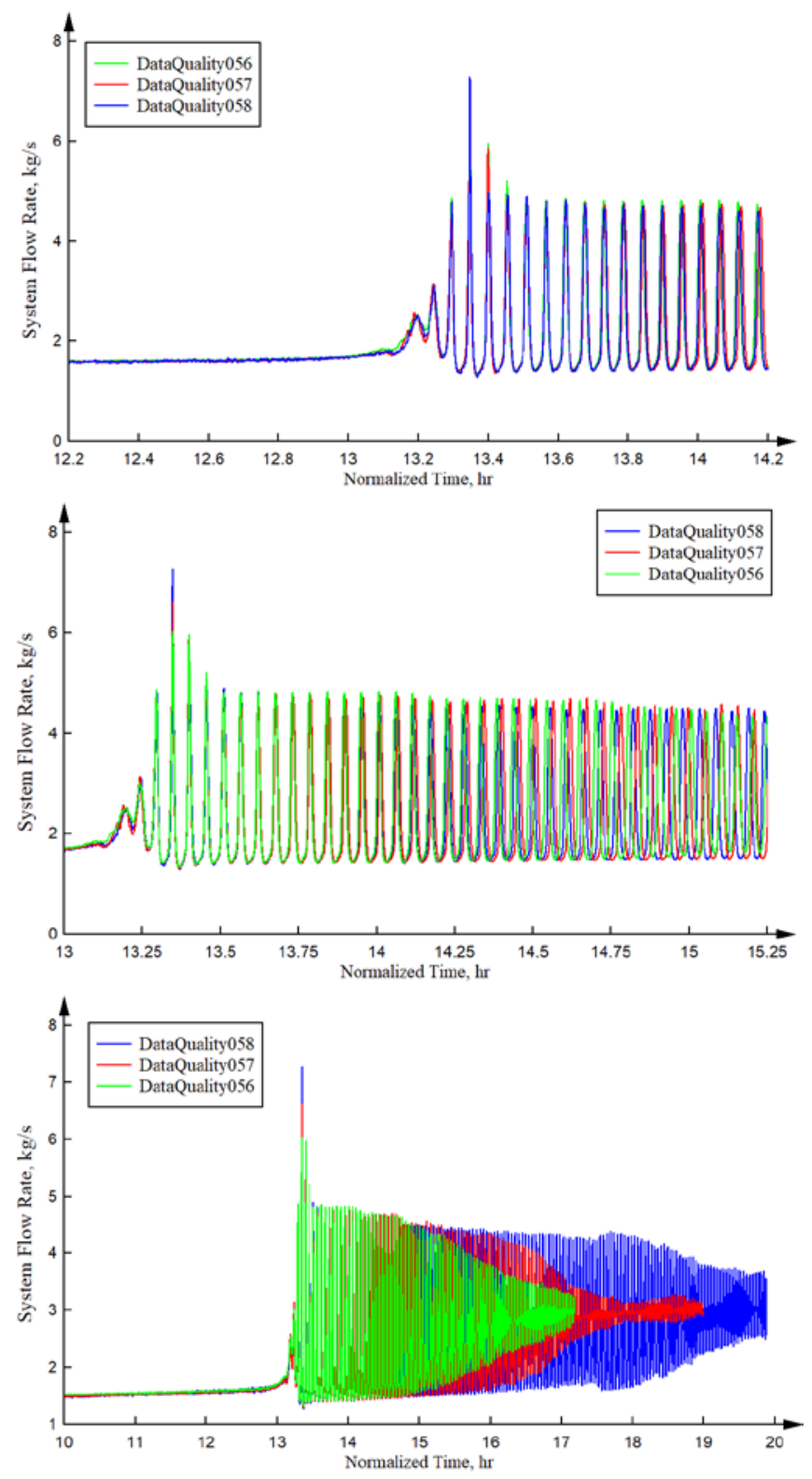

Figure 31: Progression of dissimilarities as three baseline test cases develop and begin to stabilize 


\subsection{Inventory Parametric}

The inventory parametric series, as described in the test matrix include three subcategories: a) Varying initial tank volumes; b) Accelerated tank inventory loss; and c) Full tank depletion. The first subcategory defines repeated baseline tests with varying initial tank inventories, which reference to the tank fill height as shown in Figure 32 and itemized in Table 7 and Table 8. In this year of testing, one inventory parametric test case (Run060) was conducted, which repeated the two-phase baseline Run057 but with a tank fill level at a reduced 70\%, approximately 424 liters (112 gallons) less total inventory, and $29.2 \mathrm{~cm}$ (11.5-inch) lower tank level, Figure 32. Details of the configuration for Run060 are provided in Table 9.

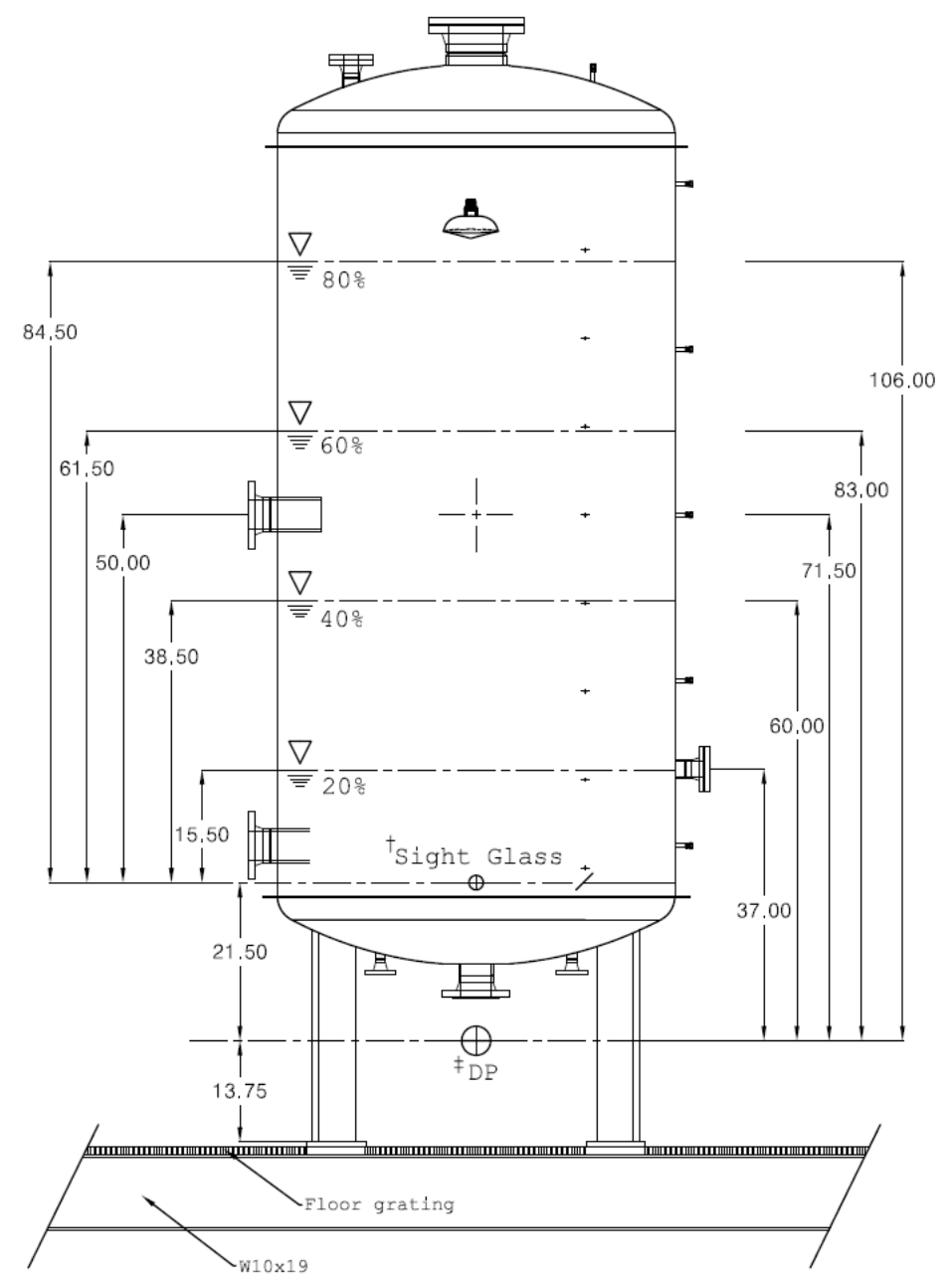

Figure 32: CAD drawing of water tank with levels shown for various fill levels. Dimensions in inches
Table 7: Inventory volumes at fill levels

\begin{tabular}{ccc}
\hline Tank & \multicolumn{2}{c}{ Inventory, gal } \\
Fill & Tank & Full System \\
\hline $80 \%$ & 901 & 1004 \\
$70 \%$ & 788.5 & 891.5 \\
$60 \%$ & 676 & 779 \\
$50 \%$ & 563 & 666 \\
$40 \%$ & 450 & 550 \\
$20 \%$ & 225 & 321 \\
\hline
\end{tabular}

Table 8: Liquid height in tank at fill levels

\begin{tabular}{ccc}
\hline Tank & \multicolumn{2}{c}{ Level Reference, inch } \\
Fill & Sight Glass & AP Level \\
\hline $80 \%$ & 84.5 & 106.0 \\
$70 \%$ & 73.0 & 94.5 \\
$60 \%$ & 61.5 & 83.0 \\
$50 \%$ & 50.0 & 71.5 \\
$40 \%$ & 38.5 & 60.0 \\
$20 \%$ & 15.5 & 37.0 \\
\hline
\end{tabular}


Table 9: Initial boundary and operating conditions for Run060

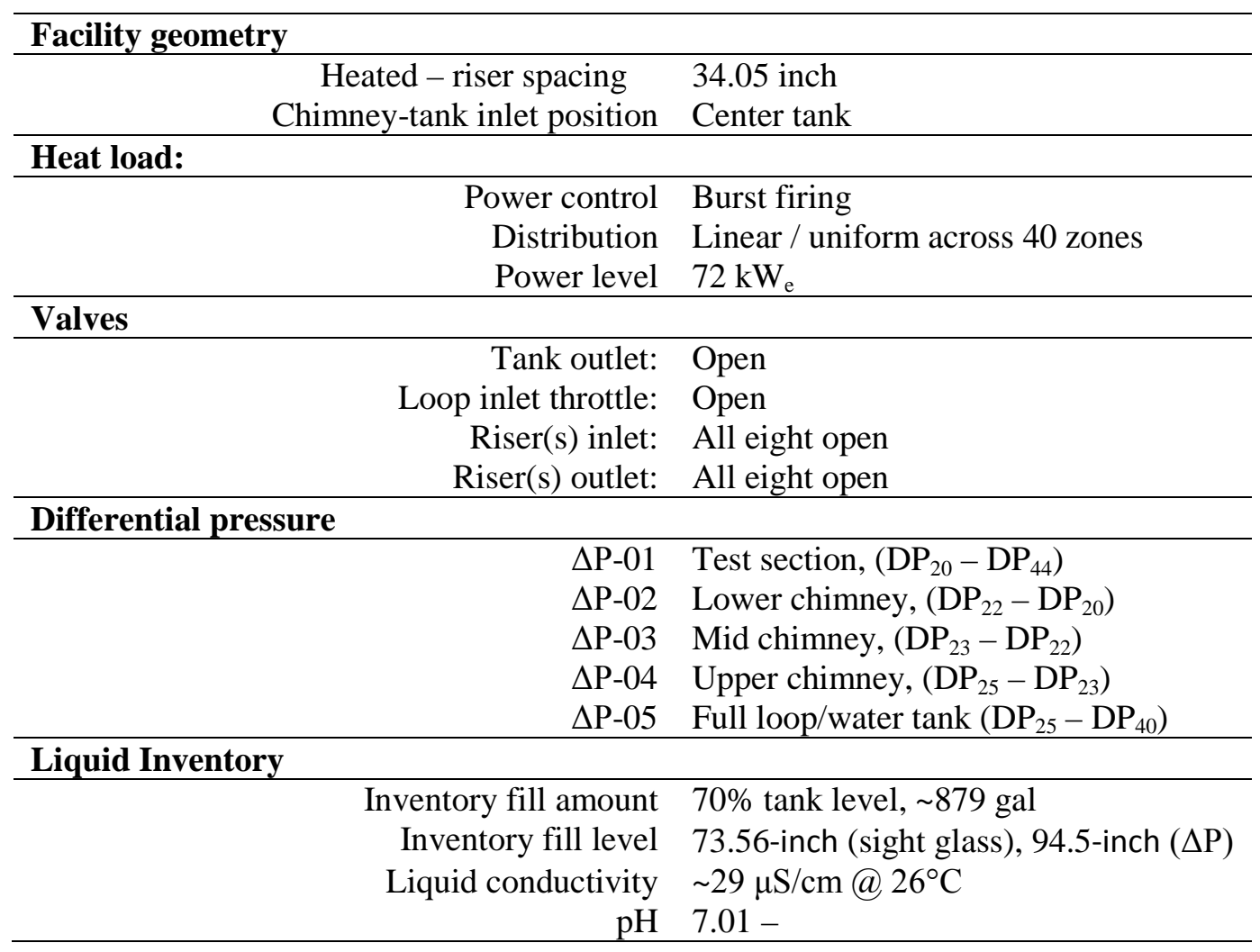

The system behaviors are shown in Figure 33 to Figure 44. The effects of the initial tank inventory on the system performance are reflected in a few aspects. First, due to the reduced tank inventory and thus reduced thermal inertia of the fluid system, initiation of boiling/flashing occurred earlier in Run060 compared to Run057, Figure 39. Second, due to the same reason aforementioned, more energy was deposited into the cavity structures during the transient, causing faster developments and thus higher values of the temperatures of the heaters, heated plate, and cavity side walls when boiling/flashing initiated. When boiling/flashing starts, the fluid temperatures are near saturation temperatures and are determined by the hydrostatic pressure at the header inlet. The reduced initial tank inventory in Run060 caused a smaller header inlet pressure and thus lower fluid temperatures after boiling/flashing started, Figure 37. The same as discussed in Run057, the riser structure temperatures are more dependent on the fluid temperatures due to the high convective heat transfer, and the lower fluid temperatures have also led to lower riser structure temperatures in Run060, Figure 35 and Figure 36.

In Run057 and Run059, the inventory level was 97.5-inch when the test was concluded, Figure 23. Based on the trend of the total system flow in both cases, Figure 21, the flow oscillations are projected to damp out completely or become insignificant at 94.5-inch, which is the starting level in Run060. However, the system still experienced significant flow oscillations when boiling/flashing initiated in Run060, Figure 39, indicating inventory level was not the only factor determining the system flow 
behaviors. As will be discussed later, the flashing flow instabilities are affected by both the inlet subcooling (affected by the inventory level and thus inlet hydrostatic pressure) and the heat flux (thermal power input). It was found that the thermal power into the test section when boiling/flashing initiated was $42 \mathrm{~kW}_{\mathrm{t}}$ in Run060, compared to a projected value of $48 \mathrm{~kW}_{\mathrm{t}}$ at inventory level of 94.5-inch in Run057. This difference in test section thermal power input may partially explain the observed flow instabilities in Run060. Lastly, looking at the peak value of the flow oscillations upon initiation of boiling/flashing, Run057 and Run060 showed similar results (6.6 vs $6.8 \mathrm{~kg} / \mathrm{s}$ ). This may suggest a different instability mechanism for the start-up flow instabilities when boiling/flashing starts, and as the transient progresses, the instability mechanism is more determined by the inlet subcooling and heat flux, explaining the quick damping of the flow oscillations in less than 2 hours in Run060, Figure 39. The measured system values during the two-phase quasi-steady state in Run060 are summarized in Table 10.

Table 10: Comparison of acceptance criteria between baseline test case and inventory parametric

\begin{tabular}{|c|c|c|c|c|c|c|c|}
\hline \multicolumn{2}{|l|}{ 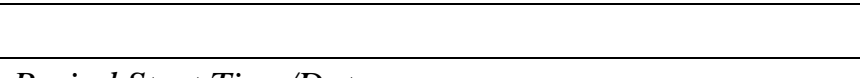 } & \multicolumn{3}{|c|}{ Run059 } & \multicolumn{3}{|c|}{ Run060 } \\
\hline \multicolumn{2}{|l|}{ Period Start Time/Date } & \multicolumn{3}{|c|}{$08: 30,03 / 05 / 20$} & \multicolumn{3}{|c|}{ 09:00, 06/26/20 } \\
\hline \multicolumn{2}{|l|}{ Period Duration } & \multicolumn{3}{|c|}{$13.3-17.3 \mathrm{hr}$} & \multicolumn{3}{|c|}{$12.45-14.85 \mathrm{hr}$} \\
\hline Loop Flow & & $\max$ & $\min$ & mean & $\max$ & $\min$ & mean \\
\hline Oscillation period (peak-to-peak) & sec & 205.0 & 156.0 & 183.5 & 195.0 & 137.0 & 170.6 \\
\hline Average flow (per cycle) & $\mathrm{kg} / \mathrm{s}$ & 2.90 & 2.21 & 2.55 & 3.12 & 2.28 & 2.78 \\
\hline Oscillation amplitude (peak - average) & $\mathrm{kg} / \mathrm{s}$ & 3.75 & 0.69 & 1.82 & 4.55 & 0.02 & 1.22 \\
\hline \multicolumn{8}{|l|}{ Two-phase Boil-Off } \\
\hline Maximum void fraction & $\%$ & \multicolumn{3}{|c|}{64.4} & \multicolumn{3}{|c|}{69.2} \\
\hline Average condensate rate & $\mathrm{gal} / \mathrm{min}$ & \multicolumn{3}{|c|}{0.263} & \multicolumn{3}{|c|}{0.257} \\
\hline Generated condensate volume & gal & \multicolumn{3}{|c|}{83.83} & \multicolumn{3}{|c|}{66.84} \\
\hline \multicolumn{8}{|l|}{ Post Loop Cool Down } \\
\hline Ending tank inventory level & inWC & \multicolumn{3}{|c|}{91.51} & \multicolumn{3}{|c|}{87.08} \\
\hline Estimate total inventory loss & gal & \multicolumn{3}{|c|}{$\sim 138$} & \multicolumn{3}{|c|}{$\sim 115$} \\
\hline
\end{tabular}


Test report on Year 2 of water NSTF matrix testing program

Heated plate (front, data-quality) temperature - DataQuality060 (LabVIEW)

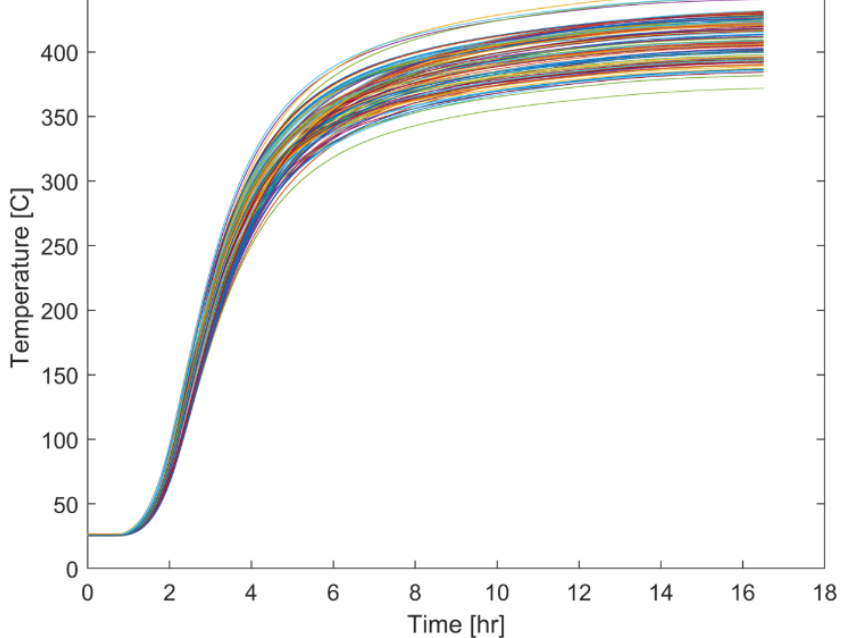

Figure 33: Heated plate surface temperatures, Run060

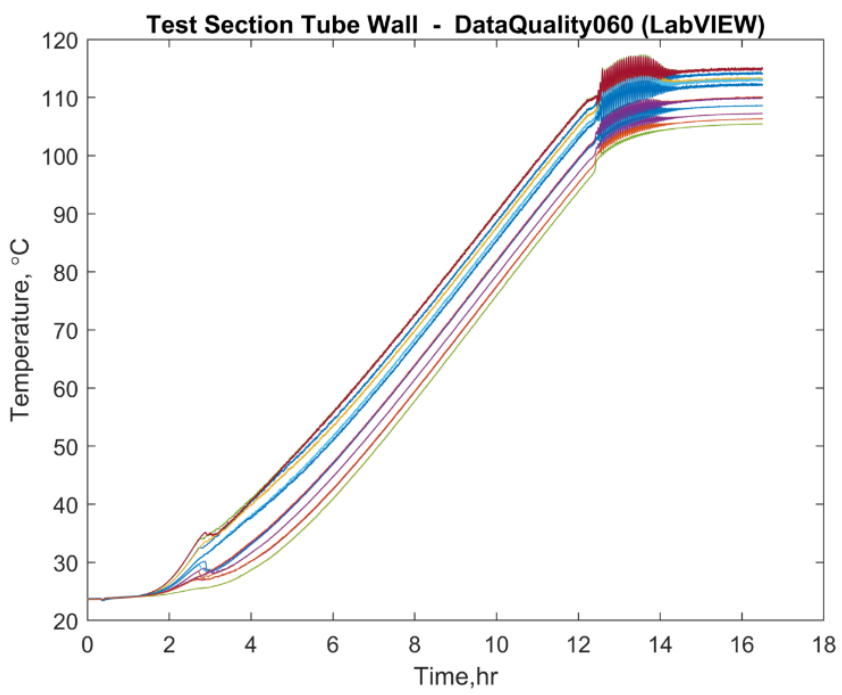

Figure 35: Test section tube wall temperatures, Run060

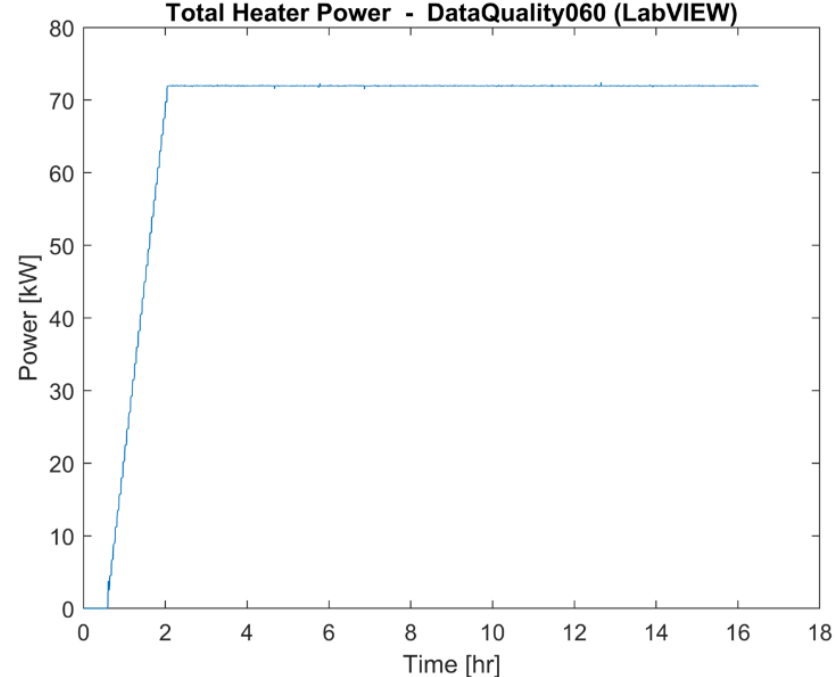

Figure 34: Total supplied electric power, Run060

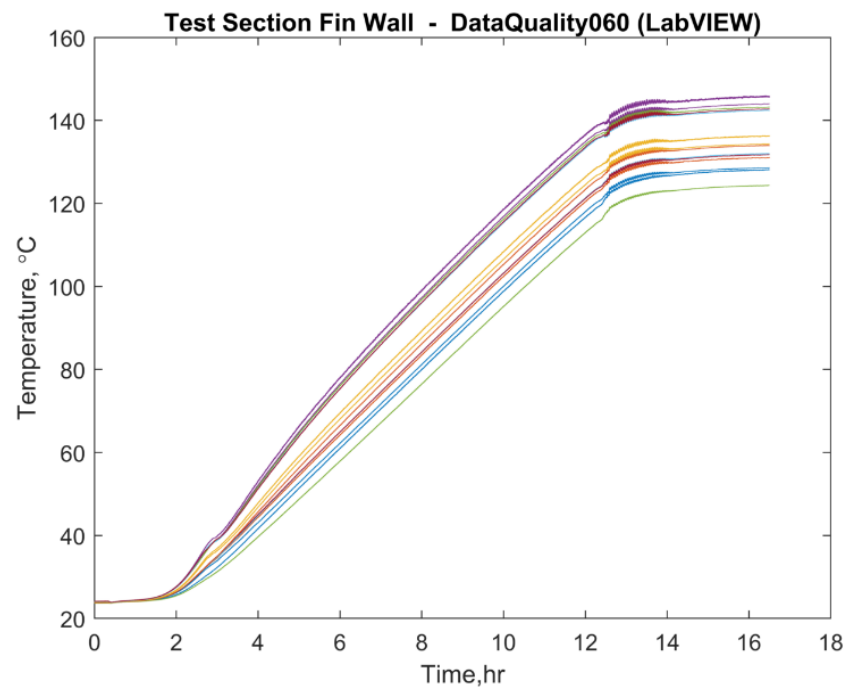

Figure 36: Test section fin wall temperatures, Run060 
Test report on Year 2 of water NSTF matrix testing program

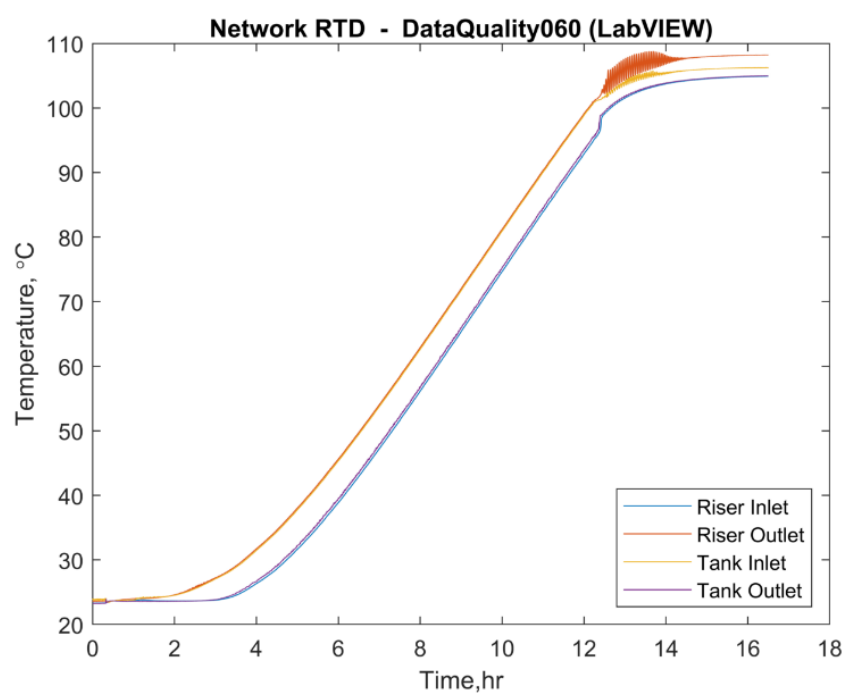

Figure 37: Network liquid RTD temperatures, Run060

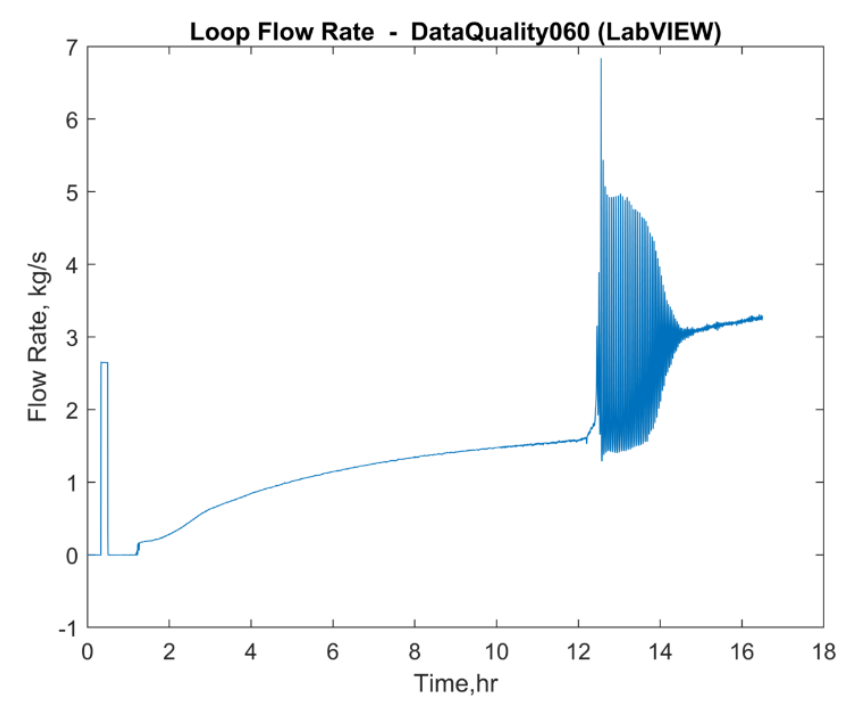

Figure 39: Total system flow rate, Run060

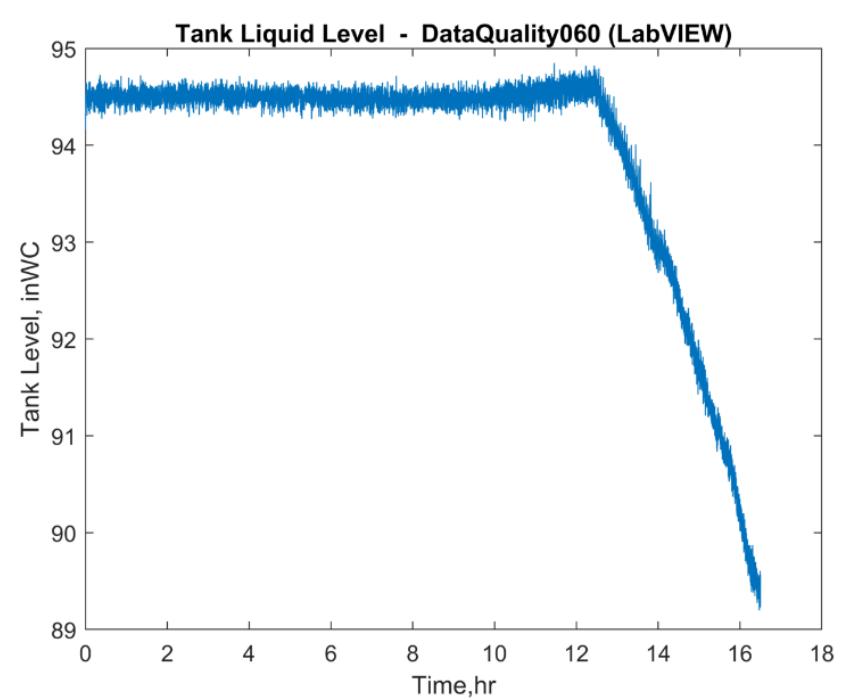

Figure 38: Tank liquid level, Run060

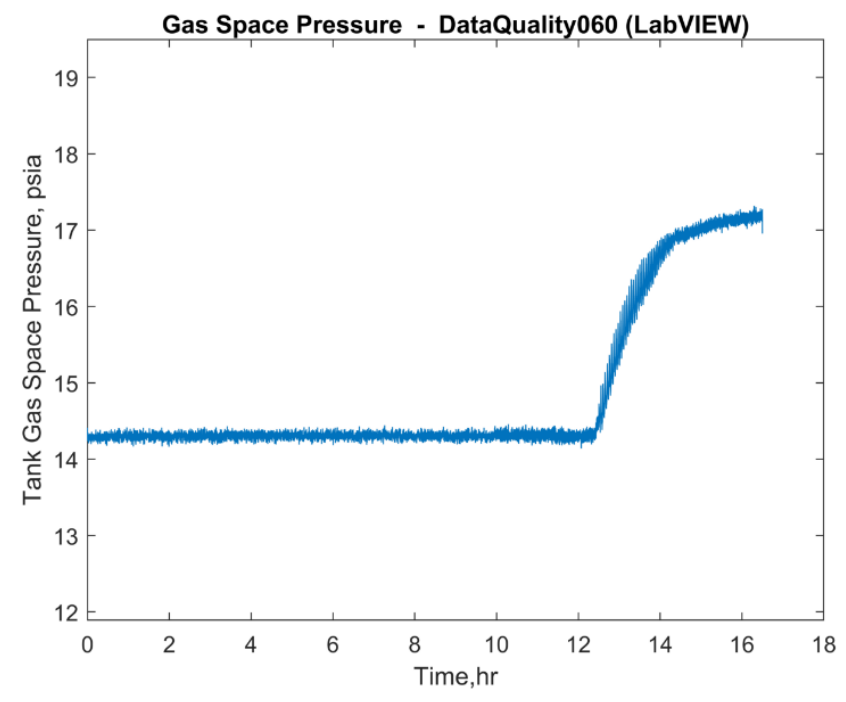

Figure 40: Tank gas space pressure, Run060 
Test report on Year 2 of water NSTF matrix testing program

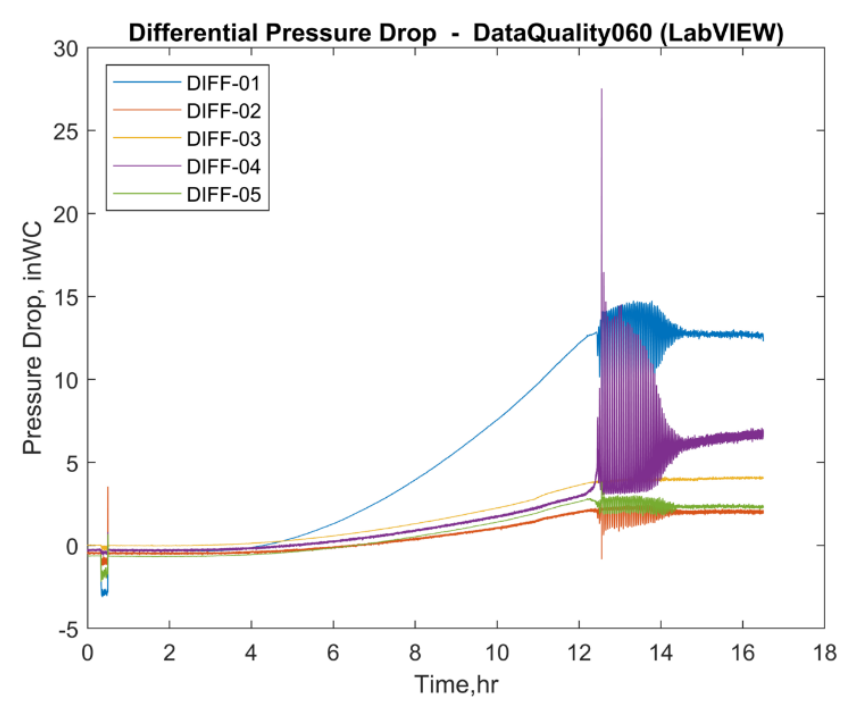

Figure 41:Differential pressure drops, Run060

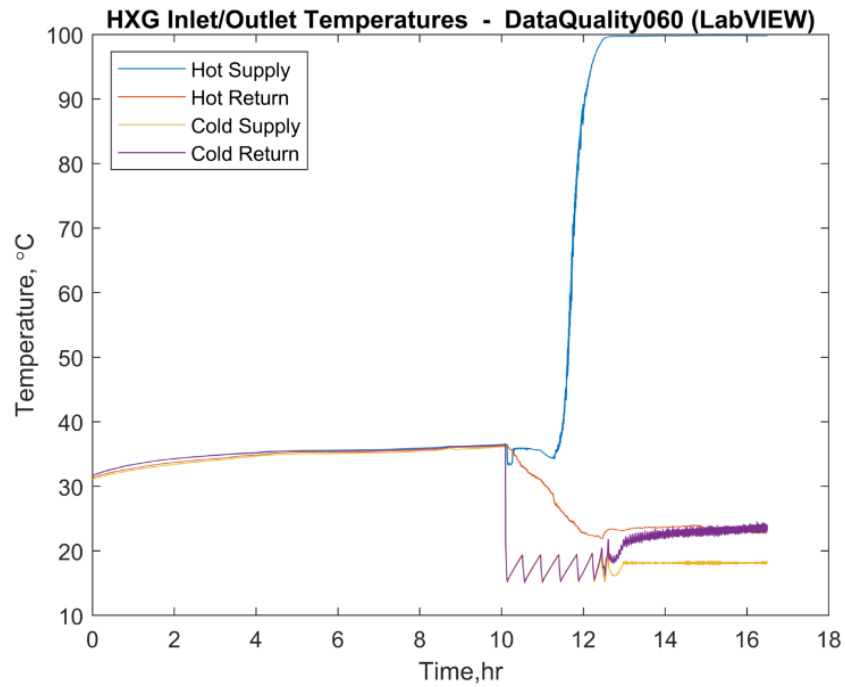

Figure 43: HXG inlet/outlet temperatures, Run060

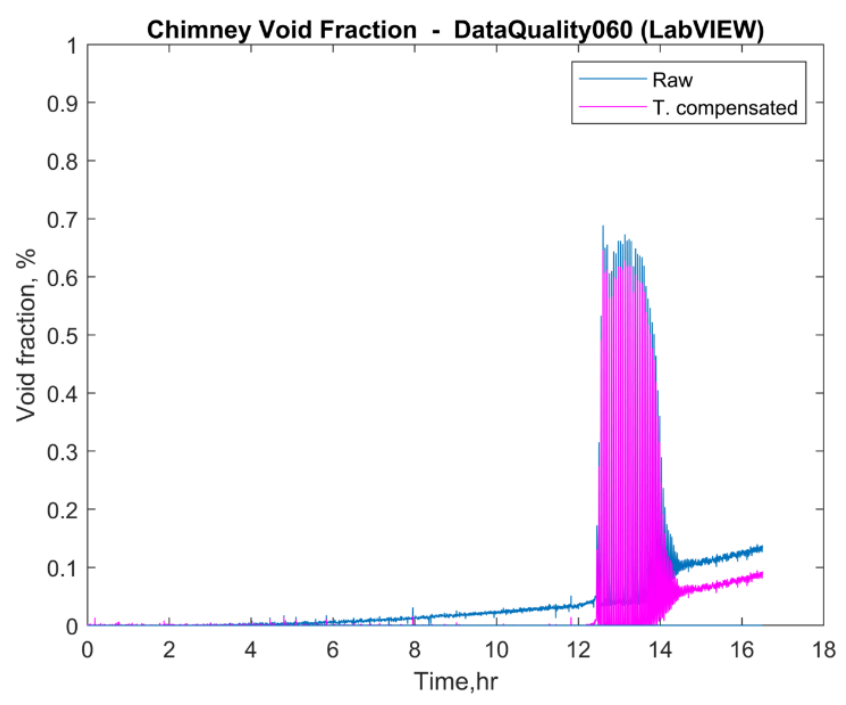

Figure 42: Chimney void fraction, Run060

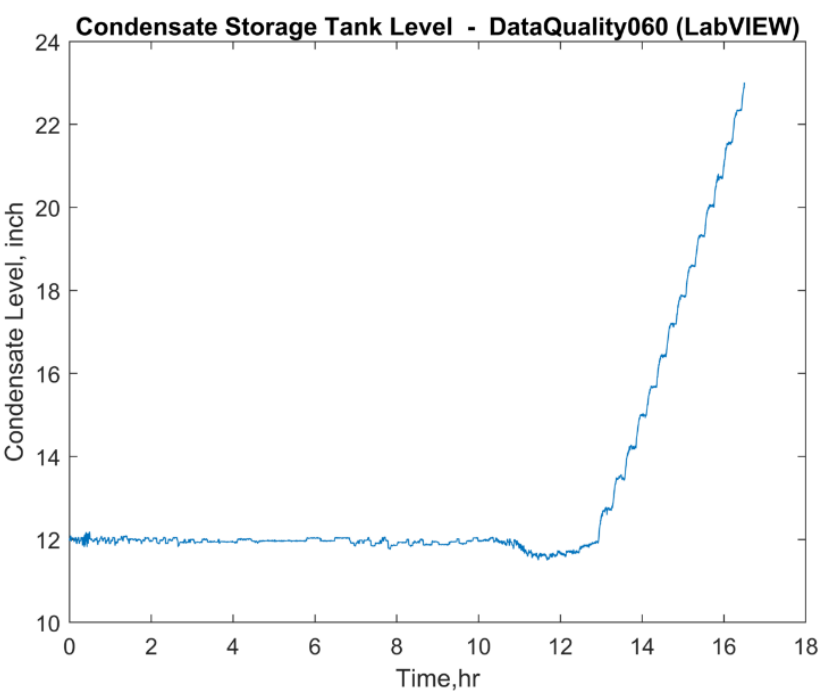

Figure 44: Near-linear condensate level increase, Run060 


\subsection{Summary of Completed Runs}

Over a 12-month period, a total of five matrix test cases were conducted at two-phase boiling operating conditions, Table 11. Of these, four were performed at standard two-phase baseline conditions for the purposes of establishing confidence in the test facility's and operator's ability to generate repeatable results. Two successful baseline cases were ultimately completed, DataQuality057 and DataQuality059. Following, the inventory parametric test series was initiated and began with conducting DataQuality060, which successfully examined the influence of a reduced inventory level at the standard baseline conditions.

Table 11: Summary of completed matrix test cases during Year 2 of Water NSTF testing

\begin{tabular}{|c|c|l|l|c|}
\multicolumn{1}{c}{ Test Name } & Date & Duration & \multicolumn{1}{c}{ Purpose } & Classification \\
\hline DataQuality056 & $10 / 08-10 / 2019$ & $054 \mathrm{~h} 14 \mathrm{~m}$ & Two-phase 2.1 $\mathrm{MW}_{\mathrm{t}}$ baseline & $\square$ Trending \\
\hline DataQuality057 & $11 / 07-08 / 2019$ & $020 \mathrm{~h} 24 \mathrm{~m}$ & Two-phase 2.1 $\mathrm{MW}_{\mathrm{t}}$ baseline & $\square$ Accepted \\
\hline DataQuality058 & $12 / 12-13 / 2019$ & $021 \mathrm{~h} 34 \mathrm{~m}$ & Two-phase 2.1 $\mathrm{MW}_{\mathrm{t}}$ baseline & $\square$ Failed \\
\hline DataQuality059 & $03 / 04-04 / 2020$ & $019 \mathrm{~h} 05 \mathrm{~m}$ & Two-phase 2.1 $\mathrm{MW}_{\mathrm{t}}$ baseline & $\square$ Accepted \\
\hline DataQuality060 & $06 / 25-26 / 2020$ & $018 \mathrm{~h} 28 \mathrm{~m}$ & $\begin{array}{l}\text { Two-phase 2.1 } \mathrm{MW}_{\mathrm{t}} \text { baseline, } \\
\text { variation of 70\% tank inventory }\end{array}$ & $\square$ Accepted \\
\hline
\end{tabular}


Table 12: Summary of fluid hydraulic parameters. Statistics spanning 1-hour period starting from 1st boiling peak

\begin{tabular}{|c|c|c|c|c|c|c|c|c|c|c|c|}
\hline & & \multicolumn{3}{|c|}{ Run057 } & \multicolumn{3}{|c|}{ Run059 } & \multicolumn{3}{|c|}{ Run060 } & \\
\hline & Test date & \multicolumn{3}{|c|}{$11 / 2019$} & \multicolumn{3}{|c|}{$03 / 2020$} & \multicolumn{3}{|c|}{$06 / 2020$} & \\
\hline & Full power reference & \multicolumn{3}{|c|}{$2.1 \mathrm{MW}_{\mathrm{t}}$} & \multicolumn{3}{|c|}{$2.1 \mathrm{MW}_{\mathrm{t}}$} & \multicolumn{3}{|c|}{$2.1 \mathrm{MW}_{\mathrm{t}}$} & \\
\hline & Initial inventory & \multicolumn{3}{|c|}{$80 \%$} & \multicolumn{3}{|c|}{$80 \%$} & \multicolumn{3}{|c|}{$70 \%$} & \\
\hline & & Mean & Min & Max & Mean & Min & Max & Mean & Min & Max & \\
\hline \multirow{3}{*}{ Static Pressure } & Inlet header & 38.24 & 37.24 & 39.32 & 38.04 & 37.02 & 39.10 & 37.60 & 36.52 & 38.73 & psia \\
\hline & Tank gas space & 15.62 & 14.58 & 16.79 & 15.43 & 14.27 & 16.62 & 15.38 & 14.14 & 16.65 & psia \\
\hline & Tank water level & 105.26 & 104.31 & 106.34 & 105.04 & 103.91 & 106.06 & 94.12 & 93.17 & 95.10 & inWC \\
\hline \multirow{5}{*}{$\begin{array}{c}\text { Differential } \\
\text { Pressure }\end{array}$} & $\Delta \mathrm{P} 01$, Test Section & 13.51 & 1.88 & 15.71 & 13.33 & 3.80 & 15.54 & 12.77 & -1.23 & 15.39 & inWC \\
\hline & $\Delta \mathrm{P} 02$, Low chimney & 2.01 & -0.74 & 2.72 & 2.07 & -0.15 & 2.67 & 2.00 & -0.84 & 3.85 & inWC \\
\hline & $\Delta \mathrm{P} 03$, Mid chimney & 4.17 & 3.27 & 10.40 & 3.91 & 3.29 & 8.33 & 3.89 & 3.33 & 14.62 & inWC \\
\hline & $\Delta \mathrm{P} 04, \mathrm{Up}$ chimney & 5.12 & 3.11 & 27.53 & 5.06 & 3.00 & 23.49 & 5.38 & 3.04 & 27.52 & inWC \\
\hline & $\Delta \mathrm{P} 05$, Tank & 2.77 & 1.59 & 9.21 & 2.68 & 1.42 & 5.20 & 2.61 & 1.34 & 7.53 & inWC \\
\hline \multirow{4}{*}{$\begin{array}{c}\text { Fluid } \\
\text { Temperatures }\end{array}$} & Tank inlet & 104.76 & 102.80 & 106.69 & 104.40 & 102.50 & 106.39 & 103.60 & 101.53 & 105.36 & ${ }^{\circ} \mathrm{C}$ \\
\hline & Tank outlet & 102.04 & 99.95 & 103.54 & 101.69 & 99.62 & 103.17 & 101.46 & 99.17 & 103.08 & ${ }^{\circ} \mathrm{C}$ \\
\hline & Header inlet & 101.79 & 99.57 & 103.31 & 101.45 & 99.32 & 102.97 & 101.21 & 98.84 & 102.84 & ${ }^{\circ} \mathrm{C}$ \\
\hline & Header outlet & 106.46 & 102.99 & 109.58 & 106.15 & 102.40 & 109.20 & 105.54 & 101.62 & 108.60 & ${ }^{\circ} \mathrm{C}$ \\
\hline \multirow{4}{*}{ HXG Loop } & Hot supply & 100.17 & 99.92 & 100.24 & 99.71 & 99.51 & 99.78 & 99.66 & 99.06 & 99.76 & ${ }^{\circ} \mathrm{C}$ \\
\hline & Hot return & 23.19 & 22.35 & 24.48 & 23.71 & 23.24 & 24.71 & 23.29 & 21.88 & 23.67 & ${ }^{\circ} \mathrm{C}$ \\
\hline & Cold supply & 18.44 & 17.54 & 20.25 & 17.22 & 15.16 & 19.59 & 17.48 & 15.14 & 19.65 & ${ }^{\circ} \mathrm{C}$ \\
\hline & Cold return & 21.05 & 19.37 & 22.60 & 20.17 & 16.71 & 23.24 & 20.33 & 16.08 & 22.88 & ${ }^{\circ} \mathrm{C}$ \\
\hline \multirow{9}{*}{ Flow Rates } & Primary loop & 2.321 & 1.289 & 6.803 & 2.316 & 1.279 & 6.154 & 2.460 & 1.275 & 7.256 & $\mathrm{~kg} / \mathrm{s}$ \\
\hline & Riser 01 & 0.288 & 0.164 & 0.814 & 0.288 & 0.163 & 0.738 & 0.306 & 0.162 & 0.894 & $\mathrm{~kg} / \mathrm{s}$ \\
\hline & Riser 02 & 0.285 & 0.155 & 0.841 & 0.285 & 0.152 & 0.766 & 0.303 & 0.154 & 0.894 & $\mathrm{~kg} / \mathrm{s}$ \\
\hline & Riser 03 & 0.283 & 0.153 & 0.831 & 0.281 & 0.153 & 0.761 & 0.298 & 0.153 & 0.877 & $\mathrm{~kg} / \mathrm{s}$ \\
\hline & Riser 04 & 0.291 & 0.162 & 0.855 & 0.290 & 0.158 & 0.777 & 0.309 & 0.153 & 0.925 & $\mathrm{~kg} / \mathrm{s}$ \\
\hline & Riser 05 & 0.293 & 0.161 & 0.862 & 0.293 & 0.158 & 0.775 & 0.312 & 0.158 & 0.913 & $\mathrm{~kg} / \mathrm{s}$ \\
\hline & Riser 06 & 0.287 & 0.161 & 0.834 & 0.286 & 0.158 & 0.767 & 0.305 & 0.156 & 0.884 & $\mathrm{~kg} / \mathrm{s}$ \\
\hline & Riser 07 & 0.293 & 0.159 & 0.865 & 0.292 & 0.157 & 0.788 & 0.312 & 0.157 & 0.932 & $\mathrm{~kg} / \mathrm{s}$ \\
\hline & Riser 08 & 0.308 & 0.171 & 0.892 & 0.307 & 0.168 & 0.815 & 0.328 & 0.171 & 0.973 & $\mathrm{~kg} / \mathrm{s}$ \\
\hline
\end{tabular}


Table 13: Summary of structural temperatures and power levels. Statistics spanning 1-hour period starting from 1st boiling peak

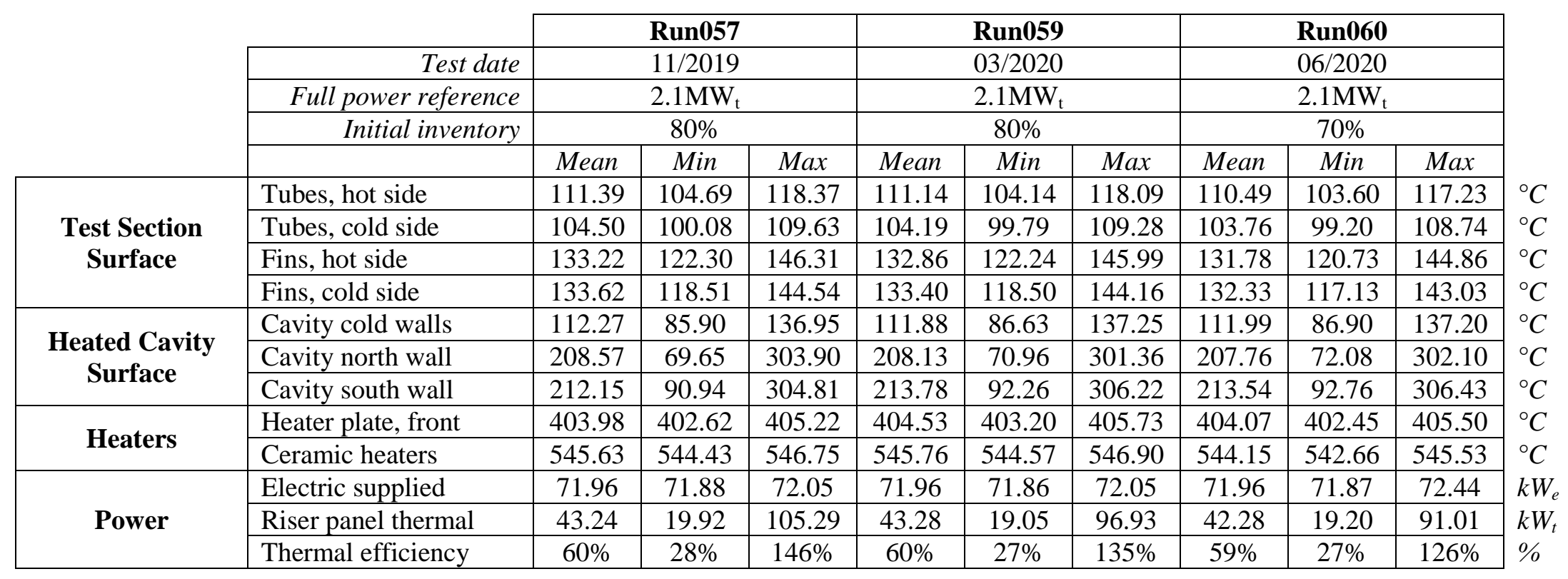


Table 14: Summary of fluid hydraulic parameters. Statistics spanning 1-hour period starting from 2.5 hours after 1st boiling peak

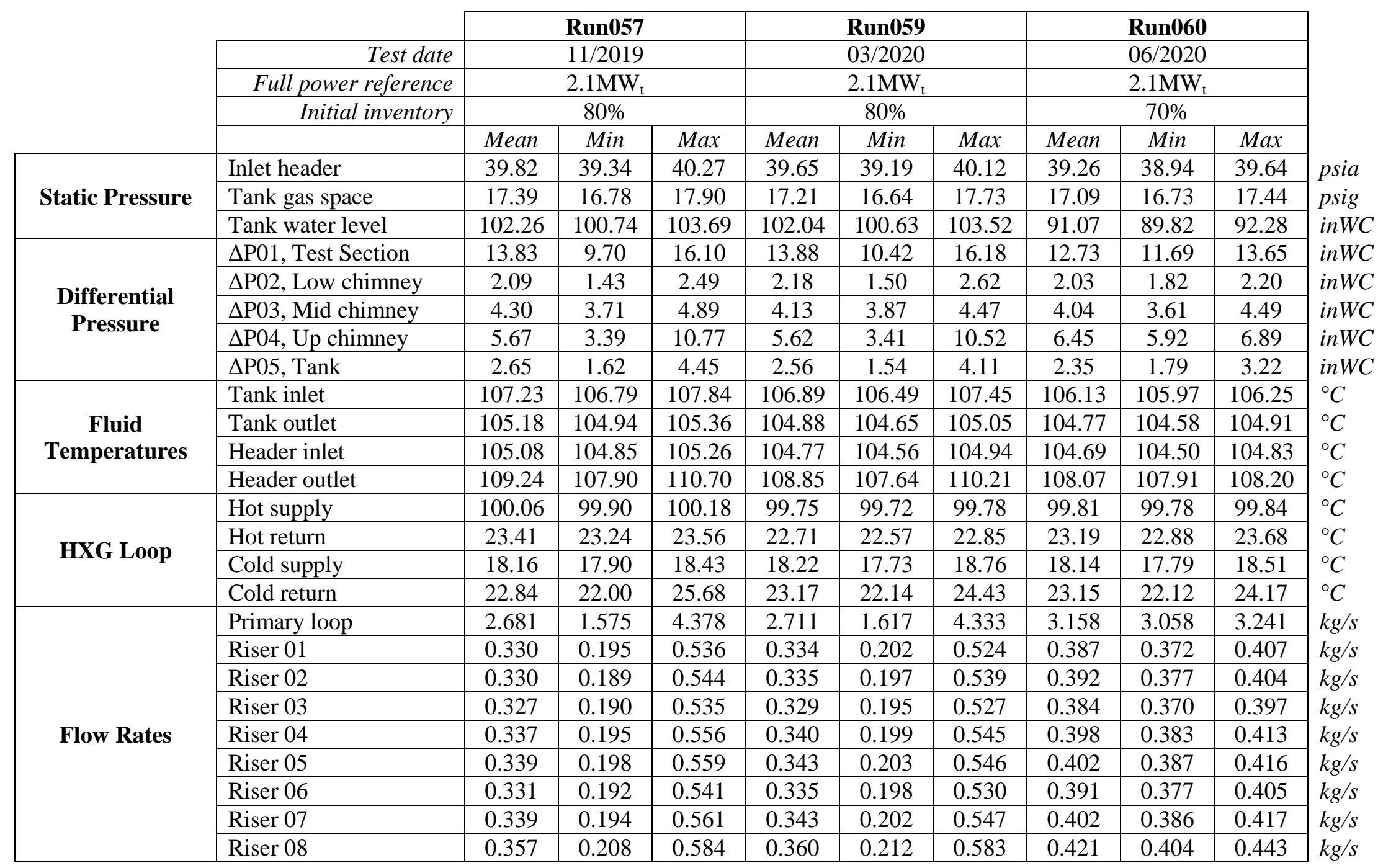


Table 15: Summary of structural temperatures and power levels. Statistics spanning 1-hour period starting from 2.5 hours after 1st boiling peak

\begin{tabular}{|c|c|c|c|c|c|c|c|c|c|c|c|}
\hline & & \multicolumn{3}{|c|}{ Run057 } & \multicolumn{3}{|c|}{ Run059 } & \multicolumn{3}{|c|}{ Run060 } & \\
\hline & Test date & \multicolumn{3}{|c|}{$11 / 2019$} & \multicolumn{3}{|c|}{$03 / 2020$} & \multicolumn{3}{|c|}{$06 / 2020$} & \\
\hline & Full power reference & \multirow{2}{*}{\multicolumn{3}{|c|}{$\frac{2.1 \mathrm{MW}_{\mathrm{t}}}{80 \%}$}} & \multirow{2}{*}{\multicolumn{3}{|c|}{$\frac{2.1 \mathrm{MW}_{\mathrm{t}}}{80 \%}$}} & \multicolumn{3}{|c|}{$2.1 \mathrm{MW}_{\mathrm{t}}$} & \\
\hline & Initial inventory & & & & & & & & $70 \%$ & & \\
\hline & & Mean & Min & Max & Mean & Min & Max & Mean & Min & Max & \\
\hline \multirow{4}{*}{$\begin{array}{l}\text { Test Section } \\
\text { Surface }\end{array}$} & Tubes, hot side & 113.95 & 109.49 & 119.24 & 113.54 & 109.19 & 118.60 & 112.63 & 109.39 & 115.23 & ${ }^{\circ} \mathrm{C}$ \\
\hline & Tubes, cold side & 107.52 & 105.38 & 110.82 & 107.16 & 105.11 & 110.34 & 106.70 & 104.98 & 108.65 & ${ }^{\circ} \mathrm{C}$ \\
\hline & Fins, hot side & 136.70 & 128.80 & 147.83 & 136.11 & 128.41 & 147.36 & 134.93 & 127.37 & 145.92 & ${ }^{\circ} \mathrm{C}$ \\
\hline & Fins, cold side & 137.05 & 124.93 & 146.07 & 136.60 & 124.64 & 145.45 & 135.38 & 123.71 & 143.87 & ${ }^{\circ} \mathrm{C}$ \\
\hline \multirow{3}{*}{$\begin{array}{l}\text { Heated Cavity } \\
\text { Surface }\end{array}$} & Cavity cold walls & 118.49 & 93.24 & 142.83 & 117.10 & 93.01 & 142.34 & 118.75 & 94.73 & 143.85 & ${ }^{\circ} \mathrm{C}$ \\
\hline & Cavity north wall & 218.13 & 76.97 & 313.07 & 216.99 & 77.63 & 309.80 & 218.46 & 80.04 & 312.91 & ${ }^{\circ} \mathrm{C}$ \\
\hline & Cavity south wall & 221.05 & 98.80 & 314.05 & 221.74 & 99.38 & 315.00 & 223.82 & 101.59 & 317.50 & ${ }^{\circ} \mathrm{C}$ \\
\hline \multirow{2}{*}{ Heaters } & Heater plate, front & 408.31 & 407.72 & 408.83 & 408.60 & 408.09 & 409.05 & 408.94 & 408.31 & 409.53 & ${ }^{\circ} \mathrm{C}$ \\
\hline & Ceramic heaters & 549.93 & 549.31 & 550.49 & 549.86 & 549.28 & 550.39 & 549.27 & 548.60 & 549.87 & ${ }^{\circ} \mathrm{C}$ \\
\hline \multirow{3}{*}{ Power } & Electric supplied & 71.96 & 71.83 & 72.08 & 71.96 & 71.25 & 72.20 & 71.96 & 71.86 & 72.06 & $k W$ \\
\hline & Riser panel thermal & 45.72 & 28.15 & 76.63 & 45.49 & 29.14 & 72.94 & 45.08 & 44.01 & 46.06 & \\
\hline & Thermal efficiency & $64 \%$ & $39 \%$ & $106 \%$ & $63 \%$ & $41 \%$ & $101 \%$ & $63 \%$ & $61 \%$ & $64 \%$ & $\%$ \\
\hline
\end{tabular}




\section{Stability Analysis}

At the forefront of this program is an objective to provide data that is suitable for supporting the development and validation of passive safety decay heat removal systems for advanced nuclear power plants. Given the complexity inherent to natural circulation system, an integral feature of several advanced safety concepts, there is a need to ensure understanding of the underlying phenomenon that can occur in these two-phase boiling water loops. Current observations from test conditions and behavior examined thus far suggest that the heat removal performance remains largely unaffected by the observed instabilities. This means that regardless of the magnitude or frequency of system wide flow oscillations, heat is likely to continue being effectively transferred from the core to an ultimate heat sink.

However, the oscillations do poise unique structural challenges for any future implementation. If large magnitude vibrations are sustained, piping supports, bolted mating assemblies, loosened securement hardware, etc. are at risk and must be engineered accordingly. Thus there continues to be a strong interest in understanding the instability mechanism, which at a minimum will provide a shift away from uncertainty and into predictability. With continued development and further understanding, engineering controls or design features can then be incorporated to allow these systems to operate only in stable regimes. In an attempt to answer these questions, a cursory analysis of the flow phenomena and instability mechanisms has been performed and presented in the following section. As the testing program continues along the planned matrix and new data sets become available, continued development of this analysis may provide valuable insight on the stability and performance expected from a full scale installation.

\subsection{Flow Instability Mechanisms}

Two-phase flow instabilities are not desirable in nuclear systems as they may cause forced mechanical vibrations and deteriorated heat transfers. Boure et al. [11] performed an extensive review of two-phase flow instabilities, and classified the phenomena into different types based on their specific mechanisms and characteristics. For low-pressure boiling systems, typical types of instabilities that should be considered include natural circulation oscillations (also called thermal hydraulic oscillations [12], or hydrostatic head fluctuations [13]), density wave oscillations (DWO), flow pattern transition instability, and geysering.

Natural circulation oscillations can occur in a loop with a part in which bubbles can accumulate [14], e.g., the Argonne water-based NSTF with both horizontal and vertical chimney sections. This phenomenon usually starts with a perturbation causing insufficient generation of vapor that accumulates in the non-heated horizontal chimney section. As vapor generation continues, accumulated bubbles coalesce with incoming vapor and cause the hydrostatic head to decrease. The decrease of hydrostatic 
head in the chimney results in an increase of flow rate, which forces the accumulated bubbles out and subcooled water in. The chimney hydrostatic head is then recovered and the flow is reduced, allowing the process to start again and repeat. One characteristic of this instability is the presence of 2-5 fundamental frequencies in the measured oscillations [15], which will be discussed later.

In boiling systems, density wave oscillations are due to multiple regenerative feedbacks between the flow rate, vapor generation rate, and pressure drop [11]. Their phenomenon stems from a density difference between the inlet and outlet fluid states, which can trigger a delayed and alternating feedback from the subcooled liquid inertia and compressibility of the two-phase mixture. One characteristic of DWO is the oscillation period being approximately 1.5 to 2 times of the fluid transit time in the channel [16]. Flow pattern transition instabilities have been postulated as occurring when the flow conditions are close to the point of transition between bubbly flow and annular flow. In bubbly-slug flow, a temporary increase in bubble population may change the flow pattern to annular flow with decreased pressure drop. The flow rate then increases which may cause insufficient vapor generation and revert the flow pattern to bubbly-slug flow. Lastly, geysering has been observed in a variety of closed end vertical columns of liquid which are heated at the base. The process mainly consists of boiling delay, condensation or expulsion of vapor, and liquid returning.

For the two baseline tests (Run057 and Run059) and the inventory parametric test (Run060), the main instabilities encountered are the natural circulation oscillations and DWO. The former occurs upon initiation of boiling/flashing, and lasts for most of the two-phase duration when the voiding is not continuous and features intermittent excursions. As the test proceeds and inventory level decreases, vapor generation transitions to a continuous mode due to reducing hydrostatic head, and the instability mechanism slowly transitions toward the DWO.

\subsection{Hydraulic Analysis}

\subsubsection{Oscillation Period}

The loop flow oscillation periods in the three tests are compared as shown in Figure 45. As discussed in previous sections, baseline repeatability is demonstrated by the good agreement of loop flow oscillation period between tests of Run057 and Run059. The starting inventory level in test Run060 is lower than the ending inventory level in tests Run057 and Run059. However, the loop flow oscillation period in Run060 does not follow the extrapolations of oscillation periods in the other two tests, indicating inventory level not the only factor determining the system behavior.

One characteristic of the natural circulation oscillations is the presence of multiple fundamental frequencies. The presence of additional modes within the larger system oscillation can be examined by a 
time domain frequency analysis. The fast Fourier transform results of the pressure drop in the upper chimney section $\left(\Delta P_{4}\right)$ are shown in Figure 46. The first fundamental frequency $(\sim 0.005 \mathrm{~Hz}$ for Run057 and Run059, and $\sim 0.0053 \mathrm{~Hz}$ for Run060) represents the primary system wide fluctuations, while the additional peaks represent the higher order harmonics (integer products of the fundamental) characteristic of the natural circulation oscillations mechanism.

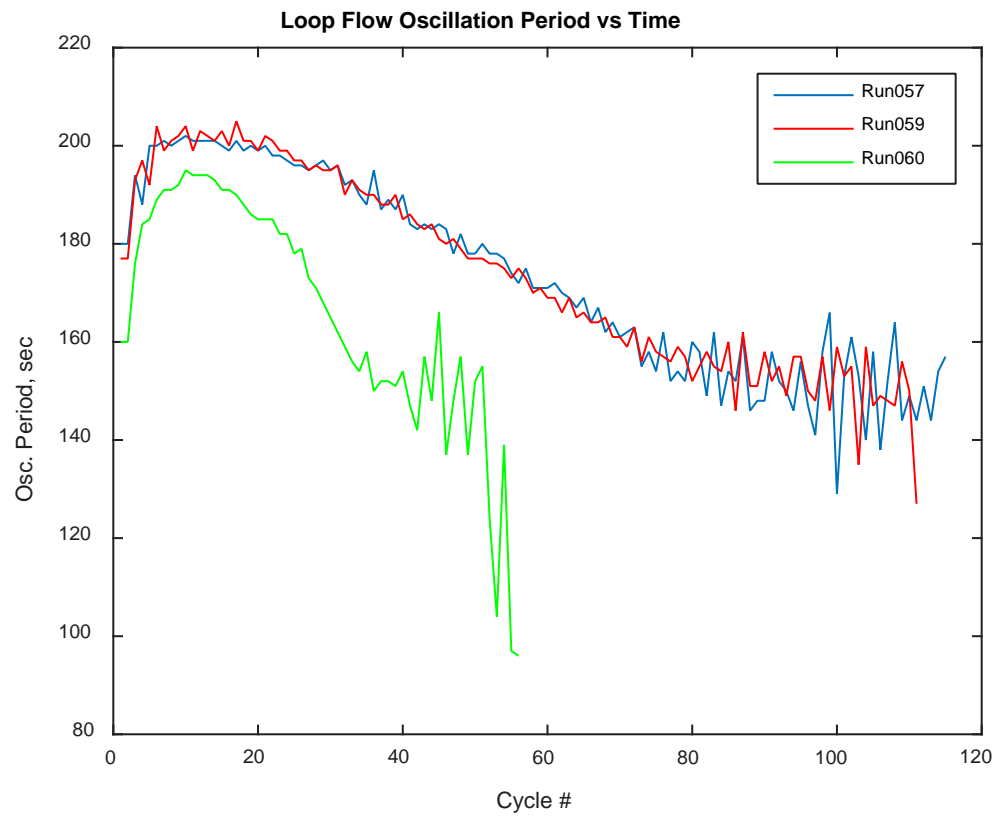

Figure 45: Loop flow oscillation period comparison

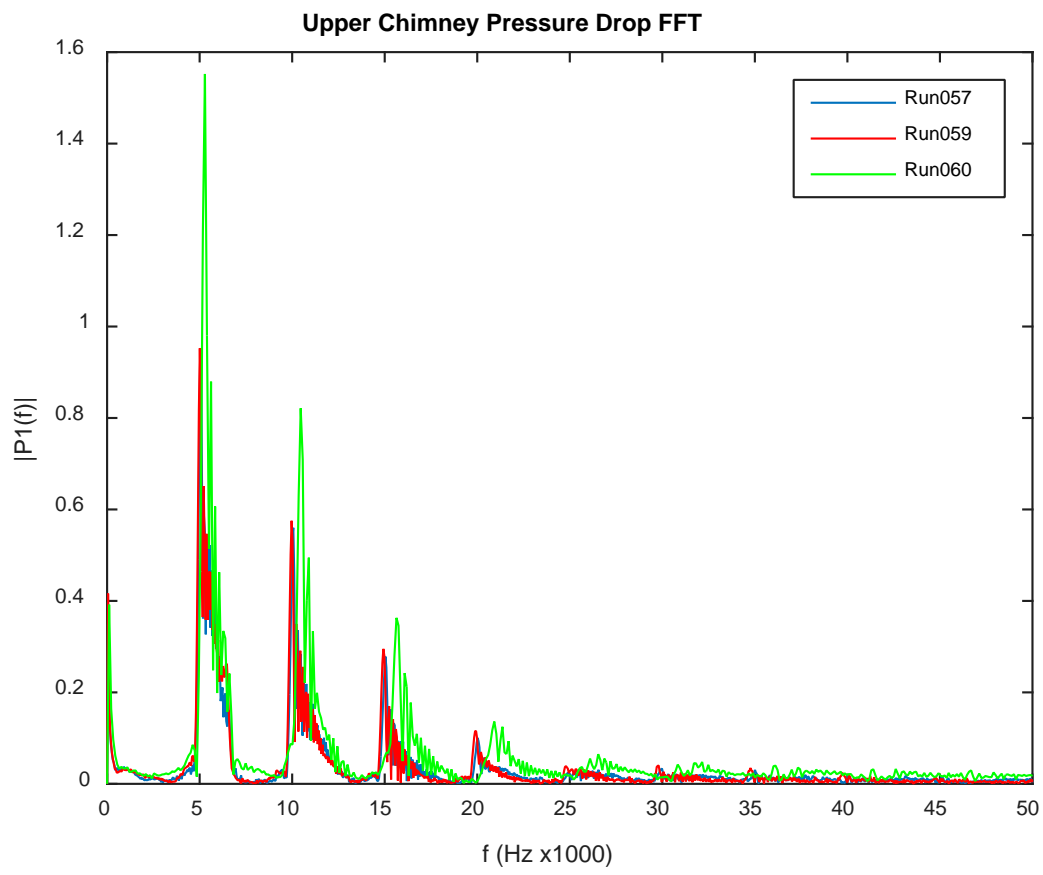

Figure 46: Fundamental frequencies in the upper chimney pressure drop 


\subsubsection{Transit Times}

The fluid transit time is an important parameter to consider when determining the two-phase flow instability mechanisms. The DWO features an oscillation period approximately 1.5 to 2 times of the fluid transit time in the channel which is defined as including the full length of the chimney region and half of the heated core/test section [16]:

$$
\tau_{\text {Channel }}=\frac{V_{\text {Chimney }}+0.5 V_{\text {Core }}}{\dot{Q}_{\text {bulk }}}
$$

where $V$ denotes the fluid volume, and $\dot{Q}_{\text {bulk }}$ denotes the bulk volumetric flow rate. The two-phase flow oscillation periods are plotted against the fluid transit times in the channel for tests Run057, Run059, and Run060, Figure 47. Although the system behaviors observed in the three tests exhibit similar characteristics of DWO, it is believed that natural circulation oscillations is the dominant instability mechanism here. According to Figure 47, only the later period of the examined two-phase window in Run060 lies in the DWO operating zone (between x1.5 and x2 lines). In all tests, the flow oscillations start with natural circulation oscillations due to insufficient vapor generation, reflected as the $0 \%$ plateau of void measurement in each oscillation cycle in early two-phase stage (will be discussed later). As the voiding becomes continuous, the instability mechanism slowly transitions to DWO, shown as the curves trending toward the DWO operating zone in Figure 47. Lisowski et al. [15] identified a different characteristic transit time that could represent the observed flow oscillations during the full growth and decay of oscillations. This transit time accounts for the flow path of the entire system from the tank outlet to inlet, and defined as:

$$
\tau_{\text {System }}=\frac{V_{D C}+V_{\text {Core }}+V_{\text {Chimney }}}{\dot{Q}_{\text {bulk }}}
$$

where the subscript $D C$ denotes downcomer. The fluid transit time in the entire system is shown in Figure 48 for the three tests. As seen, the plotted data of the three tests overlap well, and the majority lies in between $\mathrm{x} 1$ and $\mathrm{x} 1.5$ lines, indicating that this new transit time definition may be viewed as a means to further identify the mechanism of natural circulation oscillations observed in the tests. 


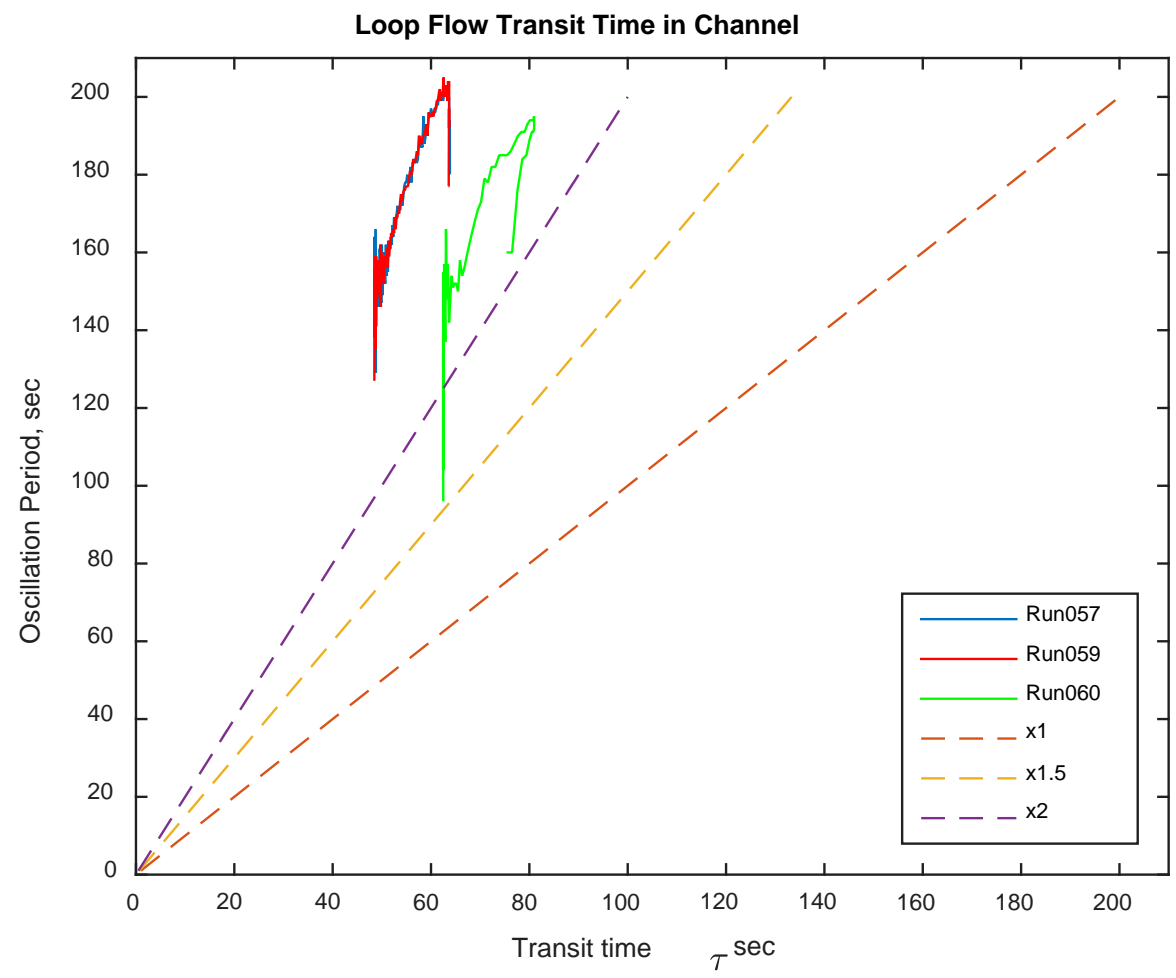

Figure 47: Fluid transit time in the channel vs oscillation period

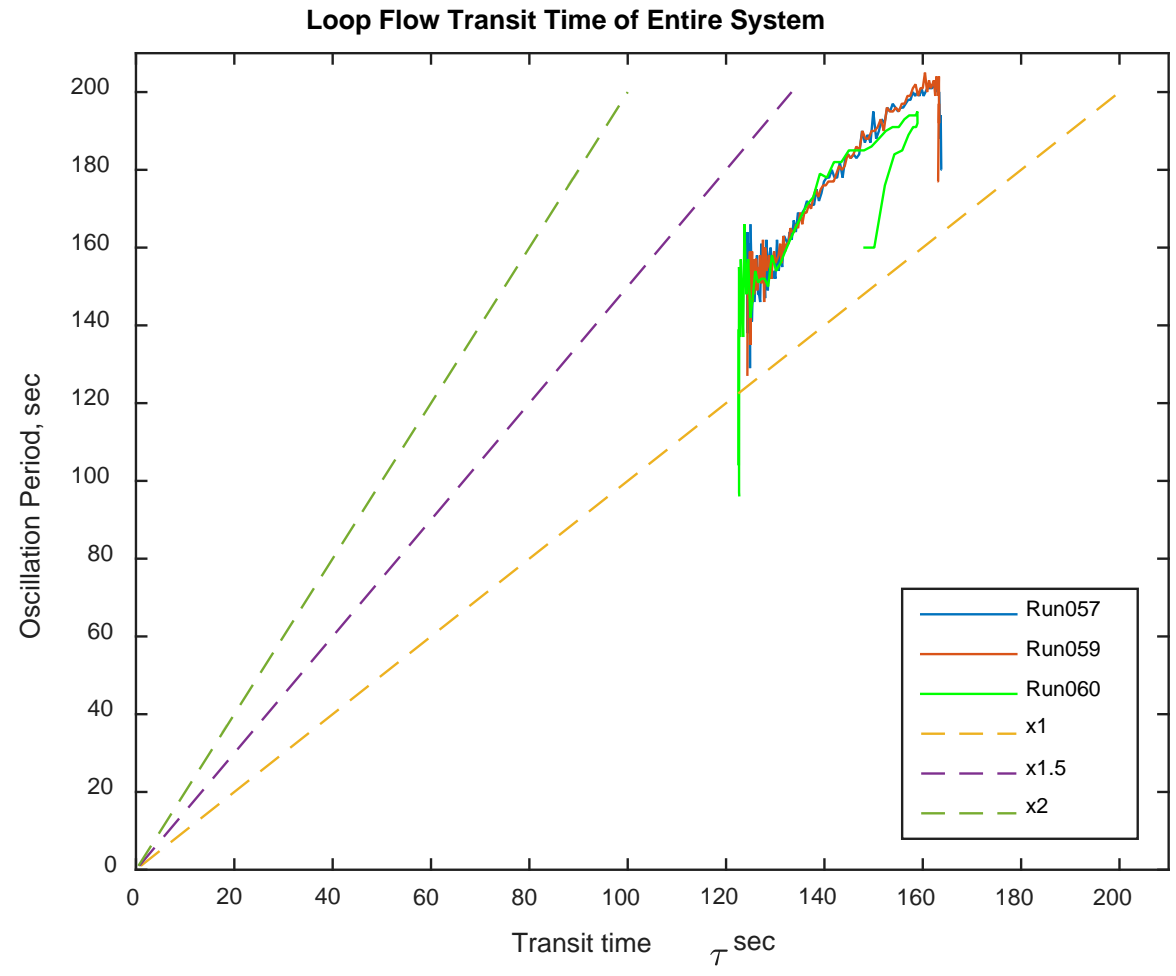

Figure 48: Fluid transit time of entire system vs oscillation period 


\subsubsection{Phase Shift of Measurements}

As the inventory level decrease after boiling/flashing initiates, local saturation temperature decreases while the rate of enthalpy addition remains the same. Therefore, voids start to form at a lower elevation, with oscillation periods decreasing and the boiling boundary transitioning to a new physical location. To locate the void formation and boiling/flashing boundary movement, phase shifts of the pressure drops across the different chimney sections are examined, Figure 49. It should be noted that the differential pressure transducers are connected in a way that the dip in the plot represents an increase of the frictional pressure loss or loop flow rate, and a peak represents a decrease in the chimney hydrostatic head by either temperature increase or void formation. As can be seen, the differential pressure over the lower chimney section is in-phase while the differential pressure over the upper chimney is out-of-phase with respect to that over the test section. This indicates that boiling/flashing occurs in the upper chimney section during the two-phase operation. The differential pressure over the mid chimney is stable, which is mainly due to the short length of this vertical section and thus negligible frictional loss, and also indicates no void formation in this section.

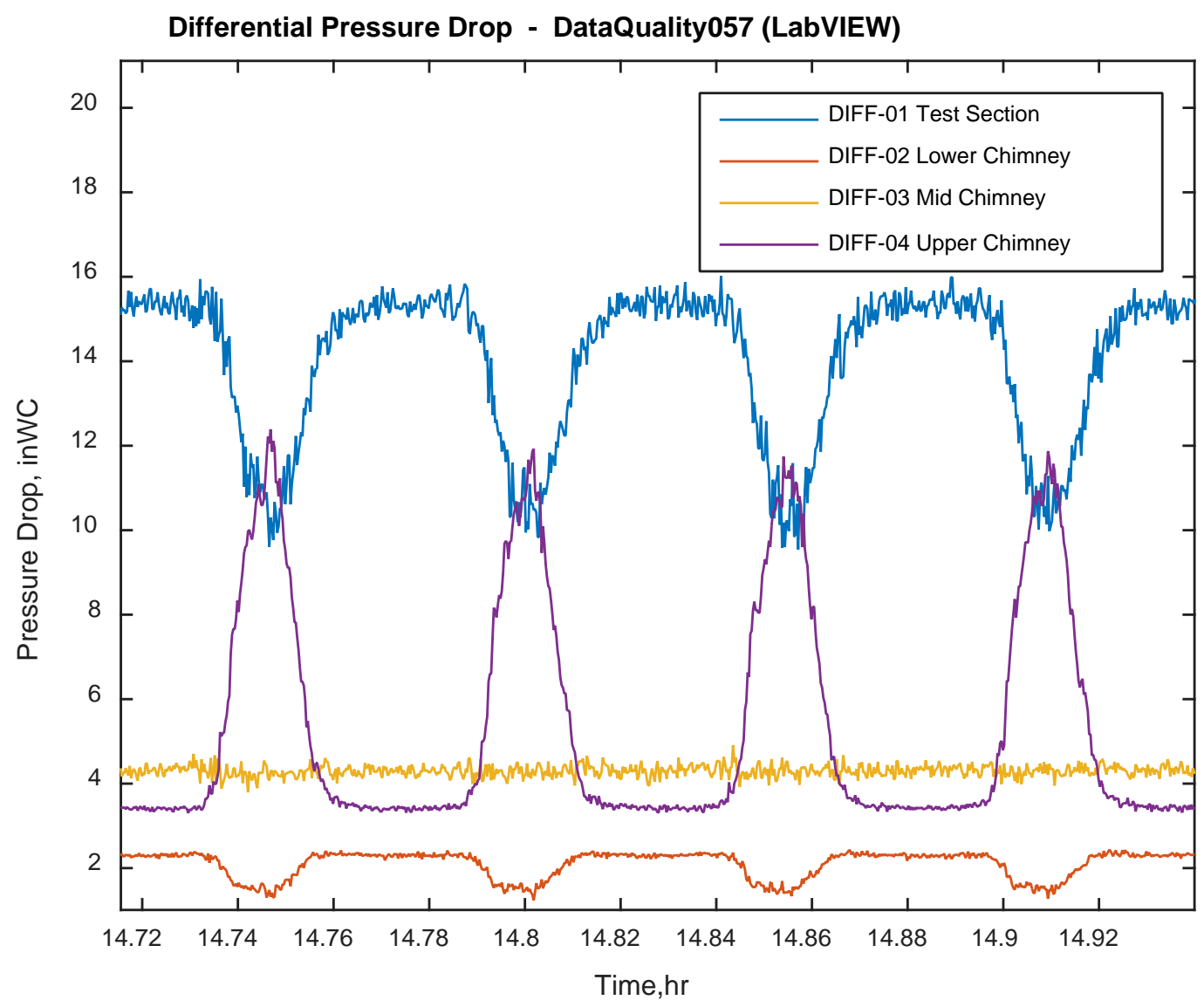

Figure 49: Phase shifted differential pressure curves during two-phase oscillations 


\subsubsection{Phase Portraits of $\Delta P$ vs Flow Rates}

The classification of the system behavior is further examined by the phase portrait drawing, which depicts the coupling between different variables. The phase portrait drawing of the upper chimney pressure drop vs the loop flow rate is shown in Figure 50, divided into four stages of the two-phase oscillations. An elliptically shaped operating region is seen in the relation between flow and pressure parameters during stages $\mathrm{A}-\mathrm{C}$. The periodic nature outlines a discrete path that bounds both the differential pressure and flow rate. The gradually shrinking operating region from stage A through C indicates the damping of system behavior oscillations. As it progresses to stage $\mathrm{D}$, a linear rise is obvious from the tight flow-pressure coupling. Also the lack of well-defined elliptical shape suggests a chaotic relation.
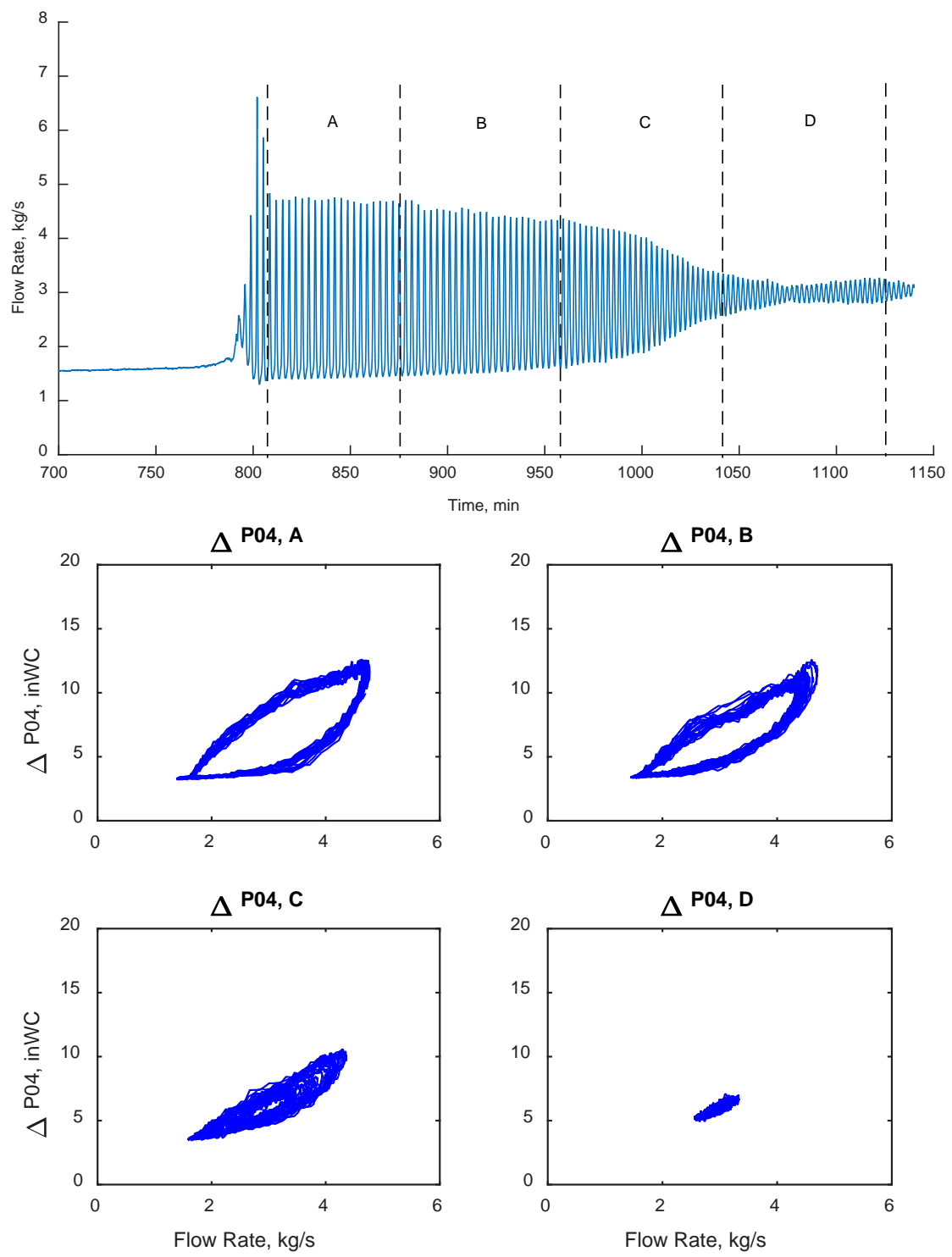

Figure 50: Phase portrait of flow-upper chimney pressure drop in Run057 


\subsection{Two-phase Analysis}

Measurements from two void fraction sensors were used to quantify the two-phase boiling flow. All test cases were performed with the gamma densitometer active, while only select runs utilized the local RBI probes. Both devices are able to provide insight into the actual two-phase flow and allow quantitative assessment of the total void fraction. When overlaid with the system flow oscillation, one is able to identify the time delay between generation of local voiding and onset of system oscillations, Figure 51.

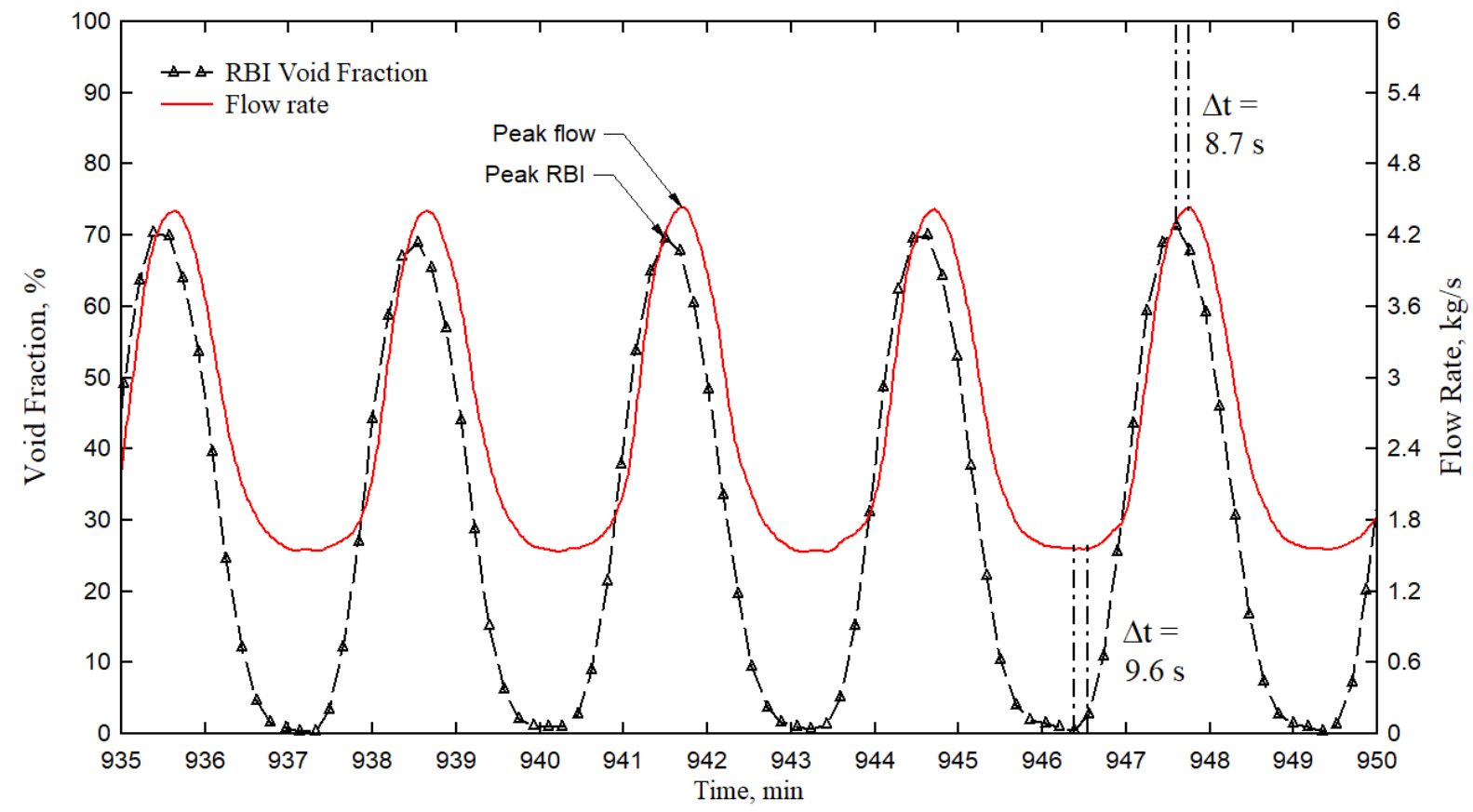

Figure 51: Overlay system flow rate and measured void fraction, Run058

While similar, these two sensors have different operating parameters and thus provide complimentary data. The primary difference is the region of measurement - the RBI measures void fraction at a single point in the centerline of the top chimney, while the gamma densitometer measures a bulk volumetric void fraction along a 15-inch tall portion of the upper chimney. Additionally, the RBI is positioned approximately 9.5-inchs higher in elevation than the gamma densitometer. Finally, there is a time constant used for calculating the void fraction. Since the RBI probe signals are binary, meaning either 0 for liquid or 1 for gas, the time history of the void fraction will change depending on which user specific time constant is selected. An example is shown below in Figure 52, where the time constant is varied for the RBI signals while kept constant for the gamma densitometer. For the 30 second time constant, it is clear that the rate of change in physical void fraction occurs at a higher frequency than the calculation period, thus the true time history cannot be accurately captured. With a reduced time-constant of 10 
seconds, the full temporal history of the void fraction is made available and able to provide a more represented metric for actual phenomena.

An additional comparison of the two sensors is made for the boiling duration of Run060, which experienced a range of flow regimes, Figure 53. Note the gap in the RBI data between 790 and 800 minutes occurred due to buffering errors on the data acquisition and thus data during these times is not available. Beginning with fully liquid subcooled, the void fraction transitioned into periodic slug flow with void fractions jumping from 0 to upwards of $80 \%$. With the correct time constant, both sensors measure comparable void fractions. However, as the boiling transitions into continuous void generation and the loop stabilizes, the flow shifts into a churn or wispy-annual regime. At this point strong differences are measured by the two sensors, the result of the point vs bulk measurement region, compounded by the difference in elevation.

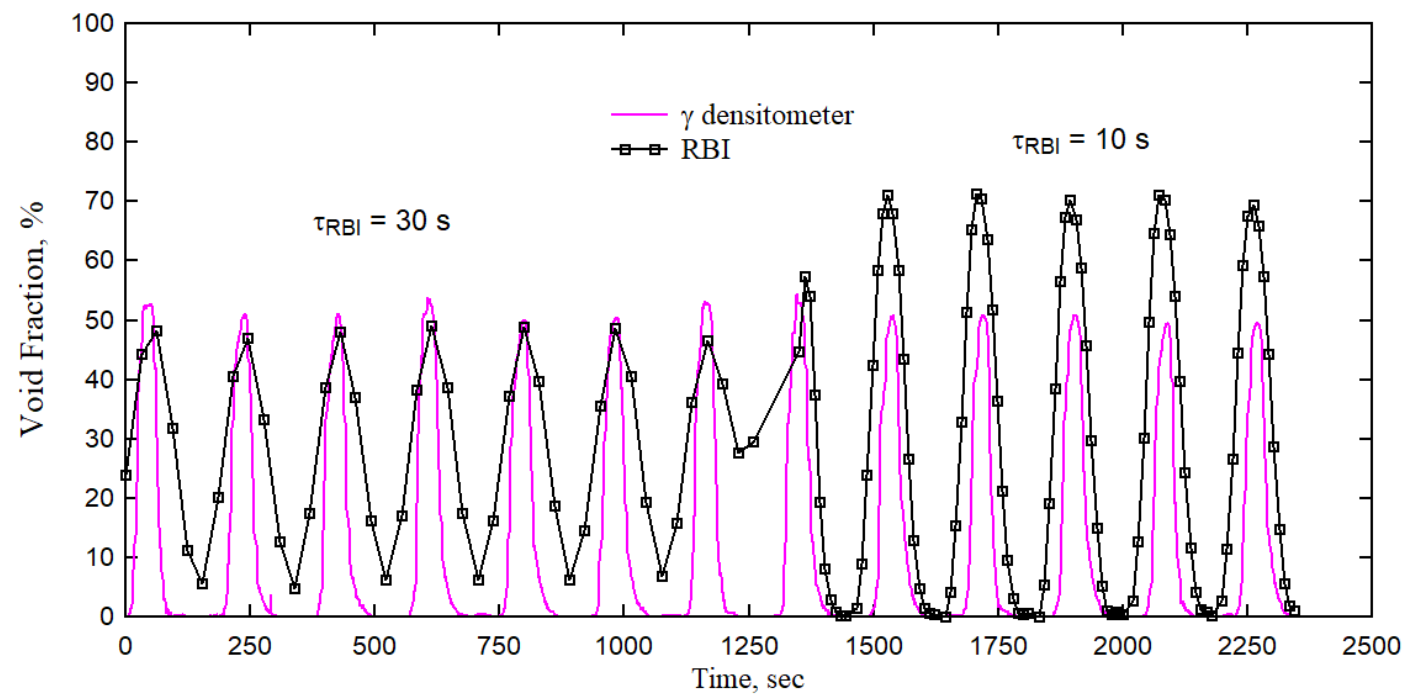

Figure 52: Influence on calculated void fraction with varying time constants 


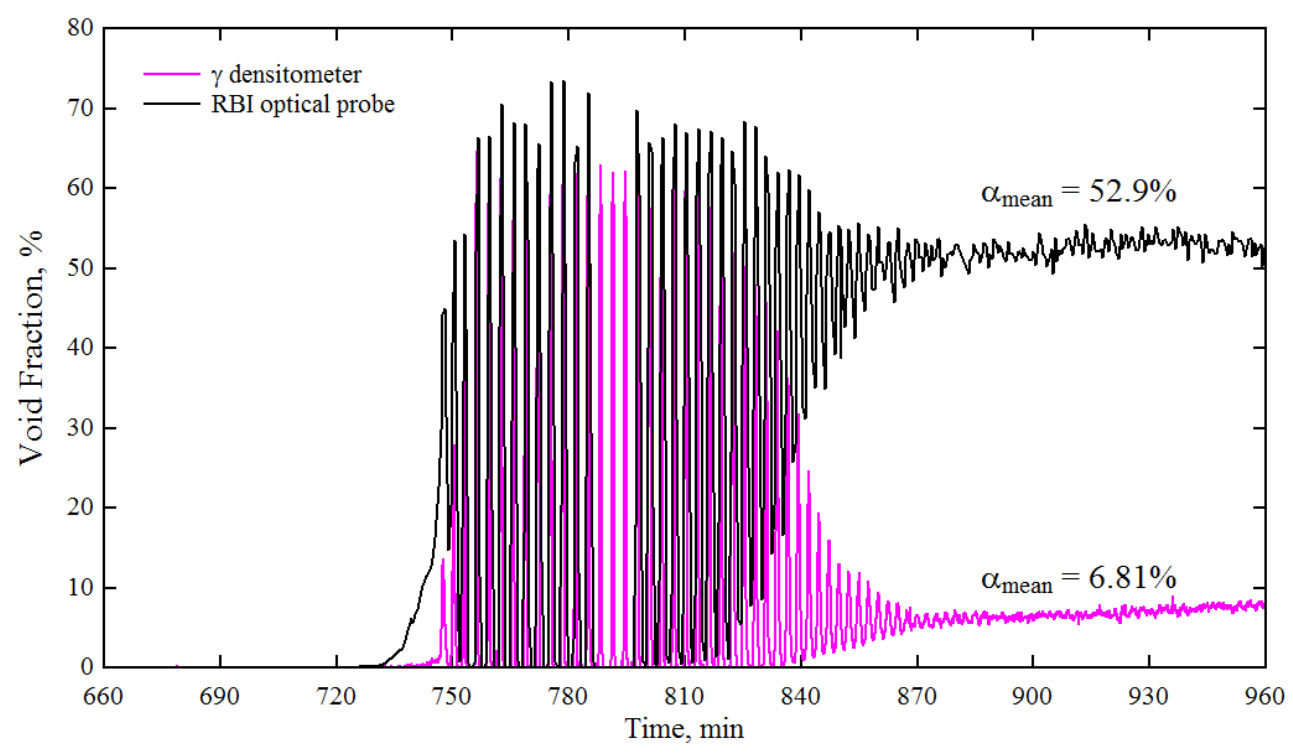

Figure 53: Comparison between two void fraction sensors during boiling operation in Run060

\subsubsection{Flow Regime}

An analysis of the superficial vapor and liquid velocities provide insight into the flow regimes of the two-phase flow. Specifically, these parameters can be used to draw gas-liquid flow maps and identify if the flow falls within bubbly, slug, churn or annular flow regimes [18][19]. Calculation of these two-phase parameters assumed a homogenous model of the phase mixture with a slip ratio of 1 , meaning that the gas and liquid phases are traveling at the same velocities. The bulk flow rate measured at the subcooled inlet was referenced to provide the superficial liquid velocity, while the time of flight from the RBI probes were used for the superficial gas velocity. Figure 55 - Figure 58 portray the flow regimes at various times in Run060, which exhibited both unstable large system wide oscillations, and stable steady boiling. 


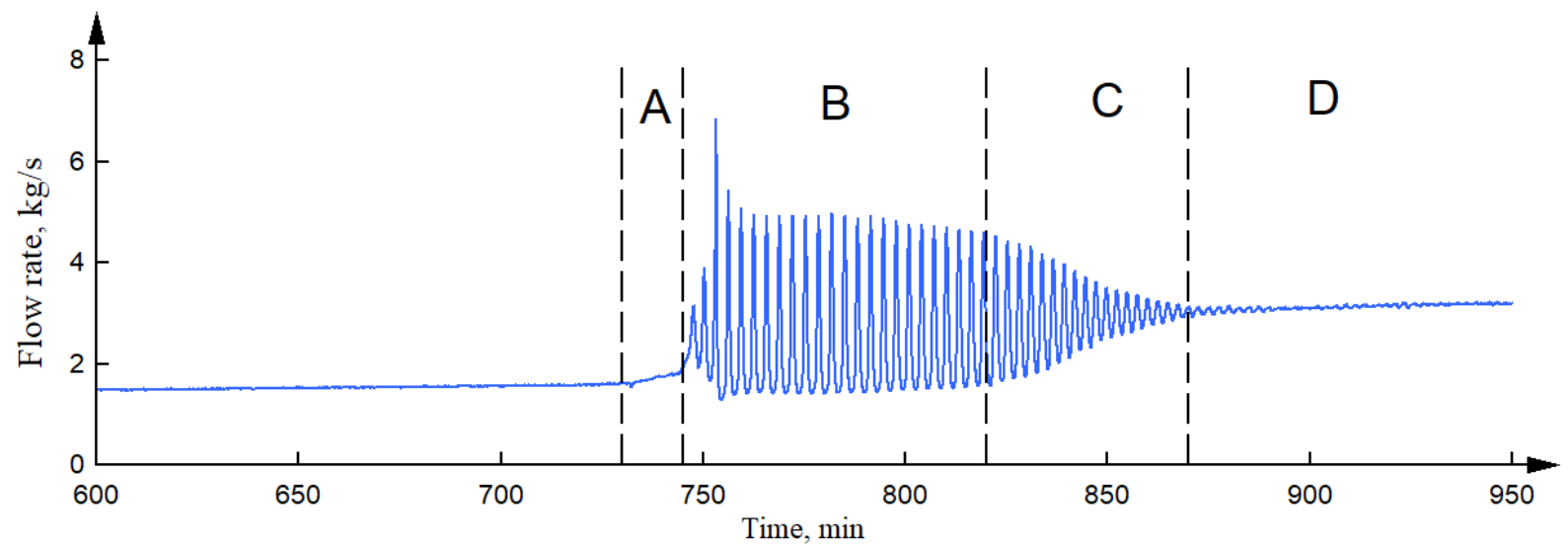

Figure 54: System flow rate during Run060; reference for two-phase flow regimes periods A-D

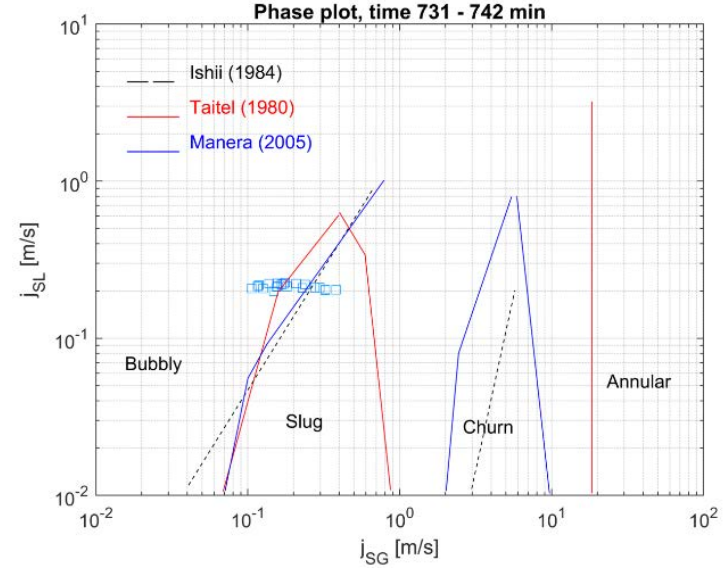

Figure 55: Regime path during approach to boiling, period A

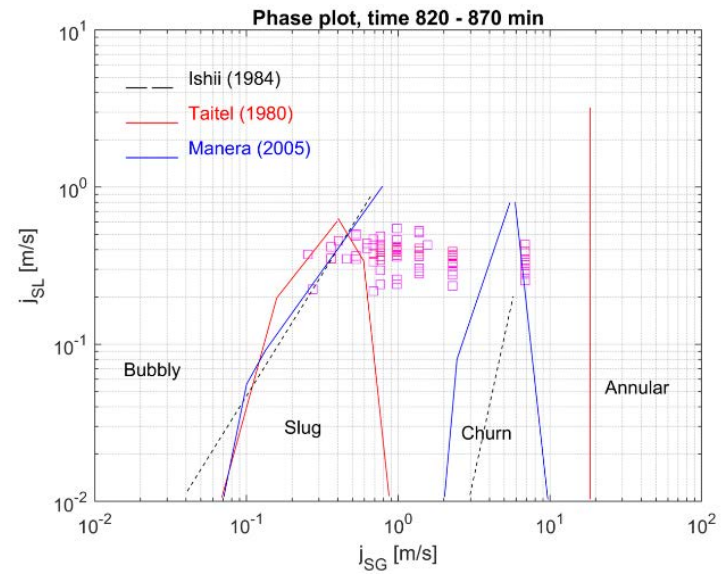

Figure 57: Regime path during decay into stability, period C

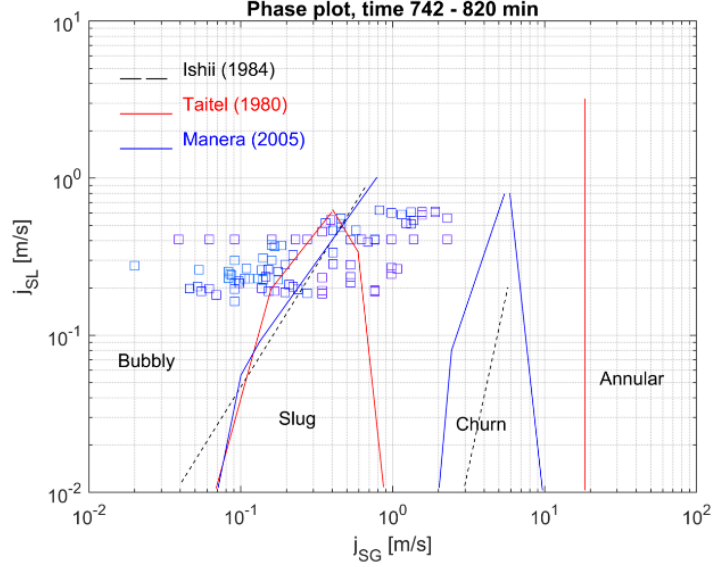

Figure 56: Regime path during large oscillations, period B

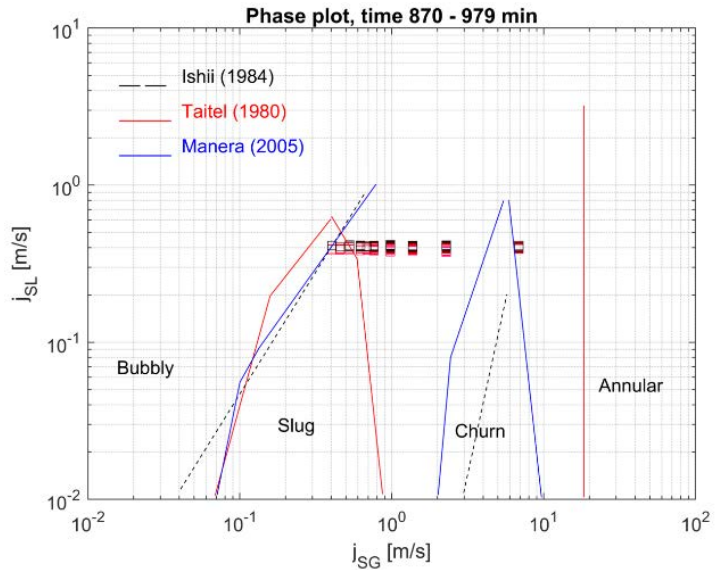

Figure 58: Regime path during stable two-phase, period D 


\subsection{Stability Mapping}

Two-phase flow instabilities have been extensively studied through stability map in terms of Subcooling number $\left(N_{s u b}\right)$ and Zuber/phase number $\left(N_{p h}\right)$. A typical stability map for two-phase flow system by Fukuda and Kobori [20] is illustrated in Figure 59, where the dimensionless numbers are defined respectively as:

$$
\begin{gathered}
N_{s u b}=\frac{c_{p l} \Delta T_{\text {sub }}}{h_{f g}}\left(\rho_{f} / \rho_{g}-1\right) \\
N_{p h}=\frac{Q}{W h_{f g}}\left(\rho_{f} / \rho_{g}-1\right)
\end{gathered}
$$

Here $c_{p}, \Delta T_{\text {sub }}, \rho, h, Q$, and $W$ are specific heat capacity, inlet subcooling, density, specific enthalpy, heating power, and mass flow rate, respectively. Subscript $l$ denotes subcooled liquid, while $f$ and $g$ denote saturated liquid and vapor.

For natural-circulation boiling systems, two types of flow instabilities can be encountered, namely, Type-I and Type-II. Type-I instabilities are mainly attributed to hydrostatic head variation along vertical direction and usually appear in a system with a long adiabatic section above a heated section. Type-II instabilities are due to phase shifts between the one- and two-phase frictional pressure losses in the system. For low pressure boiling systems, the Type-I instability region is enlarged due to the flashing phenomenon. The single-phase boundary in Figure 59 inclines more toward the vertical axis while the instability boundary shifts in the right direction [21].

The stability map will vary based on the system configurations and operation conditions (mainly the pressure). For illustration purpose, the two-phase flow behavior in Run060 is compared with the typical stability map by Fukuda and Kobori [20], Figure 59. The examined two-phase window starts from the initiation of boiling/flashing until the flow instabilities almost damp out completely, and is divided into four stages A - D in Figure 59. The initial system flow oscillations due to perturbation of void formation are drastic, crossing all four regions in the stability map (stage A). During this stage, flashing is not continuous but more in periodic excursion mode. Single-phase subcooled liquid periodically prevails through the chimney when system flow peaks. As time progresses, flashing trends toward a continuous mode, leading to a shift away from the single-phase region for the system behavior (stage B). Damping of the system flow instabilities is reflected as the collapse of the plot and shift toward the stable two-phase region (stage C). Eventually the system flow becomes stable and it is represented as the almost completely collapsed dot in the two-phase stable region. 

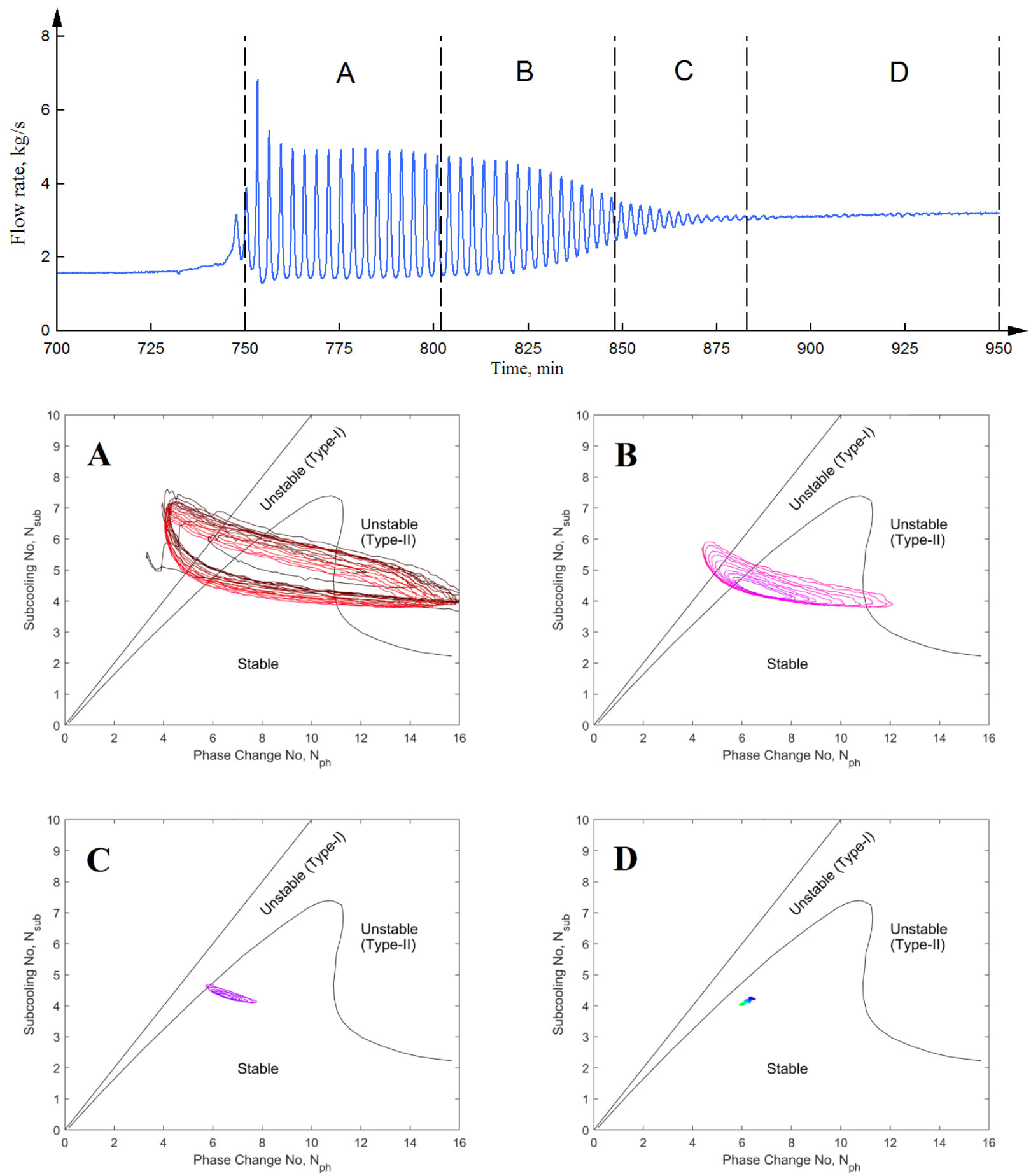

Figure 59: Flow instabilities in Run060 compared with the stability map by Fukuda and Kobori [20] 


\subsection{Vibrational Analysis}

Included in the overall data acquisition suite are accelerometer sensors used to measure physical vibrations. The sensors have an average sensitivity coefficient of $10 \mathrm{mV} / \mathrm{g}$, and are able to detect signals at frequencies between 10 and 10,000 $\mathrm{Hz}$ within $2 \%$ uncertainty. Across the test facility, three of such sensors were mounted and sampled during one of the two-phase baseline test. The first accelerometer was mounted directly on the chimney pipe wall at mid-height, a second mounted on the structural I-beam directly supporting the primary water tank, and a third mounted on the primary water tank outside walls, also at mid-height.

Measurements were recorded using a NI-9234 module, which allows sampling of all three sensors simultaneously. During the entirety of the boiling duration, sampling occurred at $2 \mathrm{kHz}$ and measurements recorded to the computer disk in files spanning 30 seconds each. A sample of the raw data from a 20 minute period during boiling operation is shown below in Figure 60.

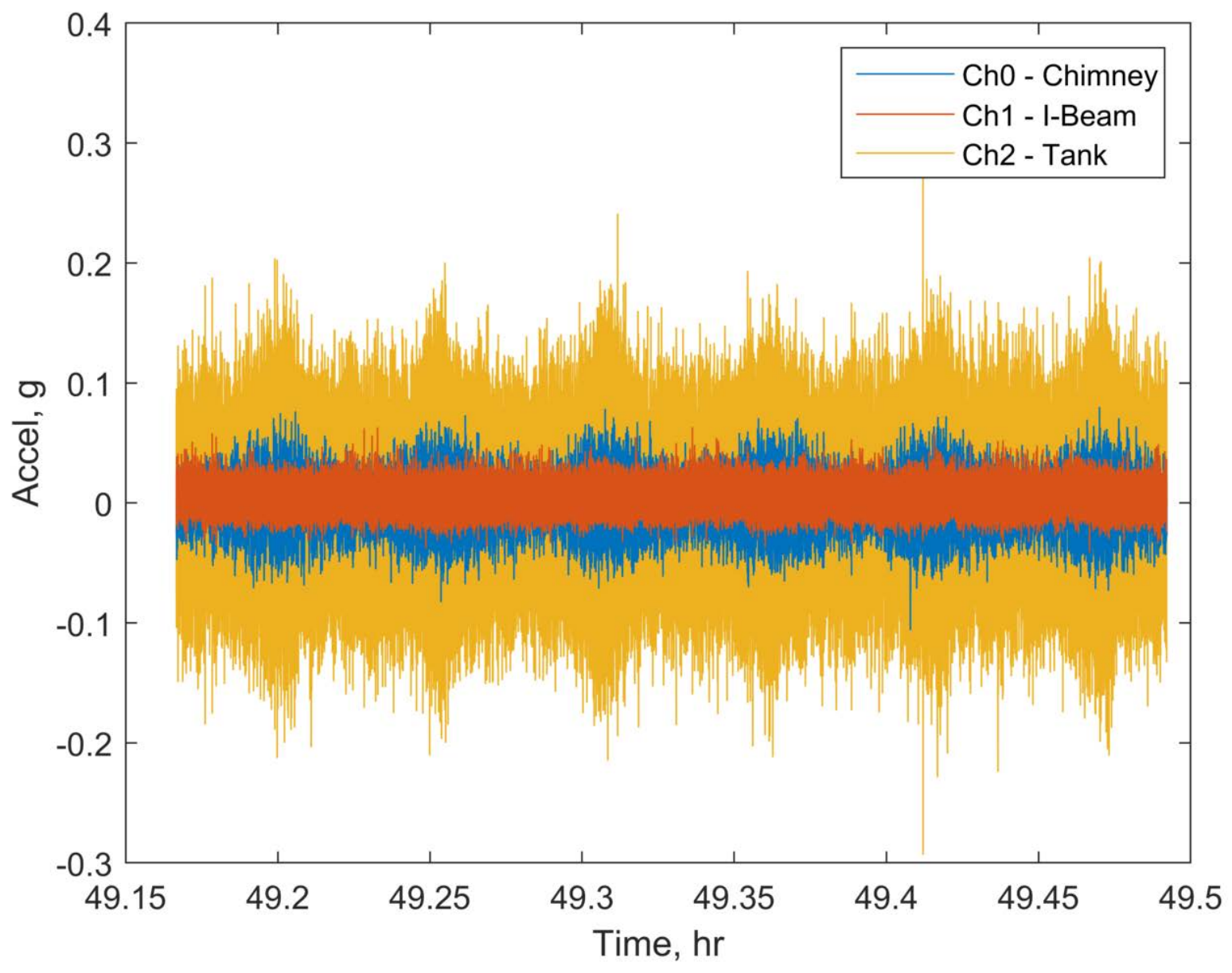

Figure 60: Unprocessed raw data from accelerometers 
A Fast Fourier Transform (FFT) was performed to represent the data in a frequency domain, Figure 61. This decomposes the signal and allows separation of the pure operating frequencies from the surrounding noise. Lastly, peak vibration amplitudes were identified across each thirty second acquisition period and plotted versus total test run time. With the current piping configuration and structural support designs, peak vibrational amplitudes up to 0.28 g were observed during a typical boiling event, Figure 62.

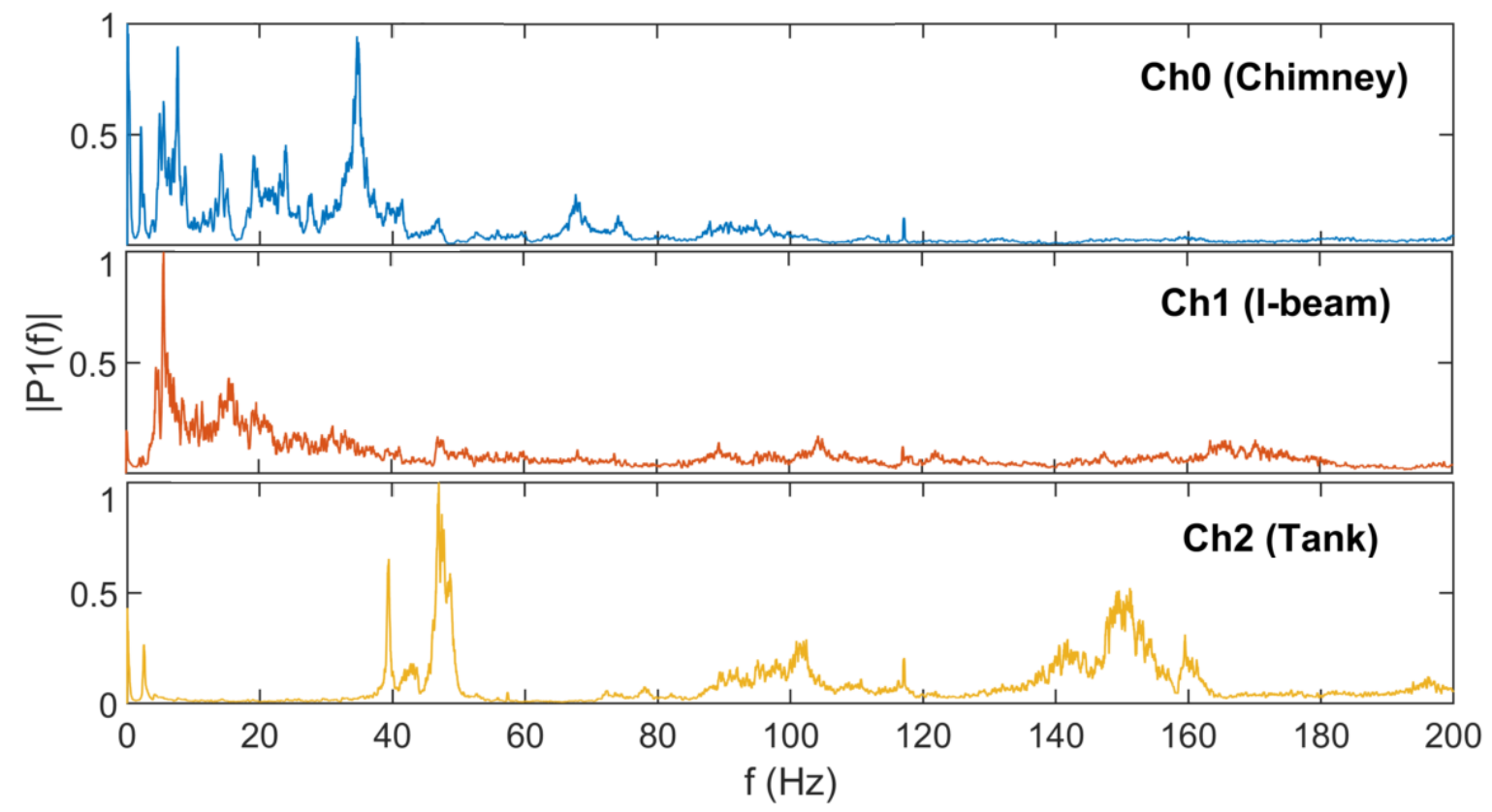

Figure 61: Fast Fourier Transform (FFT) phase plots of vibrations along chimney, structure, and tank

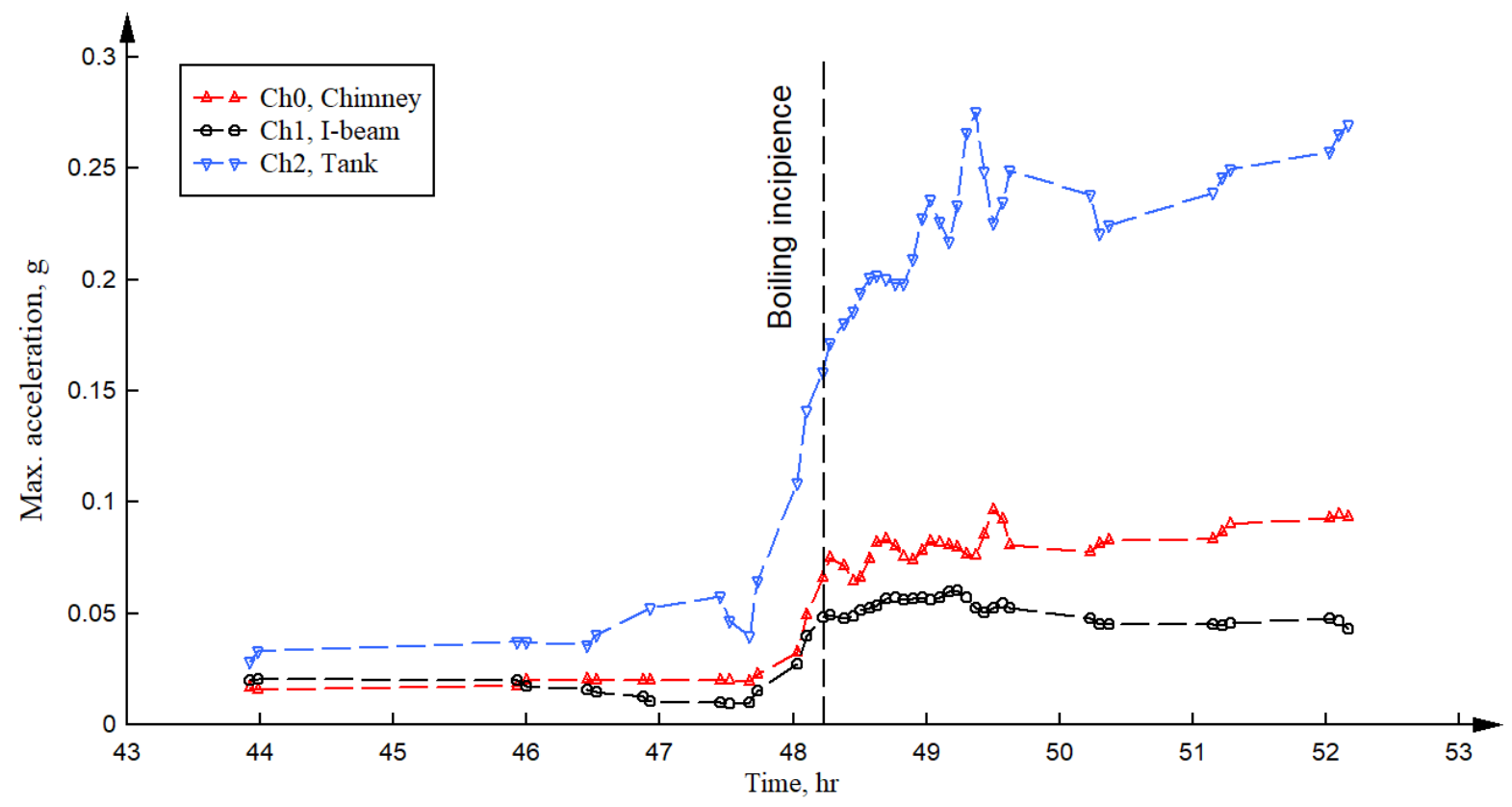

Figure 62: Time history of measured peak acceleration magnitude 


\section{Acknowledgements}

This work was supported by the U.S. Department of Energy Office of Nuclear Energy's Advanced Reactor Technology (ART) program under contract number DE-AC02-06CH11357. The program team wishes to extend our gratitude for the funding, support, and guidance from our program sponsor and associated laboratories. We also wish to acknowledge the technical, laboratory, and QA support that has been provided by other Argonne staff including Art Vik, Roberta Riel, John Woodford, and Matt Bucknor. 


\section{References}

[1] Lisowski, D., Gerardi, C.D., Kilsdonk, et. al., 2016. Final Project Report on RCCS Testing with Air-based NSTF, ANL-ART-47. Argonne National Lab. (ANL), Argonne, IL (United States).

[2] Lisowski, D., Lee, T., Kilsdonk, D.J., et. al., 2015. Status Report on the Water-Based NSTF RCCS Capability: Preparations and Design for the Transformation of the Natural Convection Shutdown Heat Removal Test Facility (NSTF) From Air to Water-based Cooling, ANL-ART-23. Argonne National Lab. (ANL), Argonne, IL (United States).

[3] Lisowski, D., 2016. Progress Report on Water Conversion of the Natural convection Shutdown heat removal Test Facility (NSTF) during FY2016, ANL-ART-69. Argonne National Lab. (ANL), Argonne, IL (United States).

[4] Lisowski, D.., Gerardi, C.D., Hu, R., Kilsdonk, D.J., Bremer, N.C., Lomperski, S.W., Kraus, A.R., Bucknor, M.D., Farmer, M.T., 2017. Water NSTF Design, Instrumentation, and Test Planning, ANL-ART-98. Argonne National Lab. (ANL), Argonne, IL (United States).

[5] Tzanos, C.P., Farmer, M.T., 2007. Feasibility study for use of the natural convection shutdown heat removal test facility (NSTF) for VHTR water-cooled RCCS shutdown, ANL-GenIV-079. Argonne National Lab. (ANL), Argonne, IL (United States).

[6] AREVA, No.: 12-9237246-000, “Water-Cooled RCCS RD Designer Observation Report”, Technical Data Record, 2014

[7] Lisowski, D., Lv, Q., Hu, R., Kraus, A., Bremer, N., Kilsdonk, D.J., Farmer, M., 2019. RCCS Testing with the Water-based NSTF: Year-1 Single-Phase Results, ANL-ART-175. Argonne National Lab. (ANL), Argonne, IL (United States).

[8] Lv, Q., Kraus, A., Hu, R., Bucknor, M., Lisowski, D., Nunez, D., 2017. Progress Report on Computational Analyses of Water-Based NSTF, ANL-ART-103. Argonne National Lab. (ANL), Argonne, IL (United States).

[9] ASME NQA-1-2009 (with 1a 2009 addenda), “Quality Assurance Requirements for Nuclear Facility Applications”, 2008

[10] Shaikh, A., Al-Dahhan, M., 2013. “A new method for online flow regime monitoring in bubble column reactors via nuclear gauge densitometry”, Chemical Engineering Science, 89, 120-132

[11] Boure, J.A., Bergles, J.E. and Tong, L.S., 1973. “Review of Two-phase Flow Instability”, Nuclear Engineering and Design, 25, 165-192

[12] Wu, C.Y., Wang, S.B., and Pan, C., 1996. "Chaotic Oscillations in a Low Pressure Two-phase Natural Circulation Loop under Low Power and High Inlet Subcooling Conditions”, Nuclear Engineering and Design, 162, 223-232

[13] Subki, M.H., Aritomi, M., and et al., 2004. "Multi Parameter Effect of Thermohydraulic Instability in a Natural Circulation Boiling Water Reactor During Startup”, JSME Int. J. B, 277-286

[14] Chiang, J.H., Aritomi, M., and Mori, M., 1993. "Fundamental Study on Thermohydraulics During Start-up in Natural Circulation Boiling Water Reactors, (ii) Natural Circulation Oscillation Induced by Hydrostatic Head Fluctuations”, J. Nucl. Sci. Technol, 30, 203-211

[15] Lisowski, D.D., Omotowa, O., Muci, M.A., Tokuhiro, A., Anderson, M.H., and Corradini, M.L., 2014. "Influences of Boil-off on the Behavior of a Two-phase Natural Circulation Loop", International Journal of Multiphase Flow, 60, 135-148

[16] Marcel, C.P. et al., 2010. "Experimental Investigations on Flashing-induced Instabilities in One and Two-parallel Channels: A Comparative Study”, Exp. Therm. Fluid Sci, 34, 879-892 
[17] Francois, F., Garnier, J., Cubizolles, G., 2003. "A new data acquisition system for binary random signal applications in multi flow measurements”, Meas. Sci. Technol, 14, 929 - 942

[18] Manera, A., Prasser, H.M., Lucas, D., and van der Hagen, T.H.J.J., 2006. "Three-dimensional flow pattern visualization and bubble size distributions in stationary and transient upward flashing flow", Int. J. of Multiphase Flow, 32, 996-1016

[19] Mishima, K., Ishii, M., 1984. "Flow regime transition criteria for upward two-phase flow in vertical tubes”, Int. J. Heat Mass Transfer, 27, 723-737

[20] Fukuda, K., and Kobori, T., 1979. “Classification of Two-Phase Flow Instability by Density Wave Oscillation Model”, Journal of Nuclear Science and Technology, 16, 95-108

[21] Manera, A., de Kruijf, W.J.M., van der Hagen, T.H.J.J., and Mudde, R.F., 2000. "Experiments with the circus facility on flashing-induced instabilities during start-up of natural-circulation-cooled BWRs”, In A. Haghighat (Ed.), Proceedings of PHYSOR 


\section{Argonne}

\section{Nuclear Science \& Engineering}

Argonne National Laboratory

9700 South Cass Avenue, Bldg. 206

Argonne, IL 60439

www.anl.gov 